\title{
A Prairie Doctor of the Eighties: Some Personal Recollections and Some Early Medical and Social History of a Prairie State
}

Francis A. Long

Maggie E. Long

Tell us how you used this information in this short survey.

Follow this and additional works at: https://digitalcommons.unmc.edu/cent_com

Part of the History Commons, and the Medical Education Commons

\section{Recommended Citation}

Long, Francis A. and Long, Maggie E., "A Prairie Doctor of the Eighties: Some Personal Recollections and Some Early Medical and Social History of a Prairie State" (1937). Centennial Trilogy of the University of Nebraska College of Medicine. 1.

https://digitalcommons.unmc.edu/cent_com/1

This Book is brought to you for free and open access by DigitalCommons@UNMC. It has been accepted for inclusion in Centennial Trilogy of the University of Nebraska College of Medicine by an authorized administrator of DigitalCommons@UNMC. For more information, please contact digitalcommons@unmc.edu. 
A Prainie Doctor of the Eirghthities

Hg.Men 


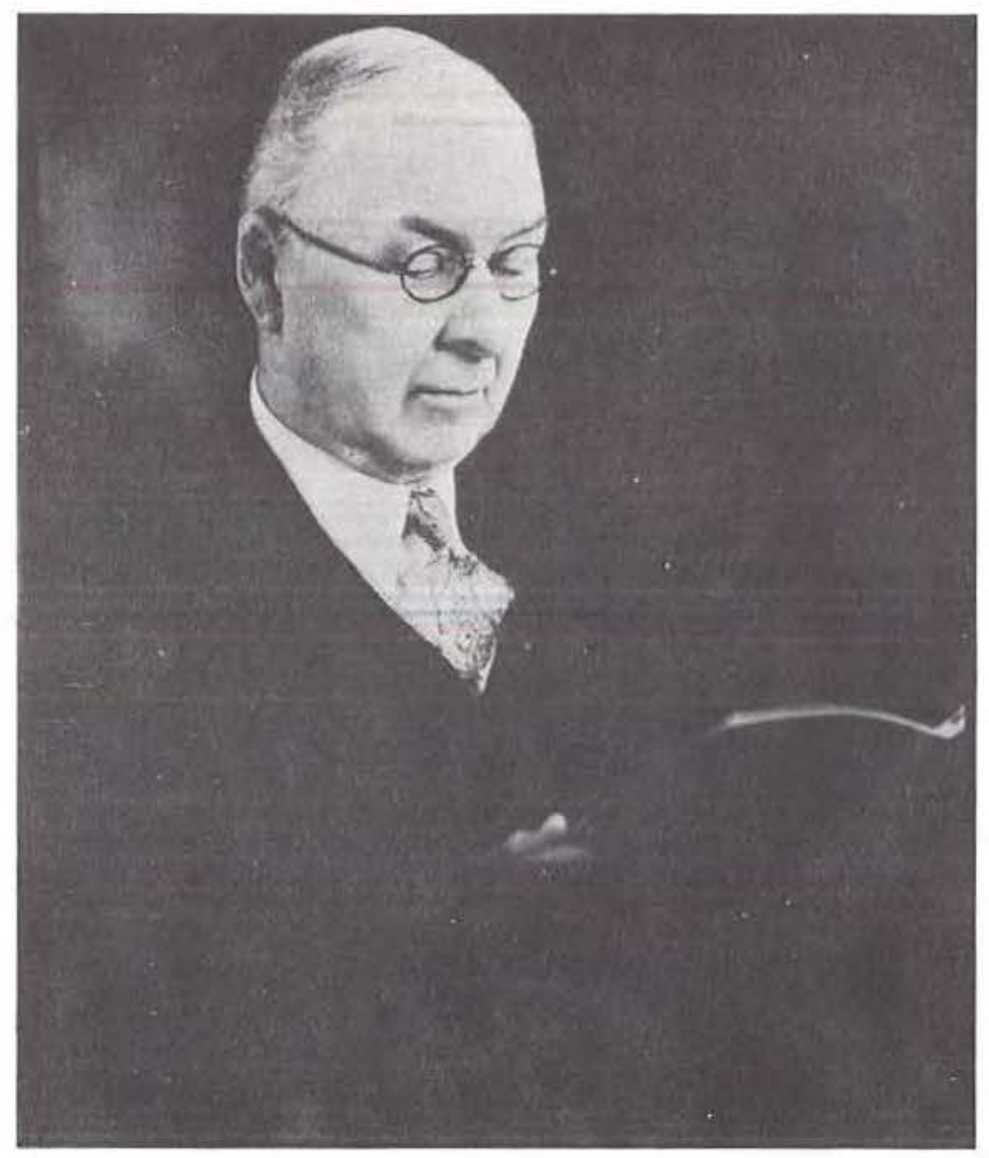

The Author After Fifty Years of Service. 



\title{
A PRAIRIE DOCTOR OF THE EIGHTIES
}

Some Personal Recollections and

Some Early Medical and Social History of a Prairie State

\author{
By \\ FRANCIS A. LONG, M. D. \\ Editor, The Nebraska State Medical Journal \\ Member, Nebraska Historical Society \\ Member, Nebraska Writer's Guild

\section{With Two Chapters on \\ "THE PRAIRIE DOCTOR'S WIFE"} \\ By Maggie E. Long
}

With IIlustrations

HUSE PUBLISHING COMPANY

NORFOLK, NEBRASKA

1937 
Copyright, 1937, by

The Huse Publishing Co.

Huse Publishing Company, the parent company of the Norfolk Daily News, first published A Prairie Doctor of the Eighties in 1937. The Centennial Committee of the University of Nebraska College of Medicine would like to thank Mr. Emil Reutzel, current editor of the Norfolk Daily News, and the Huse Publishing Company for granting permission to reissue this book. 
To my sainted wife who shared these experiences and to the three daughters born and reared in the pioneer atmosphere 


\section{PREFACE}

On the occasion of the Centennial of the University of Nebraska College of Medicine, it is most fitting that the Centennial Committee of the Medical Center reissue this quite marvelous autobiography by $\mathrm{Dr}$. Francis A. Long. A Prairie Doctor of the Eighties is a valuable book, both in the literary and the historical sense. It is thus my pleasure to provide a Preface to a book about a man I knew and admired.

Francis Long was born on February 16, 1859 and grew up near Kreidersville, Pennsylvania. He worked as a common laborer about the coal mines, in car shops and as an accountant in a lumber yard in Carbon County, Pennsylvania. He came west with his family in December 1976 to Moulton, Iowa. Following graduation from Normal School, he taught school for two years near Moulton. He studied medicine in an apprenticeship under a physician with whom he boarded while teaching school. In 1880 he entered the Medical School of the University of Iowa. Following graduation in 1882 he located in Madison, Nebraska, where he began the medical practice he describes so vividly in this book.

A pioneer in early medicine in Nebraska, he was active in local, district, and state medical organizations such as the Madison-Five Counties, the Elkhorn Valley, and the Missouri Valley. In fact, every association with medicine as its dominating interest received his cooperation and active support. He was president of the Nebraska Medical Association in 1906-07. He was the Nebraska delegate to the American Medical Association in Atlantic City in 1907, in Chicago in 1908, and in Los Angeles in 1911. He was the Nebraska delegate to the A.M.A. Council on Medical Education in 1909-10. He became a Fellow of the American College of Surgeons in 1915.

His great role, in his latter professional years, was that of medical editor and publisher. A state medical association publication was first proposed by Francis 
A. Long in his presidential address before the State Association in 1907 . He made a study of sixteen medical publications then in circulation. Nothing further was done until 1913 when Dr. Long was made chairman of a committee to investigate the contract with the then-existing journal. He was empowered to establish a state medical association journal in 1916.

Under Dr. Long's editorial direction, from 1920 to his death in 1937, the Nebraska State Medical Journal flourished both as a medium for excellent scientific papers and as a common visible bond that united the urban physician of Nebraska with his counterpart practicing in the far-flung towns of western Nebraska. For those of us who knew Dr. Long personally, we found that he was always fair and supportive in his editorial comments and judgements. $\mathrm{He}$ was soft spoken and a perfectionist in his craft.

Dr. Long carried on a large practice even while his editorial labors took a great deal of his time. Eventually, his health made it necessary for him to retire from medical practice to devote full-time to the editorship of the Journal and to the duties required for the supervision of organized medicine on both state and national fronts. He felt that the Nebraska State Medical Journal was perhaps the most cohesive thing in the state's medical organization, and its influence should be widened by catering to the human side of all physicians of the state. He felt that the physician is, first of all, a scientific personage; but he is also a human being with tastes for the lighter things pertaining to his professional life. He felt the esprit de corps of the profession must be nurtured. To him this implied that sympathy, devotion, enthusiasm and a zealous honor of the body as a whole should be preserved at all times. $\mathrm{He}$ also believed that frank discussion in open forum of the problems of the profession was vital to its progress.

For those of us that were privileged to know this unusual man during our formative years, he was a figure of great stature. He was indeed a physician of 
multifaceted disciplines. First and foremost, he was industrious, imaginative, honest, and forthright in his thinking and the execution of his many offices. As physicians or as citizens, we should be proud of this pioneer of the medical profession in Nebraska, and pleased that this excellent book is here available to us again.

Harley Anderson, M.D. University of Nebraska

College of Medicine, Class of 1925

Omaha, Nebraska, June, 1980 


\section{THE GENERAL PRACTITIONER}

(By Permission)

As many of my readers know, I am an ardent admirer of the General Practitioner, especially those of the country variety. Here comes in a poem on the subject from one of my correspondents. The ideal seems higher than Kipling's, but I know men who illustrate it.

\section{IF}

If you can change tires at four below at four a. m.!

If you can set a fractured femur with a piece of string and a flat iron and get as good results as the mechanical engineering staff of a City Hospital at ten per cent of their fee;

If you can drive through ten miles of mud to ease the little child of a deadbeat-

If you can do a podalic version on the kitchen table of a farmhouse with husband holding leg's and grandma giving chloroform-

If you can diagnose tonsillitis from diphtheria with a laboratory forty-eight miles away,

If you can pull the three pronged fish-hooked molar of the 250 pound hired man-

If you can maintain your equilibrium when the lordly Specialist sneeringly refers to the General Practitioner-

Then you are a real Country Doctor!

-William Lyon Phelps, in Scribner's Magazine. 


\section{ACKNOWLEDGMENT}

For years I have felt that some permanent record should be made of the transition period of medicine, particularly in the Pioneer West. More recently I have been impressed with the idea that unless I undertook to do this work it might be left undone.

My narrative is essentially a contribution to the medical and social history of the Middle West in the Eighties-and after. It is believed that the narrative covers an almost untouched field.

The encouragement of such men as Dr. Olin West, Secretary of the American Medical Association; the late Dr. George H. Simmons, for twenty-five years Editor of the Journal of the American Medical Association; the late Dr. Franklin H. Martin, Founder and Director-General of the American College of Surgeons, and Dr. Palmer Findley, noted gynecologist and author, has spurred me on in the preparation of this volume. Many thanks are also due to Dr. Addison Sheldon, Superintendent of the Nebraska Historical Society, for suggestions and assistance. Other friends have rendered assistance.

Finally if it had not been for the constant encouragement of my wife and three loyal daughters, the task would never have been completer.

I have had the temerity to attempt to show by illustration the seven ages of the physician, from which one may see what can happen to a cross-roads country doctor, rather than to show classic beauty. I trust the reader will approve.
Madison, Nebr:
-F. A. LONG.
July, 1937. 


\section{CHAPTERS}

A Medical Student of the Early Eighties_.............. 9

A Medieal Tyro of the Early Eighties................. 28

North Nebraska in the Early Eighties_.............. 32

North Nebraska in the Early Eighties, Continued_.... 47

Some Memories of Early Day Professional Contacts_.... 59

Some Memories of Early Day Professional Contacts, Continued _ _ _ . 71

Fmergency Surgery in Pioneer Homes: First Appen-

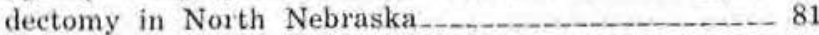

Pioneer Obstetrics _ _ _

The Physician as Father-Confessor______.___._._._. 103

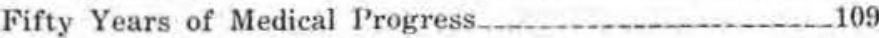

Fifty Years of Medical Progress, Continued__.____._. 120

Early Medical Society Contacts: Author Becomes President _

The Presidency, the Annual Meeting, Medical Editor_..._.144

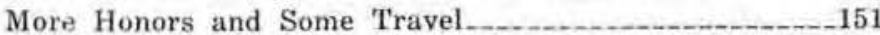

Celebrating Fifty Years of Service to One Community_-159

The Prairie Doctor's Wife, By Herself__________________

The Prairie Doctor's Wife, By Herself, Continued_......171

The Practice of Medicine Among the Prairie Indians__._. 180

Some Early Medical History of a Prairie State________._193

Appendix A: Chronology of Medical Progress_..._.....-212

Appendix B: Development of Quarantine and Health Laws in Nebraska _......214

Appendix C: Early Laws Regulating Practice of Medicine in Nebraska _.... 218

Appendix D: The Malarial Mosquito in Nebraska___.___-_219 Appendix E: Physicians Who Settled in Nebraska at an

Early Date, With Place of Settlement__________._220

A ppendix F: First Medical Societies in Nebraska__._._._.222 


\section{LIST OF ILLUSTRATIONS}

1. Frontispiece.

2. A Teacher at 19.

3. Old South Hall. The south half of the first story and basement only was used for the medical students,

4. The Faculty in the Early Eighties.

5. The Present Iowa University Medical School.

6. A Medical Graduate at 23.

7. Type of a Pioneer's Frame House 16 by 24 feet, 11/2 stories high.

8. Sod House, Sod Roof, Madison County, Nebr. (From an old photo).

9. A Sod House of the Early Eighties, with Thatched Roof, Madison County, Nebr. (From an old print).

10. A Madison County, Nebr. Dugout of the Early Eighties. (From an old print).

11. A Pen Sketch of Madison, Nebr. Made in 1881.

12. The Author's Office in 1882.

13. The Author's First Piece of Furniture, Secretary-bookcase, writing desk, instrument drawers combined.

14. The Author's First Examining and Operating Table. Homemade. Now in use in basement of the home.

15. The Physician's First Office Chair.

16. The Author's Saddlebags.

17. Prospective Physician's Bride of the Eighties.

18. A Benedict at 26 .

19. A Homesteader's Well.

20. Going Full Speed at 33.

21. Dr. George H. Simmons, for Twenty-five Years Editor of the Journal of the American Medical Association.

22. President State Association at 48.

23. Dr. Irving S. Cutter, Dean of Northwestern University Medical School.

24. In the Serene 60 's.

25. Salle des Malades. Hotel Dieu, Beaune, France.

26. The Doctor's Wife.

27. A Daughter in Sailor Suit.

28. The New Home,

29. Pen Sketch of Ft. Atkinson.

30. $\mathrm{Ni}-\mathrm{Ku}-\mathrm{Mi}$.

31. Dr. Susan LaFlesche and LaFlesche Memorial Hospital.

32. Dr. George L. Miller, Omaha's first Physician in the Early Seventies.

33. Dr. Phoebe A. Oliver.

34. Dr. W. M. Bancroft. 


\section{A MEDICAL STUDENT OF THE EARLY EIGHTIES}

Skeleton and Sorghum Pan. Teaching at Thirty a Mointh, I Decide to Study Medicinc, Three Schools of Medicine. Teaching Nobraska Swedes. I Enter Medical College. Requirements in Early Eighties. Harvard, Rush, Jefferson, Missouri Medical, State University of Iowa, Omaha Medical. Listerism. Laudable Pus, More Teaching. Graduation.

THE OLD SKELETON AND THE SORGHUM PAN

I see them as if it were yesterday - although it is close on to sixty years since I dug that trench under spreading trees in the woods on my father's farm in southeastern Iowa. The trench was about five feet long, less than three feet wide and two feet deep. I gathered dried twigs and cut dead timber ready to build a roaring fire. Across the top of the trench and straddling it I placed the big old sorghum evaporating pan which $I$ had bought from a neighbor.

Into the pan I carefully placed the dismembered and mummified portions of a skeleton-a human skeleton. To them I added buckets of water from a near-by creek. Then with a backward glance to make certain everything was right I crept home to bed-if not to sleep. Next morning I early made my way through the woods and came again to the spot.

Yes, the soaking had done some good to the ancient bones with ligaments and parts of muscle attached-but more was needed. I lighted the twigs underneath the pan and built a roaring fire. For the greater part of two days I kept those old bones boiling until they emerged clean and white. These bones were to be my first steps in the real study of anatomy. Let me hasten to allay the reader's mind. I was not a grave robber. The skeleton was given 


\section{A MEDICAL STUDENT OF THE EARLY EIGHTIES}

to me by the village doctor who had just promised to serve as my preceptor. I was about to embark on the study of medicine.

In the early eighties the embryonic follower of Esculapius began training in the office of a practicing physician-called a preceptor, who directed the reading of the medical student for a three-year period while at the same time he gave instruction in practical matters of the profession. The preceptor served without compensation, but at times fortune favored him with a bright student who really rendered valuable assistance while undergoing these years of training.

TEACHING AT THIRTY A MONTH, I DECIDE TO STUDY MEDICINE

My own decision to study medicine had been a matter of chance. When I had finished the second year's work in the high school at Moulton, then a village of seven hundred people in southern Iowa, I began teaching a district school. I lived in the home of a retired physician, who in his youth had gone to district school in Ohio with General Ulysses S. Grant and who was said to closely resemble him. His medical library, a rather creditable one for that day, was stored in my bedroom. Any kind of book attracted me and as I pored over these books I found myself getting more and more interested in the art of medicine. At last my decision was made-I would be a doctor! But, what kind of a doctor?

THREE SCHOOLS OF MEDICINE

At this time-the early eighties, there were three rival schools of medicine; but instead of the Regular physician, the Osteopath and the Chiropractor of today, these three schools were the Regular (derisively 


\section{A MEDICAL STUDENT OF THE EARLY EIGHTIES}

called "Allopaths"), the Homeopaths (whose medicine was chiefly in the form of little pills and infinitesimal dilutions and whose basic principle was that a drug that produced certain symptoms if given in health, would cure a disease presenting those symptoms), and the Eclectics who claimed to use vegetable remedies only.

Medical ethics strictly forbade the so-called Reg-

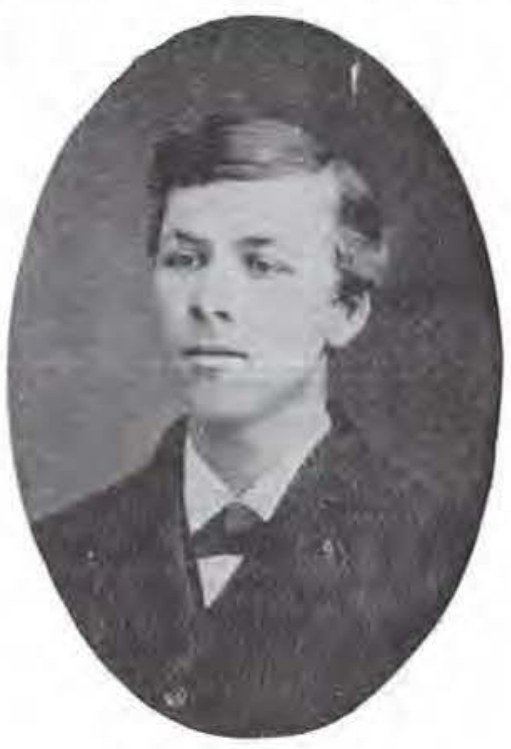

A Teacher at 19.

ular physician from consultation with the Homeopath or Eclectic, because it was said neither had the knowledge of the basic sciences on which medicine is founded and the therapeutics was wholly different. The reorganization of the American Medical Association in 1901 eliminated this ethical ban by providing in effect that any physician of honorable 
conduct who promised not to practice sectarian medicine shall be eligible to membership.

The prospective medical student of my day did not know the fundamental differences between the three schools. He was guided by his medical friends. My medical friends happened to be "Regular," so I was led into their fold in spite of the fact that two of my father's uncles had been trained at the North American Academy of Homeopathic Healing Art at Allentown, $\mathrm{Pa}$., which incidentally, was the first Homeopathic medical school in the United States.

The man whom I asked to serve as my preceptor was a young and brilliant physician in Moulton who had been graduated the previous year from the Missouri Medical College, St. Louis.

$\mathrm{He}$ it was who gave me the skeleton, the remains of a college dissection of the previous year which he had brought home with him and stored on the haymow where the soft structures mummified. He also gave me a copy of Gray's Anatomy over which I pored many an evening comparing the bones of my skeleton with the plates of the text and fixing for all time in my mind the correct names and the relations to adjoining structures.

\section{TEACHING NEBRASKA SWEDES}

But I was eager to get the funds in hand for medical school. I realized that the thirty dollars a month I earned taaching in that district school were accumulating all too slowly. Many people were migrating to the newer Nebraska where it was said better opportunities offered and I decided to try my luck. Fortune favored me. I found a school in a Swedish community in Burt county, Nebraska, which paid thirty-five dollars - and later I received forty dollars. 


\section{A MEDICAL STUDENT OF THE EARLY EIGHTIES}

It was the custom of these Swedes to have as much school in the summer as possible. So that year I taught a six months summer term in the Swedish community, then immediately began a five month winter term in a German district and in the spring returned again to teach among the Swedes.

This year-round teaching program was strengthening my financial condition materially-for my wants were very simple. For a number of years I never had more than one suit, one pair of shoes, and a change of underwear, socks and handerchiefs. Pioneer life required no more. But my medical studies were not neglected while my funds were growing. The foremost physician in this new Nebraska community gave me the freedom of his library and under him I read Materia Medica and Therapeutics, Ramsbotham's Obstetries and that masterpiece of medical literature, Flint's Practice. I rode and drove those prairie trails of Burt and Cuming counties with him every week-end opportunity and absorbed from him practical details that came back to me many years later as I too, rode the prairies of Nebraska in my line of duty.

I ENTER MEDICAL COLLEGE

In the fall of 1880 , with a fair reading background and less than two hundred dollars I enrolled in the Regular Medical Department of the Iowa State University.

\section{REQUIREMENTS IN THE EARLY EIGHTIES}

It is interesting to note the development of medical education in the last half century. To the younger men and women in the profession the progress made in medical education since the early eighties is almost unbelievable and to those who are the 


\section{A MEDICAL STUDENT OF THE EARLY EIGHTIES}

product of that early system, it is an interesting fact recalled with smiles and pleasant memories.

Under our system of individual state's rights, the regulation of educational institutions and of licensure belong to the several states. No national law can cover the matter. The laws pertaining to medical education and licensure were somewhat lax in all states up to the beginning of the present century.

Following the Civil War and particularly during the two decades preceding 1885 , the Middle West was developing rapidly under the Homestead law and new communities and new towns sprang up as if over night. The demand for physicians to supply the needs of the settlers was somewhat urgent and medical colleges eame into being in middle western cities and elsewhere to supply the supposed demand.

The requirements for graduation in medicine in the early eighties, speaking generally, were three years of study under a preceptor, including two courses of lectures in a medical college. This might be and was, variously construed to mean constant study, or part time study, under a preceptor. The college courses varied from twenty to twenty-four weeks. Competition for students was rather keen and the moral stamina of the student often determined the selection of a school, as much as the condition of his purse.

\section{HARVARD - RUSH - JEFFERSON - MISSOURI MEDICAL BELLEVUE - STATE UNIVERSITY OF IOWA - OMAHA MEDICAL}

Harvard Medical College, always foremost in medical education in America, in 1880-1881, required for entrance a degree from a recognized college or the passing of an examination in English, Latin, Physics 


\section{A MEDICAL STUDENT OF THE EARLY EIGHTIES}

and an elective subject. The course was four years of 20 weeks each year.

Rush Medical College in the announcement for 1881-82 gave a three year attendance requirement of twenty-one weeks each year, but mentioned no entrance requirements. Jefferson Medical College, the Missouri Medical College, Bellevue Medical College, the State University of Iowa and Omaha Medical College, either had no entrance requirements in 1880-81 and 82 or merely nominal ones. These five colleges required three years of study under a preceptor including two courses of lectures for graduation. An elective third course of lectures was offered.

My choice of school was partially influenced by its proximity and the modest tuition fees, but also by the belief a state institution would maintain high standards even though its facilities might be limited. I was not alone in these first college days, for one of my friends from northeastern Nebraska had accompanied me and we started our medical training together.

Iowa City, situated on the wooded bluffs overlooking the Iowa river, was then a beautiful city of seven thousand people. It had been the territorial capital of Iowa and the old Capitol building (restored) is even now the administrative building of the University. The prosperity of the city was largely dependent on the University and its students, although it did boast a packing house and a distillery.

I found myself one of about one hundred and fifty students who registered that fall for work in the medical school. Three of the students had bachelor degrees, a number had been teachers, several had some knowledge of pharmacy, while others came di- 


\section{A MEDICAL STUDENT OF THE EARLY EIGHTIFS}

rect from the farm and one was a cowboy fresh from the western range. It was soon evident that those who had some previous college work led all others in scholarship. In later years in the struggle with the world, one academic degree man suicided, one died of tuberculosis, and the third after a brilliant career died in middle life as a remote result of an infection. Three of the students, Guthrie, Littig, and Chase later became teachers in our Alma Mater. Guthrie served as dean for a number of years. One, Ruth, became a surgical teacher in a rival medical college.

My friend Syl and I were going to live together, so we started out to find a boarding house. We had both been born in Pennsylvania, of sturdy Pennsylvania-German parentage. Therefore when our eyes lit upon a large old brick structure, formerly a hotel and still bearing the sign "Pennsylvania House," offering board and room to students, we did not hesitate, but settled under its supposedly hospitable roof. Fortunately for us it was one of the least expensive places to be found. Board and room cost two dollars and a half per week. We were required to furnish our own fuel, but cord-wood was readily obtainable at the market square. Syl did hate to do his share of wood chopping however!

Food was mediocre in quality and although abundant enough for our hearty student appetites, might have been improved. There were about twenty of us medical students at the table. We were always served a soup course with oyster crackers at the hearty noon meal. I remember that on one occasion some of the students expressed dissatisfaction with the meal by throwing handfuls of these little round oyster crackers at the waiters. As usual, one thing led to another, and in the excitement some one 


\section{A MEDICAL STUDENT OF THE EARLY EIGHTIES}

grabbed the rancid butter and aimed at one of the waiters. It struck the kitchen door! Immediately the portly frame of the Irish landlady appeared in the doorway and demanded to know who was guilty. The guilty one was to be expelled at once. But no one had done it! And so the episode ended.

The cook was a Bohemian girl named Mary, who had evidently loved not wisely, but too well. One night the landlady called one of the oldest senior students to attend Mary in childbirth. The next day when the boys reached the table they burst into song-

"Mary had a little lamb. Little lamb, little lamb, _-"

Medical students at that time were considered outlaws by the other students at the University, principally, I believe, because some years before there had been a scandal about body snatching that involved the Medical School and some of its students.

I cannot recollect that we paid much attention to baseball, although I know it was played by students of the academic department. We did attend the Friday night debates of the Zetagathian and Erodelphian Literary societies and found them quite entertaining. I particularly remember an intercollegiate debate which was a great event. Once in a great while we spent a small sum on some entertainment. 1 recall that we paid fifty cents to hear the young and lovely Mary Anderson as. Parthenia in "Ingomar the Barbarian" during the winter of 1880-81.

If we had few outside activities, our college work kept us very busy. At that time the Medical Department was housed in the south half of what was then called the South Hall. The first floor was the 


\section{A MEDICAL STUDENT OF THE EARLY EIGHTIES}

lecture room and the basement was used for dissection. The entrance corridor housed the nucleus of a museum, both botanical and pathological. This antedated the first medical building erected in the summer of 1882 which was later destroyed by fire.

Most of the classwork was given by lectures, which held the attention of the entire class of one hundred

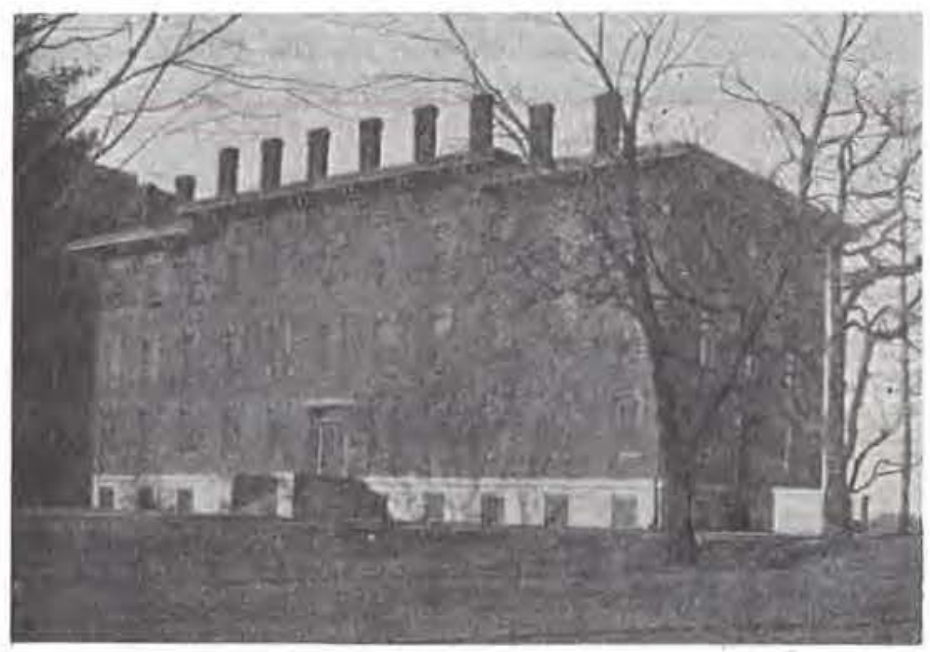

Old South Hall. The south half of the first story and basement only, was used for the medical students.

and fifty students. We used indelible pencils to take lectures notes, for the modern fountain pen was unknown. Of course, like all students, we occasionally found fault with the lectures, but I realize now that most of the lectures were excellently given. The chemistry lectures were the most difficult, because the professor, a very learned man and a graduate of the University of Copenhagen, spoke with a decided accent.

Except for the simple tests in urinalysis, almost 


\section{A MEDICAL STUDENT OF THE EARLY EIGHTIES}

no practical laboratory work was offered. We were required to dissect one part of the human body, but as material was scarce, seven students were assigned to one cadaver. It happened that my friend Syl who did not like dissection, was assigned to the neck and face. He worked at it for a little while, then tiring of it, he boldly cut off the entire cheek, Stenson's duct, the masseter muscles and all, and chrew it into the garbage receptacle! Thus ended his practical work in dissection.

\section{LISTERISM}

The Mercy Hospital which had about thirty-five beds, offered an abundance of material for the surgical clinic which was given every Thursday. It is interesting to note that at that time there was still considerable skepticism about antiseptic and aseptic methods. Pasteur had advanced the germ theory of disease. Sir Joseph Lister, an English surgeon in 1861 developed a system of antiseptic surgical practice that in time effected a revolution in the treatment of all surgical affections, but a generation passed before his method was generally accepted. This led to aseptic surgery and the primary union of wounds, which in effect means that a clean wound if the edges are approximated will promptly unite, without pus formation.

Lister was first to recognize and publicly set forth in his lectures the now universally accepted fact that infection is the chief danger in treating wounds. Lister's system was, in brief, the exclusion of microbes that induce the septic process or the eradication of those microbes after they had gained access to the wound. This was accomplished by carbolic acid in solution or spray. All objects near the wound were kept thoroughly purified and "surgically clean," 


\section{A MEDICAL STUDENT OF THE EARLY EIGHTIES}

as were the hands of the operator and assistants. During the operation, the wound and adjacent parts of the body were kept continually moistened with the antiseptic solution.

\section{LAUDABLE PUS}

But antisepsis had not been universally accepted in the early eighties. Listerism was nuch discussed. Up to the time of my graduation in the spring of 1882, Dr. W. F. Peck, our professor of surgery, had not accepted it. Dr. Peck had been a surgeon in the Civil War and was by many considered the foremost surgeon west of Chicago. In 1880 , he had a record of having performed thirty-six ovariotomies (removed thirty-six ovarian tumors), a notable record for that time of an operation now rarely performed except for very special reasons. Dr. Peck practiced and taught cleanliness in his surgical work. He insisted upon an extremely hot operating amphitheatre - a fact which annoyed the students. At that time "laudable pus" was still taught. This term "laudable pus" was applied to a thick creamy pus which was thought to imply a healthy condition of the wound and believed to be a necessary part of the healing process.

I well recall the first surgical case presented before us in the surgical service of the teaching hospital. Oakum - a material obtained by picking hemp into a loose fibre and treating it with pine tar (used also for caulking boats and ships) - had been used for surgical dressings during the Civil War, and was still the standard absorbent surgical dressing. Marine sponges were used in place of the gauze sponges of the present time. This first surgical case was that of a young woman who was operated on for a 


\section{A MEDICAL STUDENT OF THE EARLY EIGHTIES}

bone disease, osteomylitis, of the humerus. Oakum was of course used as the absorbent dressing. A week later when the wound was redressed for the first time, it literally "smelled to heaven." Professor Peck marched the patient around the pit of the amphitheatre, arm upheld, remarking, "Gentlemen, laudable pus."

This theory was not so far from the present day Orr method of saucerization, iodine sterilization, sterile vaseline gauze pack and infrequent redressing. Within a few years oakum was supplanted by antiseptic gauze, which was sublimated or carbolizedsome wet, some dry. Iodoform gauze also made its appearance in the eighties.

As further evidence that there was divided opinion on the subject of Listerism as late as 1882, I quote from the "Address for the Faculty" given by Dr. H. B. Ransom at our Commencement exercises on March 1, 1882. This address was printed in full in the Daily Iowa City Republican a copy of which I still cherish. Dr. Ransom said: "The three healing graces, physiological rest, support and cleanliness have been exalted and will remain upon their thrones, whether Listerism is true or not, whether there are pathogenic bacteria or not."

Clinical material for the study of eye, ear, nose and throat was abundant and used to good advantage. As I look back on it, I think the clinics in internal medicine were good too. The gynecological clinic had but one patient during the two years I was in school. Her case was diagnosed as uterine hyperplasia, and was treated with local applications of carbolic acid, tincture of iodine and glycerine, equal parts. Obstetrics was taught by the aid of a manikin, and the principles were well drilled into the 


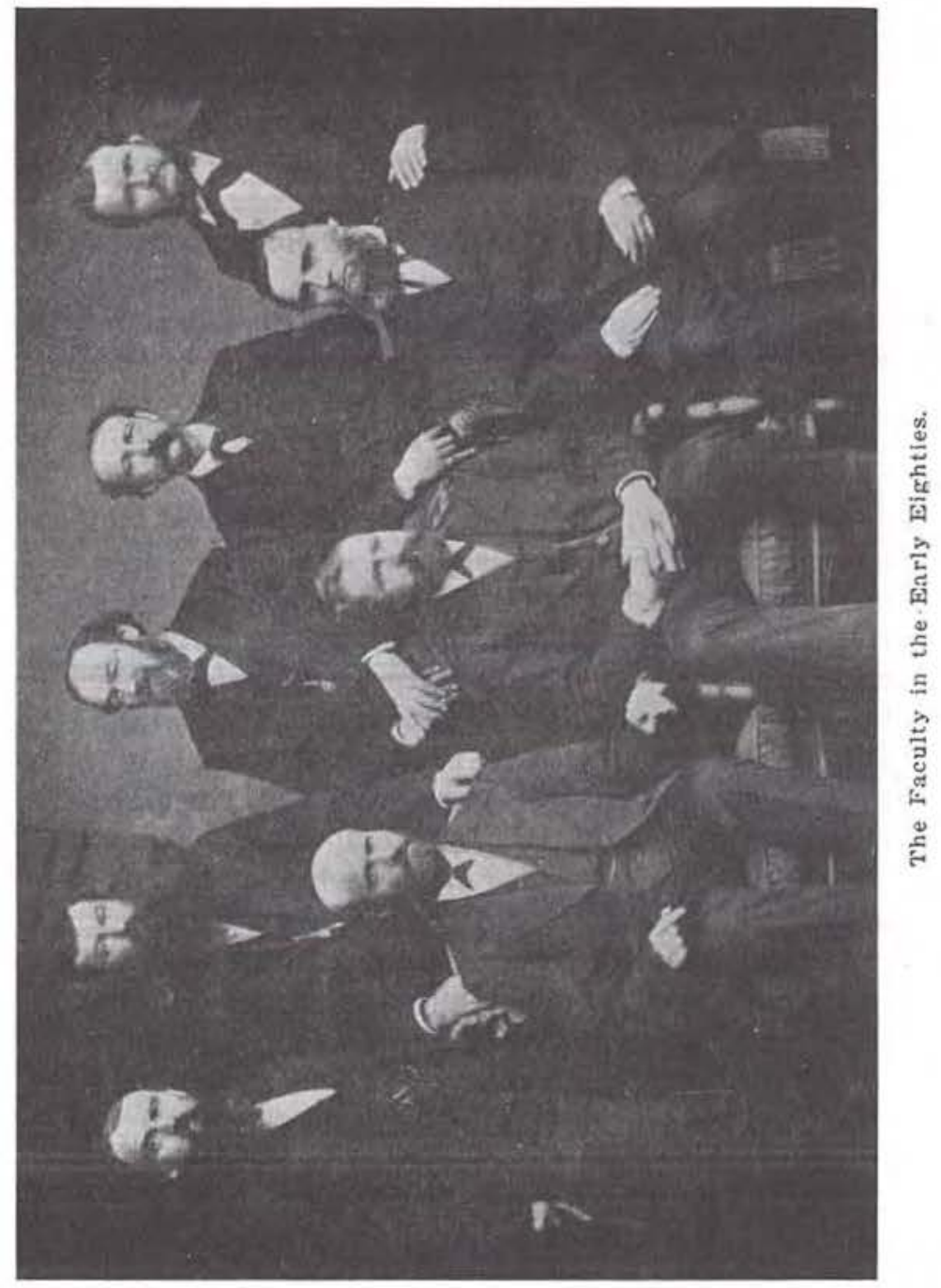




\section{A. MEDICAL STUDENT OF THE EARLY EIGHTIES}

students. No obstetric cases were seen by the students while in school.

In spite of the sparseness of clinical material, my friend Syl whose parents resided in Pennsylvania, and who attended Jefferson Medical College, Philadelphia, in his senior year, always insisted that we students at Iowa City received just as much good out of the little clinical material at hand as they did at Jefferson, with the wealth of material. His reasoning was that we used all the material to good advantage, while at Jefferson they brought patients in one door and presently pushed them out the other, with little regard to their clinic teaching value.

Students were selected by rotation from an alphabetical list, to assist in the diagnosis of cases in the hospital. Occasionally, a student was allowed to assist at an operation.

Training in Materia Medica and prescription writing was excellent. The student of that day acquired a knowledge of drugs and their uses. Moreover, he learned how to write a prescription. The young medical man of today is so apt in prescribing proprietaries that one wonders whether modern teaching is weak at this point, or whether it is the drift toward serums and vaccines and the giving of so-called specific remedies, intra-venous medication and the like that has brought the change.

We had excellent instruction in the art of bandaging-a skill in which $I$ have always taken great pride.

Chloroform and ether masks were home-made affairs during my student days. Our anesthetist, Dr. Moon, made them by rolling newspapers into a cone shape and covering them both inside and outside with a towel. 


\section{A MEDICAL STUDENT OF THE EARLY EIGHTIES}

The teaching on the use of morphine must have been very emphatic for my room-mate and I were so impressed with its dangerous qualities that we decided never to give it by hypodermic injection, but to place it under the tongue* for quick effect! Needless to say we changed our minds soon after we began practice.

Our texts were few. Of course, we used Flint's Practice of Medicine, for many years the authority in that field. Even after the death of Austin Flint, Sr., the edition revised by his son Austin Flint, Jr. commanded a wide sale. The descriptions of the symptomology and the course of disease as given by the elder Flint have never been excelled in medical literature. We also used Watson's Practice of Medicine. For surgery we used Ashhurst's Surgery and Gross' Surgery. Ashhurst's International System of Surgery, which appeared early in the eighties became the reference work of all ambitious physicians. Biddle's Materia Medica and Bartholow's Materia Medica and Therapeutics were our texts in that important field. As I recall it now, Lusk's Midwifery, Thomas' Diseases of Women, Dalton's Physiology, and Heinrich's Chemistry completed our shelf of text books. I had been out of college a short time when Pepper's System of Medicine appeared, and it was promptly added to the shelves of most physicians.

It is significant that the period just before and immediately after the turn of the century brought a flood of medical literature on special subjectstexts, manuals and handbooks. Modern developments in Medical Science and procedure were unfolding rapidly.

- Meticine in powder form plneed under the tongue is ahsorbed ulmost immediately. 


\section{A MEDICAL STUDENT OF THE EARLY EIGHTIES}

\section{MORE TEACHING}

At the end of my first year, I proceeded at once to northeast Nebraska where I again spent the summer teaching my Swedish hopefuls and replenishing my purse. During this last term of teaching, a Swedish farmer in the district developed quinsy, sent for me and asked that I get him some medicine. I demurred and suggested instead that I call a physician from town for him. He was insistent, and said he knew none of the physicians, but did know that I could help him, if I would. I obtained something for him

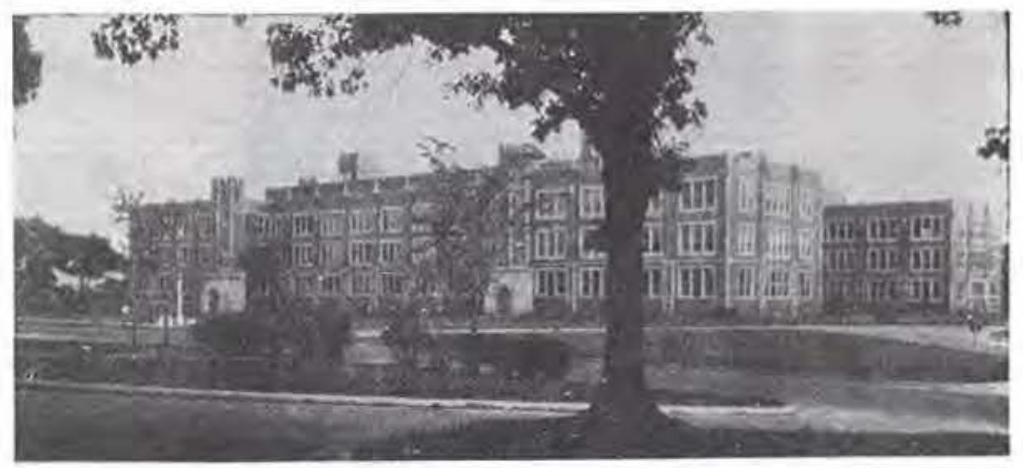

The Present Iowa University Medical School.

- just what I do not recall. He recovered, via medicatrix naturae, and insisted on giving me three dollars for my services, saying he knew I saved his life. This was the first money I ever received for medical services, but I have aiways doubted that I earned it!

\section{GRAIUUATION}

That fall I returned to college. My preceptor not only supplemented my scanty earnings of the summer, thus making my second year possible, but offered me an assistantship with him when I gradu- 


\section{A MEDICAL STUDENT OF THE EARLY EIGHTIES}

ated. I had intended to take three terms at medical school before coming up for graduation. Most of my classmates however, planned to come up for graduation at the end of the second year and they persuaded me to join them. They argued that one could take a postgraduate course, after a year or

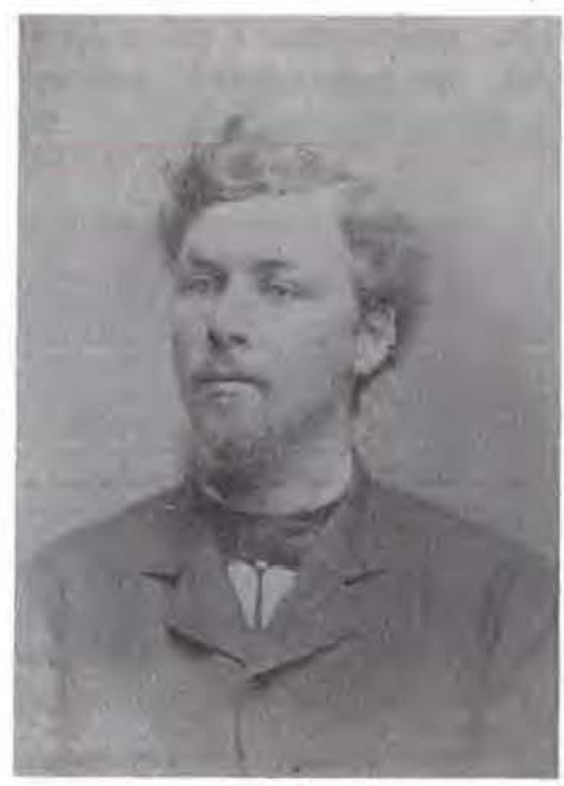

A Medical Graduate at 23.

two and that immediate experience was the best thing. Little did I dream that eleven years were to elapse before I could take a postgraduate course!

And so I was graduated with forty-five of my classmates, on March 1, 1882, two weeks after my twenty-third birthday. I had exactly forty weeks of work in Medical College a fact which I recalled with amusement when I returned to Iowa City for the for- 


\section{A MEDICAL STUDENT OF THE EARLY EIGHTIES}

tieth class reunion. At that time with several classmates, I was passing down the receiving line at the President's reception. When we reached President Jessup I remarked that we belonged to a period when it took only forty weeks to make a doctor. The President rose to the occasion gallantly remarking "And they made some pretty good ones!" To which I laughingly replied "We admit it!" 


\section{A MEDICAL TYRO OF THE EARLY EIGHTIES}

Partuership With Preceptor. My First Confinement. I Treat Convulsions. The Irishman and His "Ager." I Recoive Twenty-Five Dollars. Partuership Dissolved.

\section{PARTNERSHIP WITH PRECEPTOR}

Although I had earned the right to affix that magical "M. D." to my name, I had a deep-rooted feeling of my own inadequacy and was convinced that I did not have sufficient knowledge to practice medicine on my own responsibility. This feeling of fundamental inferiority probably saved me from making an utter failure, for it spurred me on to continuous endeavor to compensate for my deficiencies. At any rate I was very glad to accept the offer of a limited partnership with my old preceptor at Moulton, Iowa.

Our suite of offices was far from inviting. A large store room on the principal business street was partitioned into three rooms. I equipped the rear room with a bed for my sleeping quarters. The office was my home. I paid the then large sum of three dollars and a half a week for board at a near-by restaurant. I was happy as could be for was I not a practicing physician at last?

And then my experiences began. Five days after I arrived, my preceptor left me in charge of the office and his patients while he went away on a business trip for a week. The time had come to "Root, hog, or die." Fortunately for me, the wife of my partner was a brilliant and sensible woman, who had been one of my high school teachers. She helped me through these first days with good advice, and even instilled some principles of diplomacy into my blundering brain. 


\section{A MEDICAL TYRO OF THE EARLY EIGHTIES}

\section{FIRST CONFINEMENT}

The first confinement call came promptly. The patient was the wife of the section foreman. As soon as I entered the bedchamber the husband said, "Doc, have you had any experience in handling such cases?" I had schooled myself for just such a question and unhesitatingly, but shamefully, replied "Oh, yes!" (My total college experience was with a manikin, you remember). Luckily for me, the child was born about ten minutes after my arrival, else I might have fallen into grave disrepute.

\section{TREAT CONVULSIONS}

A woman, whose husband died while on a spree in Burlington, went into convulsions. I was called to treat her. Something told me to give her bromide and chloral, nerve quieting remedies; the preceptor's wife helped me to make a diagnosis of hysterical convulsions. I assumed a very sober and severe attitude, ordered the members of the household about and gave her every attention within my mental horizon. People thought her alarmingly ill. Within a few days she began to recover and my star was in the ascendant. I was told by my friends that people were speaking well of the "young doctor."

A very special friend of my partner developed a severe inflammation of the bladder and I was called to take care of him. To relieve the pain of the strangury, I prescribed an opiate together with neutralizing agents. He became delirious and the family became alarmed. The preceptor-partner returned at this critical moment and explained to the satisfaction of the family and friends that the opiate produced the mental confusion.

All my life I have been somewhat diffident; from 


\section{A MEDICAL TYIRO OF THE EARLY EIGHTIES}

adolescence on I was extremely bashful. As I grew older, and attained my medical degree, I did not completely overcome that inferiority complex, as the psychologists of today would call it. It spurred me on to a bit of assumed courage. I determined to overcome this lack of training and experience, which I felt so keenly, by faithful study. I made it my practice to read and re-read in my books every case I had to treat, so as to familiarize myself with all the symptoms and varying phases and complicatione of disease. No matter how frequently I had cases of the same general type under my care, I carried out this practice for many years. This proved a wonderful help to me in later years. I recommend it to others.

\section{THE IRISHMAN AND HIS "AGER"}

At the time of which I write, Iowa had prohibition of distilled alcoholic liquors, and local option for beer $3 \%$ and wines $15 \%$ alcohol. Alcohol liquors might be preseribed by physicians for the use of patients. This privilege was much abused, both by the laity and by some physicians. Requests for prescriptions for alcohol came as soon as it was known I was in practice. I declined all. But the variety of excuses offered were a source of amusement to me. One man whom I had known well for some years told me he had a mule with a sore hoof and he wanted alcohol to put on the hoof!

Malarial fever was common in Southern Iowa in those days and many persons called for whiskey or alcohol to take with quinine. An Irishman with a whiskey nose came to me for a "dost o' quinine for ager." When I moved to get it for him he came close and whispered he wanted "to take it in whos- 


\section{A MEDICAL TYRO OF THE EARLY EIGHTIES}

key, doctor, just a little quinine and lots of whoskey." On a later occasion at the drug store my partner fixed this ardent customer on a like request, by adding tincture of capsicum to the quinine and whiskey. The Irishman gulped it, strangled, struggled to catch his breath, and exclaimed "Jasus Carist, that would kill a hor-rse; that would kill the divil!"

\section{PARTNERSHIP JISSOLVED-1 RECEIVE TWENTY-FIVE DOLLARS}

I soon learned that my preceptor had acquired some bad habits during the years I had been at medical school. He was drinking and I suspected he was using molphine, a suspicion later events confirmed. And so I decided to go elsewhere. I had spent three and a half very eventful, and professionally very profitable months, from March third to mid-June of 1882 in this partnership. There had been little illness after March. By the time I left we had earned over $\$ 1,000$ - which was probably an average for that day. Under our agreement, I was to have one fourth, but when we settled, I was awarded exactly $\$ 25.00$.

The later history of my preceptor was rather startling. In a dispute over a bill he shot and mortally wounded a butcher-in self defense he claimed -and was sentenced to ten years in the penitentiary at Ft. Madison. After two years imprisonment, he was pardoned and located in Ft. Madison as a surgeon where some years later, he died.

Such was my beginning in the practice of medicine! 
NORTH NEBRASKA IN THE EARLY EIGHTIES

The Railroads. The Terrain. Homesteads. Dugouls, Sod Houses. Flies. Trails, Not Roads. The Lumber Wagon. Fuel, Blissards.

THE RAILROADS

Nebraska in the early eighties was still in the making. The pioneers of territorial days had dispossessed the Indian of his hunting grounds, had driven the buffalo, deer and antelope from the prairies.

In 1867 the overland trails were replaced by the railroad. The Union Pacific had extended its lines across the state and from then on the settlement and improvement of the lands was rapid; settlements sprang up in quick succession here and there over the new territory. It was a veritable "conquest of civilization over savagery;" a time when men endured hardships with little hope of reward save the making of a home that would provide the bare necessities of life. The hot winds of summer sometimes robbed them of their growing crops and the blizzards of winter drove them in hiding. There were savages to combat but there were also the horsethief and the gunman, more venomous than the savage,

This was a part of the "Great American Desert" which the earlier explorers thought could never be made habitable. They left a trail which marked the line of advance of future settlers. It was first along the north side of the Platte in the eastern part of Nebraska that settlements were established. The gold rush to California brought vast numbers of venturesome people along the trail and thus the prairies became scarred with wagon trails. Along the Platte river the land was rich with an abundance of timber. Naturally the earlier settlers were at- 
NORTH NEBRASKA IN THE EARLY EIGHTIES

tracted to such a promising land and here they built their log or sod houses, dug wells, made ditches and sod walls to corral their cattle. Wild game was plentiful, the waters teemed with fish and the land usually responded to the touch of the tiller. Surely here was the land of plenty requiring only the fortitude and resourcefulness of the white man to make it a fitting abode for themselves and for the generations to come.

The picture changes. With the coming of the railroads settlers came thick and fast.

\section{THE TERRAIN}

The Platte river bisects the state of Nebraska into almost equal parts and known, since pioneer politics created sections, as North Nebraska and South Nebraska, or "The North Platte" and "The South Platte."

North Nebraska is for the most part a gently rolling prairie with a black loam soil of varying depth and is drained by numerous streams. Timber occurs along the water courses, heaviest along the larger streams. In the days of the Indians the prairie was burned off each fall to aid the Indians in the hunt. These fires destroyed all vegetation within reach and largely account for the fact that there were no trees on the uplands. Trees along the streams were, in places, protected from fire by the meanderings of the streams and this explains their existence today.

\section{HOMESTEADS}

By the early eighties Northeast Nebraska was settled, generally speaking, about one hundred miles west of the Missouri river and further settlement 
NORTH NEBRASKA IN THE EARLY EIGHTIES

was in rapid progress. The railroads had penetrated north Nebraska about one hundred and thirty miles to the northwest; spurs had been built into the northeastern section from Sioux Ciry for about forty miles and a branch had been built from the main line of the Union Pacific at Columbus, fifty miles to the north and a railroad had reached fifty miles north from Omaha along the Missouri river.

All spring and summer emigrant wagons were on the westward trails to sections further west, to locate homesteads and timber claims or perchance to get pre-emptions. The fee for homesteading 160 acres or for timber culture entry of 160 acres was $\$ 16.00$. Pre-emptions could be secured at $\$ 1.25$ per acre plus $\$ 2$ filing fee. Homesteading required five

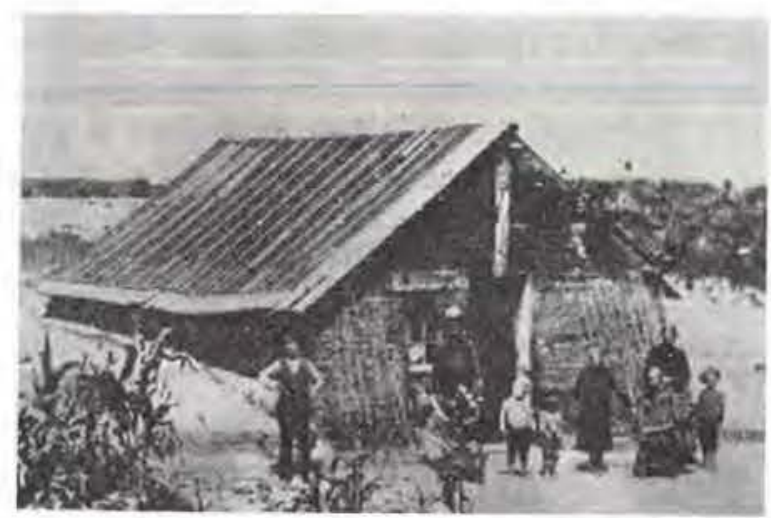

A Madison county, Nebr., Durout of the early eightles. (From an old print).

years of residence on the land and cultivation of a part of it; timber claiming, the planting of ten acres of timber and its cultivation for at least eight years before government title was given, while in pre-emptions on the payment of $\$ 1.25$ per acre and six 
NORTH NEBRASKA IN THE EARLY EIGHTIES

months residence on the land title was given to the pre-emptor.

Settlers were offered alluring inducements by the railroads to settle upon the lands granted to the railroads as an inducement to build the railroad across the plains. Land, not subject to homestead entry, was offered for two to three dollars an acre with a one-third down payment. Immigration agents appealed to homesteaders. Bohemians, Irish, Swedes, Norwegians, Danes and Germans came in great numbers to colonize the land.

Prairie chickens and quail abounded everywhere. Native waterfowl was not abundant, but the seasonal flight of ducks and geese to the Northland in spring and to the Southland in fall was an entrancing sight to behold, for they migrated in flocks of untold thousands and the flight lasted for many days. Even today relatively large flights may be seen. There were no game laws in those days and when waterfowl alighted to feed, or settled at night to rest, pot hunters slaughtered them by the hundreds. The streams were full of fish, notably bass, pickerel and catfish. During the early eighties channel catfish four feet long and weighing fifty pounds were caught below the first dam in the Elkhorn river at West Point. A four foot specimen caught at West Point about 1880 was mounted and placed in the University museum at Lincoln, probably the first catfish specimen in the museum. The channel catfish is still to be found in the larger Nebraska streams.

Buffalo, deer and antelope had disappeared westward; coyotes, raccoons, skunks, beaver, opposums and badgers were native. Wild fruits were rather abundant in pioneer days. Wild grapes, wild plums, chokecherries, elderberries, gooseberries, currants 


\section{NORTH NEBRASKA IN THE EARLY EIGHTIES}

and raspberries grew in wooded areas. Wild cherries and sand cherries abounded in protected places. In more recent years the wild plum trees and their fruit have been rendered worthless by insect pests.

The particular part of Northeast Nebraska to which this story pertains was permanently settled about 1870 and as I came to it twelve years later, in 1882 , I may be said to belong to the second invasion of pioneers.

$$
\text { DUGOUTS, SOD HOUSES }
$$

The early settler's who had come with little money

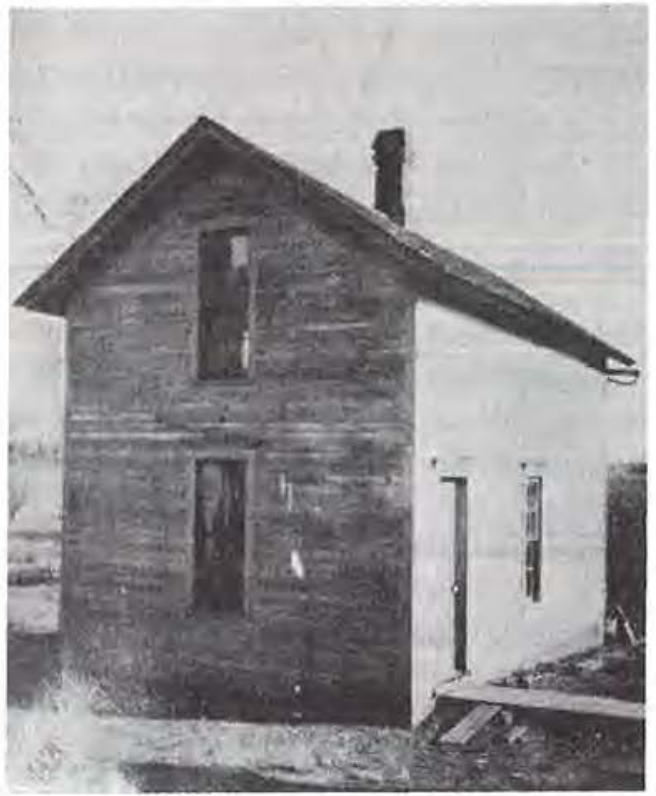

Type of a pioneer's frame house, $16 \times 24$ feet, $1 \frac{1 / 2}{2}$ stories high.

had built cheap frame houses of two, three, four or five rooms with lumber hauled by slow teams from the railhead thirty-five miles distant. A frame 


\section{NORTH NEBRASKA IN THE EARLY EIGHTIES}

house 16 by 24 feet on the ground and one and one half stories high was a standard for those who could afford it. To this, if the family need and purse justified, an addition known as an "L" was built. Frame houses rested on wooden blocks or brick pillar foundations rather than on solid walls. As a protection against the subzero weather of winter it was the universal custom to bank the houses with a heavy coating of stable manure all around the foundations.

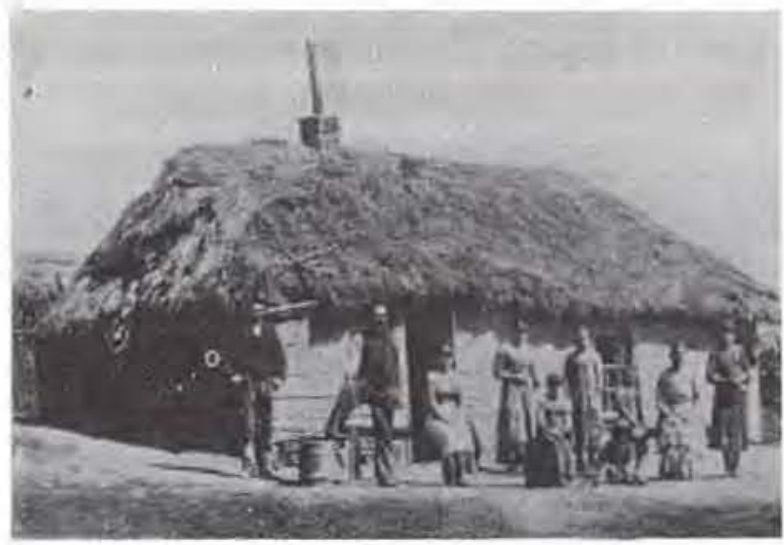

A Sod house of the early eighties, with thatched roof. Madison county, Nebr. (From an old print).

Those who could not afford frame houses, built of prairie sod cut a foot wide, laid up after the manner of brick, but without mortar, or made dugouts in the hillsides, with earth floors if they could not afford to buy flooring material. Generally rough timbers, as saplings or tree limbs were laid over the top for rafters and slough grass and sod laid on top of the rafters to form a roof of a sort. In a Swedish settlement I saw houses made of sod walls with thatched 


\section{NORTH NEBRASKA IN THE EARLY EIGHTIES}

roofs of slough grass. Heating was by small crude cook stoves. Generally two small removable windows served for light.

\section{FLIES}

Fly netting or fly screening for windows and doors was practically unknown to the pioneers of the eighties, or if known was thought out of financial reach, for the early homesteader had very little money and needed what he did have for the barest necessities. Horses, sheep, cattle and hogs, fly harborers par excellence, were kept in stables or corrals near the homes. The flies pestered men, women and children by their presence, and as germ car-

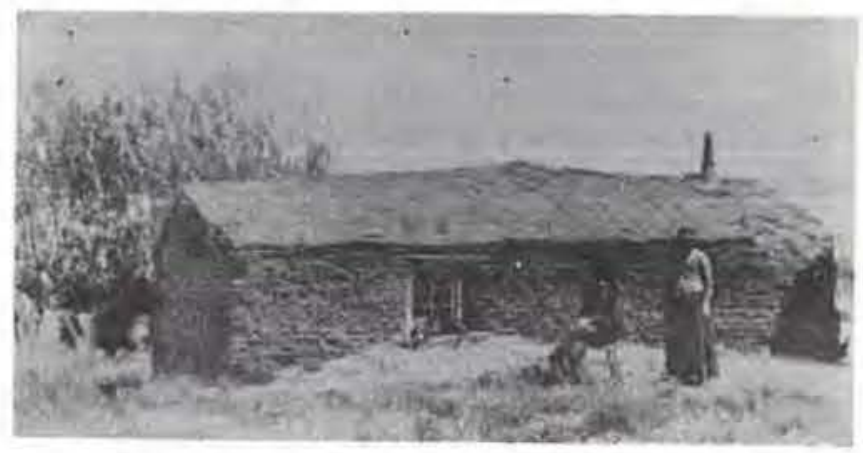

Sod House, sod roof, Madison county. Nebr. (From an old photo).

riers contaminated the food, thus causing a long list of diseases known to the pioneers, now rarely heard of. Simple diarrhoea of infants, cholera infantum, dysentery of young and old, cholera morbus, and typhoid fever germs, were conveyed by flies.

There were few barns; most people got along with sheds for horses and milch cows. Often these were made of poles and straw, or slough grass-a tall grass (sometimes growing to six feet), heavy 
NORTH NEBRASKA IN THE EARLY EIGHTIES

stemmed, coarse and strong found in swampy land in the early days. It seems to have disappeared with the settlement of the country. Cattle, not in the milking class, might have a wind-break to the northwest, or a stack of straw, or perhaps nothing, to protect them against the winter blasts.

Hogs in many cases, particularly sows with young, were kept in small portable pens which were moved from day to day over the prairie to afford fresh pasture.

In due time churches and schools were erected and the rugged individualism of the pioneer gave way to organized collectivism. Large tracts of land were secured by eastern capitalists and thus the ranch became an institution in this new land.

TRAILS, NOT ROADS

There were practically no roads over the prairie after one reached several miles from town. There were trails. If you wanted to go to a particular place you followed a trail in the general direction until you reached the desired neighborhood. When you felt you must be near the place and not sure of yourself, you asked the nearest homesteader. There were few bridges and some of these were low water bridges-three stringers thrown across the small stream covered with plank or perchance with small logs cut from nearby woodland, usually cottonwood. High water sometimes carried them away.

THE LUMBER WAGON

The lumber wagon was the conveyance of everyday use. Farmers' families came to town in it. A wide board with cleats to hold it in place served as a seat for the driver and one person who may have 
NORTH NEBRASKA IN THE EARLY EIGHTIES

accompanied him. Other members of the family, if any, sat on hay or straw with which the wagon box was bedded. The spring seat for lumber wagons was a luxury few could afford.

For want of a hearse the lumber wagon was used to carry the coffin containing the dead to the last resting place. I have seen the lines from the horses' harness taken to lower the coffin, because there were no straps for the purpose. Mechanical lowering devices are a modern invention.

There were no buggies, carriages or spring wagons in the community except at the livery stable. Indian ponies were ridden for single travel. The first spring wagon was a curiosity and the first carriage purchased was an indication of wealth of the owner, an attorney, whose wife had inherited a fortune from Illinois.

It is doubtful whether in 1882 there was anybody -farmer, banker, or merchant-in our community worth above $\$ 10,000$.

Good land within a reasonable distance from town was worth from ten to fifteen dollars an acre, or from $\$ 1600$ to $\$ 2400$ a quarter section of 160 acres. Raw, or unimproved land sold as low as $\$ 1000$ a quarter.

FUEL

Living conditions were in many cases worse than housing conditions. The fuel of the homesteader varied from hay twisted into convenient bundles to put into the stove, to sunflower seed-pods and stalks, or rosin weeds, corn cobs, or corn on the cob. When corn was nine cents a bushel and coal hard to get and high in price after being brought from Rock Springs, Wyoming, by train to the nearest railroad station (which may have been 35 miles away) 
NORTH NEBRASKA IN THE EARLY EIGHTIES

the homesteader burned his corn when much heat was needed. Corn as fuel gives out an intense heat. Sacrilege though it seemed to be to burn corn intended for food, dire necessity compelled its use at times.

Cooking utensils and dishes were scarce with most people. Large tin cans discarded after emptying, by the hotel at the railhead, were eagerly sought by the homesteader for cooking utensils.

The housewife had no refrigerator and few people had good cellars or caves in which to care for perishable foodstuffs. Milk therefore soured quickly in summer temperature. The modern methods of handling milk were not then known. The consequence was that children fed on cow's milk were constantly running serious risks and many perished. Some people lowered the milk and butter in buckets by rope into the open well pit to take advantage of the lower temperature.

The homesteader raised sugar-cane for his sweetening. Making sorghum was an event in fall. A large, homemade shallow pan was put over a fire place, which might be a ditch in the hillside or a place walled up with sod. The cane juice was expressed between two rollers and put in the pans over a fire for evaporation. Elaborate skimming and reboiling was necessary to make good sorghum. Nowadays one hears speakers at old settlers' reunions declaim against sorghum-"We had nothing but sorghum." This was no tragedy, for sorghum tasted good, although it had a little more tang than our present-day sweets. Children of those days had the treat of their lives "licking the pan" when sorghum making ended.

Bedsteads were crude, were without springs, many of them with home-made frames, bedded with straw 


\section{NORTH NEBRASKA IN THE EARLY EIGHTIES}

or corn husk ticks, which, varying with the housekeeper's ideas of cleanliness, were changed at longer or shorter intervals. Bed covers, including the feather beds, were not abundant and subject to the same care as the ticks according to the ideas of the family. Homes for the most part were without carpets, rugs or wall adornments.

The little chigger pestered people in the fall of the year by digging into the skin, causing almost intolerable itching. Fleas also were a pest. Their normal habitat is the hog, sheep, and dog. Proximity of the outbuildings containing stock, to the house, favored the conveyance of fleas into the house. The dog also in many cases had access to the house. Hence fleas infested many houses and made life miserable to the occupants by their bites. The roughly constructed houses, particularly dugouts and sod houses, favored the multiplication of bed bugs, if once they gained access to the home. I had personal experiences with them. Several times I brought bugs home from places where I had been called and where I had laid my overcoat or hat on a bed for want of a place to hang it. I had the additional experience of laying my hat on an old couch in a patient's home and of picking a specimen of pediculosis capitas (head-louse) out of my hair on returning to my home!

I would not have the reader think that I mean to reflect on the pioneer housekeeper; by no means. She did the best she could with the scant facilities at hand. Earthen floors and unplastered sod walls that crumbled from time to time, precluded neat housekeeping. If perchance people had a frame house, floor and walls were of the cheapest and coarsest. Whitewash was used by some for decoration. 
NORTH NEBRASKA IN THE EARLY EIGHTIES

Board walks there were none and mud was frequently carried into the house on the shoes.

It is worthy of remark that a few years later as people prospered they built more comfortable homes with porches and walks, bought new furniture, carpets and rugs and many a home indulged in a cottage organ-then the popular musical instrument.

\section{BLIZZARDS-THE UNGAR BROTHERS-THE MOON BROTHERS AND MCMAHON}

Blizzards belonged to the pioneer history of the west. Storms of equal intensity in a settled section of country do not claim such a toll in mortality or morbidity from frozen limbs, because shelter for man and beast is more readily reached, although a real blizzard is not to be under-estimated even at this day.

I recall that I returned home from my first term at medical college with fifty cents in my pocket. That night a three-day storm set in that blockaded all the railroads across the state of Iowa for several days. I was glad I was home and often wondered what would have happened to me if I had been caught on the train in the storm with fifty cents.

The great blizzard of 1888 , the worst in history, occurred on the 12th of January. The morning was mild with large wet snowflakes in the air by midforenoon. Business took me to a nearby town on the train. The blizzard came with an undescribable fury near one o'clock $\mathrm{p}, \mathrm{m}$. and soon wora came that the train service had been cancelled. I could not get home! Our home was a small house. In the barn were two horses and there were two pigs in a sty near-by. Our coal shed was by the barn. Realizing that my wife would be unable to breast the 


\section{NORTH NEBRASKA IN THE EARLY EIGHTIES}

fury of the storm to get fuel it occurred to me to send her a telegram, thinking, if the message were delivered that the messenger would see to it that she had fuel and that the horses and pigs were looked after. It worked. By bribing a liveryman with an extra fee I reached home by noon of the next day. This of course was as nothing compared with what hundreds of people suffered in that storm. In the community from which I write a Bohemian farmer went after his cattle when the storm broke and failed to return. His body, mutilated by coyotes, was found three miles southeastward several weeks later.

The heroism of country school teachers during that storm has become history. Minnie Freeman (now Mrs. Edgar Penny) then in her teens, led 17 children from her partly wrecked school house to safety a mile away during the storm. She was acclaimed a heroine by the press of the entire country. Several other teachers, less heralded, deserved equal praise and some perished in the attempt to reach a farm house.

On a mild early spring evening in the later eighties I answered a confinement call five miles away. A storm was brewing. I was ready to return home about two a. $\mathrm{m}$. When I asked for my team, the husband suggested.that it was extremely dark and that it was going to storm presently and urged me to remain until morning. Such a thing as being unable to travel on account of darkness I had never experienced and I insisted on going and did so. No sooner had the lantern light been turned from the team than we were in stygian darkness and the horses were against the wire fence. I turned them to the right and they crossed the road to the fence 
NORTH NEBRASKA IN THE EARLY EIGHTIES

on the other side. With the greatest difficulty and by the aid of the flashes of lightning I managed to zig-zag my way to the crossroad two miles south. By that time it was not only raining hard, but snow in large, wet flakes came with a terrific northeast wind across my path. I turned the horses to the east but could not hold them to the road on account of the fury of the windswept snow which blinded them. I thought to lead them along the fence, but they would not be led. Finally I decided there was but one thing left to do-tie them to the fence, blanket them, seek the protection of the buggy top, and await the morning light or the subsidence of the storm. This I did, and although my trousers and lower limbs were wet I dozed for a time. The storm turned entirely to snow that blocked the roads for several days but by the early morning light I managed to get the horses to move toward home.

A little earlier history of blizzards may be allowable. A colony of Jews homesteaded near the present city of Madison in 1869. Among them were two brothers Leopold and Jacob Ungar. Leopold Ungar lived in a dugout and had built a dugout stable nearby. On the 16th of January, 1870, in a blizzard of great violence, the brothers left the dugout home to care for their stock in the stable. They did not reach the stable and never returned to the home. Their bodies were found several miles southeast of the dugout home several days later. They had wandered in the blinding storm unable to locate themselves and finally drifted with the storm until they fell exhausted. When the first one fell, the brother took off his own topeoat and wrapped it around his dying brother. 
NORTH NEBRASKA IN THE EARLY EIGHTIES

Touching on blizzards without mentioning the tragedy of the Moon brothers in Madison county, Nebraska, would be a dereliction. The Moon brothers and McMahon went hunting for deer on a bright day early in November, 1871, when settlers were few. During the day the wind suddenly veered to the northwest and brought a blizzard of tremendous fury and a 20 degree subzero temperature. They could not go against the storm and became exhausted through wading the deep snow with the storm. The brothers finally concluded they could not go any further and dug into a snow bank. MeMahon, certain they would all perish unless they kept moving, kept going with the storm and early next morning stumbled onto the roof of a dugout a dozen miles from where he left his companions, his feet frozen stiff. He recovered with loss of part of his feet, anterior to the tarsal bones-Chopart's amputation. Months after the ordeal of the awful night, when the line of demarkation had been well formed he was taken on a lumber wagon sixty miles to have the amputation performed.

The Moon brothers' bodies were found frozen the day after the storm subsided. 


\section{NORTH NEBRASKA IN THE EARLY EIGHTIES}

(Continued)

I Locate June 27, 1882. The Town. My Armanentarium. Saddlebag Days. Early Social Events. A Benedict. Hard Times. Barter. I Arrive, Economically.

\section{JUNE 27, 1882}

I came to North Nebraska and located at Madison, a county seat town, June 27, 1882. I had friends living in the town from whom I learned that the place had but one physician, and this decided me to

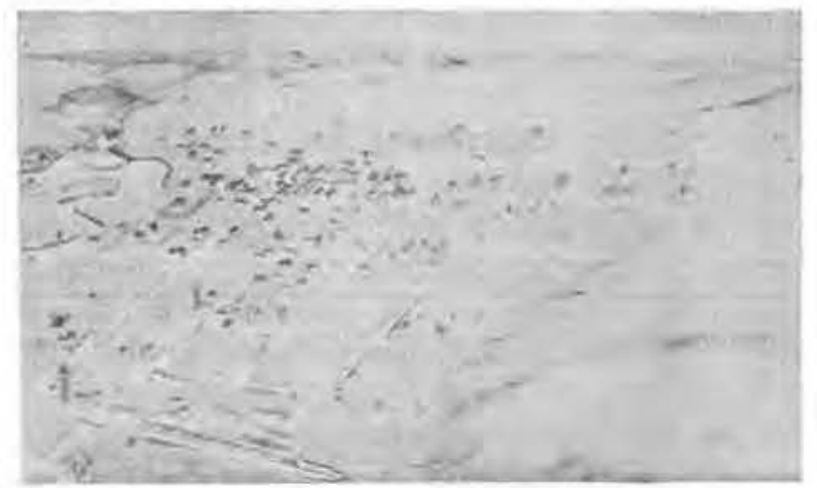

A pen sketch of Madison, Nebr. made in 1881. This sketch is ldentical with the author's recollection of the town when he located, June 27,1882 . Note railroad yards, mill lake, mill, etc.

locate. The town was said to have a population of one thousand but it always seemed to me it could not have had half that number.

\section{THE TOWN}

The buildings were all of wood construction and most of the business houses were of but one story. Small panes of glass, probably 18 by 24 inches were used in some store fronts which made them unat- 
NORTH NEBRASKA IN THE EARLY EIGHTIES

tractive. There was no established grade to the business streets and no established curb line. The plank sidewalks were, therefore, irregular, uneven, up or down, as the several adjoining property owners saw fit to lay them.

In 1882 Madison had two hotels, four general merchandise stores, one exclusive grocery, two banks, two hardware stores, one restaurant, a confectionery, two blacksmith shops, two implement stores, a flouring mill, two lumber yards, a coal yard, two livery stables, five attorneys, one other physician, four churches and a weekly paper. The above was representative of every other town of like age in $\mathrm{Ne}$ braska.

There was no court house building in 1882 although Madison had been the county seat for seven years. A story and a half frame building housed the offices of the county clerk, treasurer, sheriff and county superintendent. The county judge who was a lawyer transacted business incident to the judgeship in his law office. A number of interested business men formed an association and built a frame building modelled like a small town store room, known as the Town Hall, in which court could be held.

Business was not rushing in any of the stores and it was a common practice for persons who came in to do trading, or to gossip, to sit on the counters. The railroad had reached the town a little over two years earlier and the service consisted of one mixed train each way a day.

The only physician then located in the town had graduated seven years previously and was the community idol. He was not anxious to have a competitor. Could he have foreseen how little competi- 
NORTH NEBRASKA IN THE EARLY EIGHTIES

tion my advent would bring he would not have worried.

There were two homesteaders in the community who professed some knowledge of medicine and did

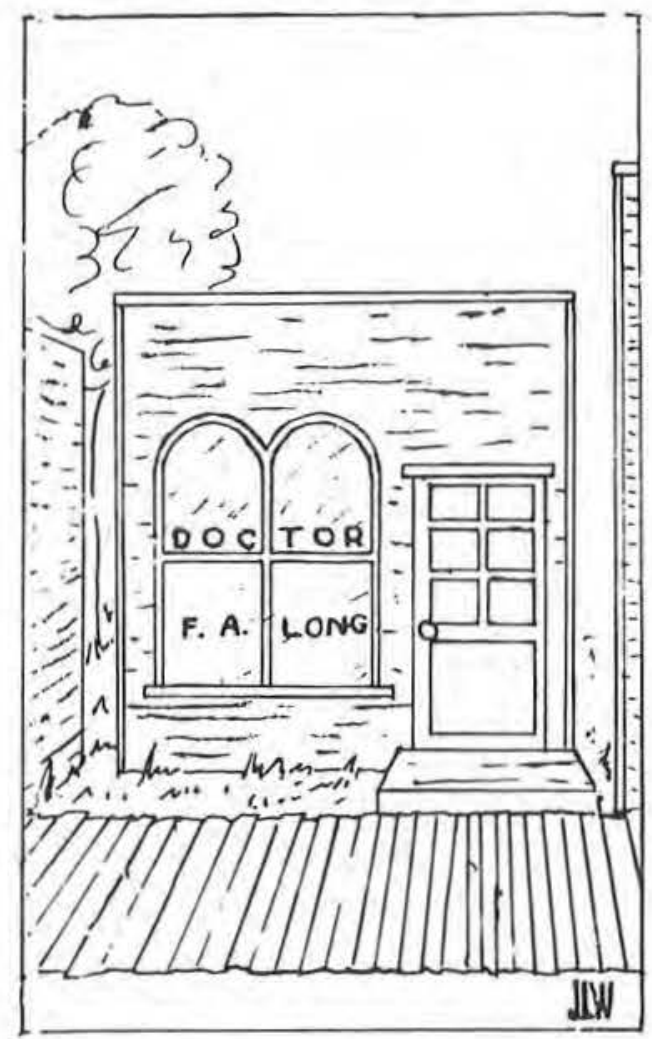

The Author's Orfice in 1882.

some emergency practice. One professed also some knowledge of the law. An attorney told me this particular "doctor-lawyer" came into his office and after looking at the law library which was a pretty good one for the day, suggested it was fairly good 
NORTH NEBRASKA IN THE EARLY EIGHTIES

and that if he had, in addition, the Indiana Reports and the Michigan Digest it would be complete! The other so-called physician claimed the euphonious name of John Quincy Adams Harvey. He was the

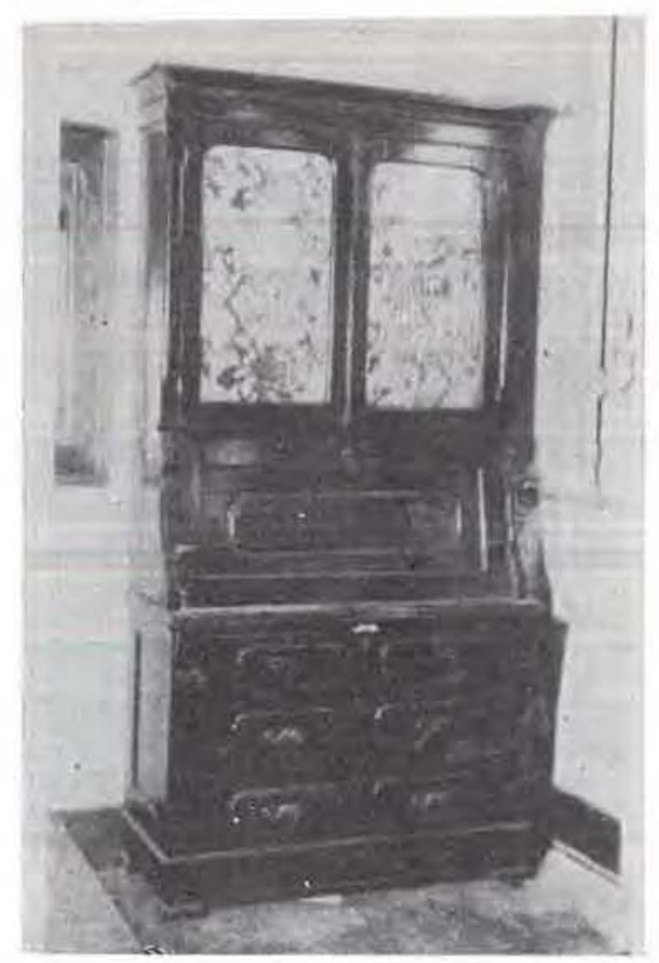

The duthor's first piece of Furniture. Secretary-bookcase, writing desk, instrument drawers, combined.

first coroner of the county. A story current in the eighties was that a homesteader having been found in his cabin frozen stiff, Coroner John Quincy Adams Harvey was summoned to inspect the corpse. On reaching the cabin he pushed the door ajar, looked 
NORTH NEBRASKA IN THE EARLY EIGHTIES

in and in his staccato voice gave his verdict, "Deader 'n hell!"'

Four months elapsed lefore I coula get an office because of the crowded condition of the business portion. During this time the owner of the hotel where I lived gave me permission to use the ladies' waiting room which adjoined my bedroom and which was little used by patrons of the hotel. On some occasions I was obliged to use the bed on which to examine the patient.

A new brick bank building was erected during my first summer's residence. When the institution was

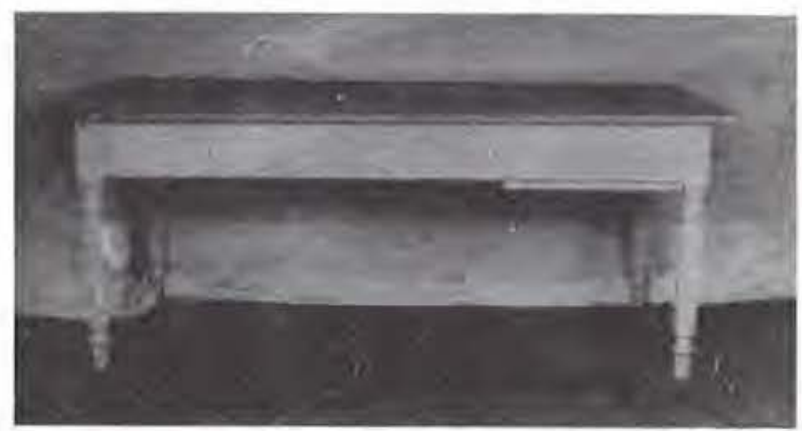

The Author's first examining and operating table. Home made. Now in use in basement of the home.

moved to the new building I rented the old one for an office at seven dollars a month. It. had three rooms.

I furnished the waiting room with a walnut secretary and a few chairs. For the private office room, I had a carpenter make a table 6 feet long, 30 inches wide and 30 inches high which served as an examining and operating table for a number of years.

As soon as my income justified the expenditure I 


\section{NORTH NEBRASKA IN THE EARLY EIGHTIES}

purchased a physicians' adjustable office and examining chair. The chair was ornamented with tassels (see cut). With the development of the principles of surgical cleanliness physician's office furniture

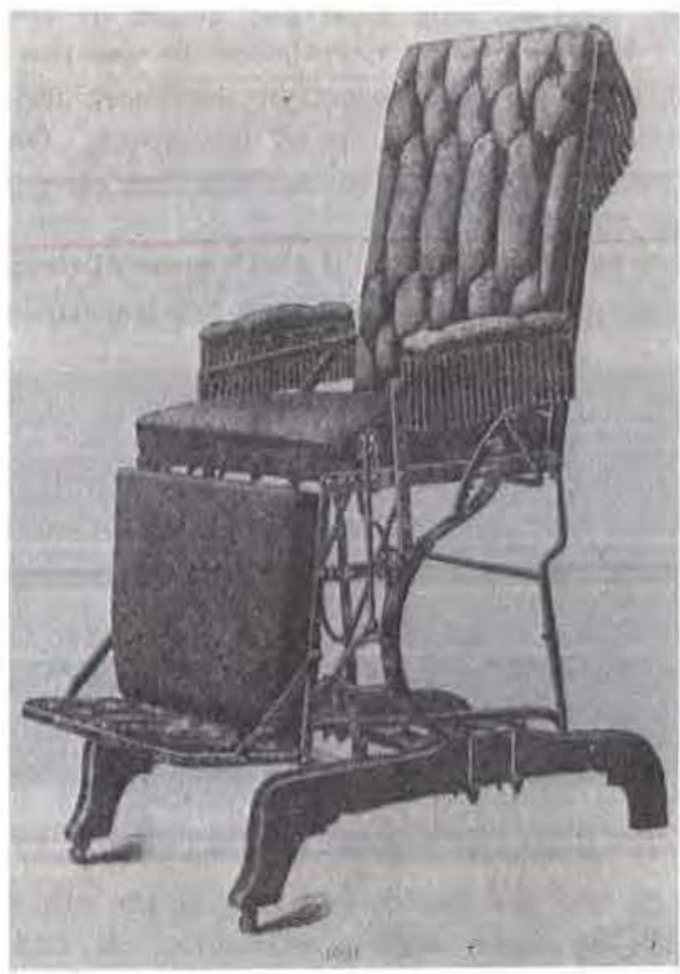

The Physician's First Office Chair

took on a more practical aspect and ornamentation disappeared. A bed in the third room completed my furnishings.

MY ARMAMENTARIUM

At this time my armamentarium consisted in addition to the furnishings mentioned, of a pocket 
NORTH NEBRASKA IN THE EARLY EIGHTIES

medicine case containing twelve remedies namely: Bismuth, Dover's Powder, Morphine, Podophylin, Compound Cathartic Pills, Calomel, Mercury with Chalk, Bromide of Potassium, Tincture Aconite, Fluid Extract of Ergot, Tincture Belladonna, Tincture Hydrastis. I had a pocket case of instruments, a fever thermometer, and an obstetric forceps. An esteemed friend in town made me an oilcloth roll to wrap the forceps. My library consisted of seven of the medical books mentioned in a previous chapter.

My father had promised me a young horse but when I claimed it he substituted an old pony that I had once owned which was subject to heaves. Only the direst necessity forced me to accept the nag. I soon disposed of the pony and got a better one. A good pony at that time cost fifty dollars.

\section{SADDLEBAG DAYS}

Practicing medicine pony-back or horseback required a pair of saddlebags. A saddlebag was never a thing of beauty, but of necessity, a clumsy work of art. It consisted of two leather pouches fitted with compartments for bottles, connected together with a heavy, broad leathern strap which fitted across the saddle and held the medicine pouches hanging on the sides of the pony or horse. About the time I began practice a refinement in the form of a convertible saddlebag or buggy case appeared and I purchased one. By doubling the leathern strap between the two pouches and fastening the pouches together with a pair of attached metal wire clips, a fairly presentable buggy case was fashioned. This was quite an asset, when, after a year, my saddlebag career ended, and I purchased an old open buggy from a liveryman. Gradually I acquired a second pony and 
NORTH NEBRASKA IN THE EARLY EIGHTIES

drove a span. Prosperity of a sort! In time I acquired better ponies and a better buggy and eventually I owned two spans of horses and physician

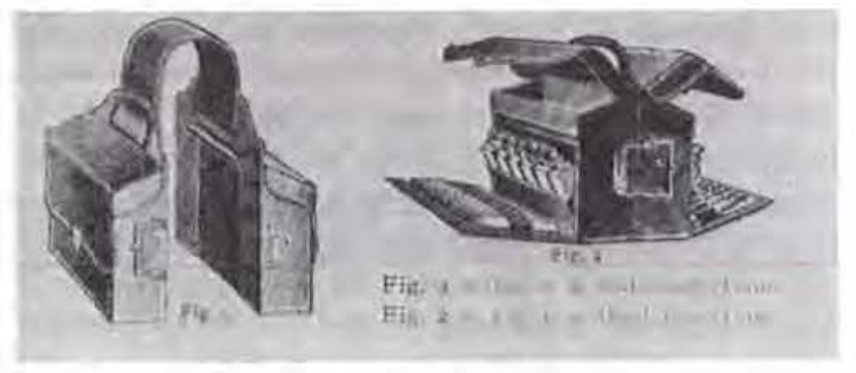

The Author's Saddlebags.

phaetons which I drove until the automobile age appeared.

EARLY SOCIAL EVENTS

The social features of the town in the early eighties were wholesome community affairs for the most part. The Fourth of July celebration resolved itself into a barbecue with a lot of pioneer sports, such as pony races, foot races, catching the greased pig, climbing the greased pole, etc. A Fourth of July celebration required a bowery for the exercises and for the dance. Posts were set in the ground to support rafters and on the rafters were placed branches of trees with their green leaves to furnish shade. This was a bowery.

The Fourth of July oration was a work of art and oratory, I well remember one given by a civil wat veteran, a minister. He began with the Creation, came down to the Noahan flood, the birth of Christ, the Dark Ages, the Renaissance, The Discovery of America, the Settlement of New England, the Revolution and finally the Civil War-and regretfully it 


\section{NORTH NEBRASKA IN THE EARLY EIGHTIES}

seemed, reached the Peroration. Levity aside, some of the finest Fourth of July orations ever heard were the products of early day orators.

The Dime Social was the creation of the protestant churches which united for the events and pooled the receipts. The entire community attended. Each group brought a basket filled with whatever of food was available. The evening was spent in social

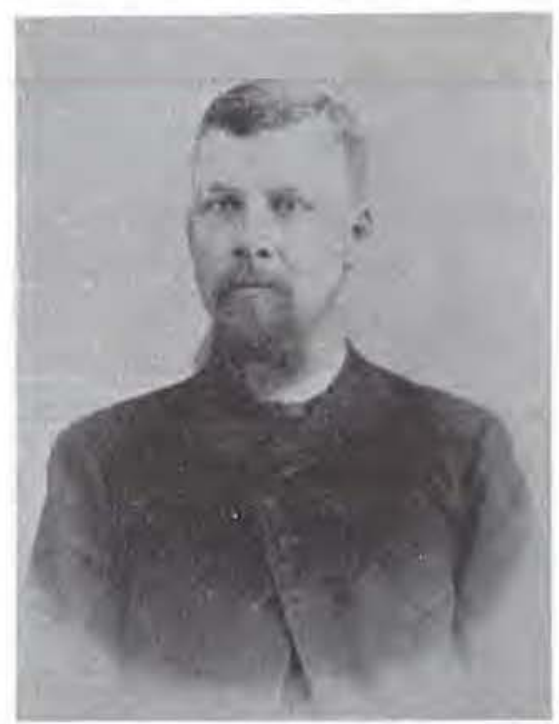

A Benedict at 26

converse and in playing light games and singing until finally the time came for the lunch and the collection of the dimes. In these later years one's heart and mind revert to the dime social as a perfect social event of pioneer days not to be surpassed in fostering community spirit.

Then, there were the Pound Parties for the ministers who were all on a missionary basis, dependent 


\section{NORTH NEBRASKA IN THE EARLY EIGHTIES}

in part on mission funds, and living on near-starvation salaries and friendly offerings from parishioners and others. Every one attending such a function took something useful for the minister's family, a

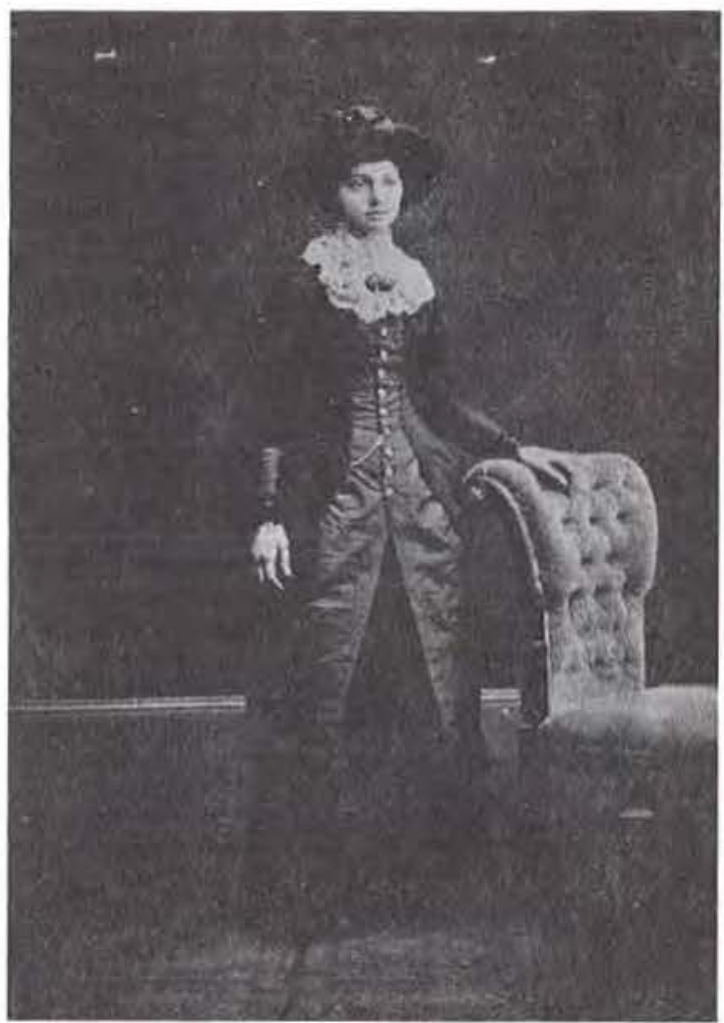

Prospective physician's bride of the Elyhties.

pound of coffee, a pound of sugar, a gallon of sorghum, a slab of home-cured bacon, or salt pork, a sack of flour, a roll of butter or any other article useful to the family. Such events always passed off 
NORTH NEBRASKA IN THE EARLY EIGHTIES

very pleasantly and were a tremendous aid to the missionary preacher and his family.

\section{A BENEDICT}

Timothy Titcomb said a single man has given no hostages to society and, therefore, has no claim on society. The third year, I acted on the theory that a single physician has no claims on society, and in spite of my financial stringency married the young lady with whom I had had an understanding for several years.

\section{HARD TIMES}

The first few years of family life were not without financial worries. The first baby of the new union arrived promptly the first year and I well recall that almost to the date of the child's arrival, lack of funds prevented us from providing the most ordinary layette. The third year I collected about a thousand dollars, the fourth year about twelve hundred dollars and the sixth twenty-one hundred dollars.

\section{BARTER}

Much has been said in the last years about community barter. Barter was a well established mode of trade in the eighties. Hay and grain for ponies, potatoes, butter, milk, cream, a hog and perhaps a quarter of beef in winter, were commodities of exchange on a barter basis for medical service. Hardship was not thought about; it was the way of the pioneer.

Many times during the first years I would gladly have left and taken any kind of a job if I could have paid my obligations and left honorably; but I would not run away from the debts, so stayed with them. The sequel proved my reasoning sound. 


\section{NORTH NEBRASKA IN THE EARLY EIGHTIES}

One reason for this slow progress was that at one time during the first few years there were five physicians in the town and business was much divided; but the principal reasons for lack of clientele was, I suspect, inherent in myself. I was green, countrified and without a practical knowledge of the world and its ways.

\section{ARRIVE, ECONOMICALLY}

Just seven years after I located, the pioneer competitor moved to the Puget Sound country. My opportunity had coms, for we had many friends, who, up to that time had not been our patrons. My business increased a thousand dollars during the next year. I had arrived! 


\section{SOME MEMORIES OF EARLY DAY PROFESSION CONTACTS}

First Patient Insane. Country Call in Lumber Wagon. Diphtheria-Tracheotomy. Family Quarrel Beside the Dying-Author Writes a Will. Surface WaterTyphoid. Night Trips on Trails. Sharp Bargains. I Get Overpaid. Fee Selhedule. Pionecr Confinements. The Way's of the Pioneer. Micals in the Country. Pugnacious Minister.

\section{FIRST PATIENT INSANE}

The very first patient to call on me after I located in Madison was a mental case, a jeweler, who was developing maniac-depressive symptoms, a form of insanity. The patient asked me to take a walk with him to the edge of the village where we sat on the prairie sod, while he told me his rambling story and I made my diagnosis. This was entirely out of my line of training and I fear I made a poor job of it. It made little difference however, for within a few days he was taken before the commission of insanity and committed to the state hospital, where he died but a few years ago.

\section{COUNTRY CALL IN LUMBER WAGON}

The first country call I received was a night call sixteen miles out. The farmer came after me with a lumber wagon, took me to his home and brought me back during the following day. His daughter, recently married to a human brute, had hysterical convulsions. I felt justified in promising that she would recover.

\section{DIPHTHERIA-TRACHEOTOMY}

The practice of medicine that prevailed in the early eighties presented many difficulties. Epidem- 
SOME MEMORIES OF EARLY DAY CONTACTS

ics were prevalent, for there were no means of preventing them.

Diphtheria was the dreaded scourge of the pioneer. The first autumn (1882), there was an epidemic in the town and surrounding community. I was employed to care for several families and fortunately my first patients recovered. I thought I had some pretty severe cases, but they may not have been so severe as I thought for I had never seen a case before. My competitor lost several cases.

People at that time were changeable-as some are now. In desperation, on the theory that the new doctor could do no worse, several changed physicians. It is a well known fact that the most severe and therefore fatal cases, are apt to be the first cases in an epidemic. This fact reacted in my favor, so that before I realized it, I was busy in the midst of an epidemic. I would not have the readers think that all the cases I attended recovered; laryngeal diphtheria took its toll, as did septic nasal diphtheria. There was no antitoxin in those days and a severe case of diphtheria meant a death sentence in almost all cases.

Tracheotomy was an operation in vogue in laryngeal diphtheria. I did several tracheotomies. In case the patient failed to breathe when the windpipe was opened, one of the things recommended in extreme cases was to lay a handkerchief over the wound made in the trachea and, with the lips, suck the secretions from the larynx. I did that once and succeeded in getting the patient to breathe. Nowadays that would be considered suicidal folly, and one must admit that it is not pleasant to contemplate or think back upon.

I told this experience to an Omaha surgeon who 
SOME MEMORIES OF EARLY DAY CONTACTS

said that he was taken out in the country on a spring wagon one night to a similar case. He aspirated the trachea with his lips. On the way home he reflected on what he had done and was prompted to beg a chew of tobacco from the driver's plug and on reaching town he indulged freely in spiritus frumenti as an antidote!

A medical friend of many years always took a personal pride in a sharp pen knife. One night he was called from his home with an urgent appeal to "Come quick" to a nearby city home. On arrival he found a child strangling from membranous or diphtheritic croup. Moments counted in the life and death struggle. He took his pen knife, made a stab wound through the windpipe and the child at once breathed easier and expelled a lot of mucus through the opening made. He asked the mother for a heavy needle and thread and passed a ligature through the skin on each side of the wound and tied the two behind the neck. The immediate emergency over he went to his office, procured a tracheotomy tube and introduced it. The child recovered.

No wonder that contagious and infectious disease played havoc with the pioneers. Huddled together in small, poorly ventilated houses, whole families contracted the disease and many died. People became panic stricken and changed from one doctor to another. One man asked me what caused diphtheria. I endeavored to explain to him that it was a germ disease of the blood, that it was contracted one person from another and that people should be isolated to stamp it out and neighbors not allowed to visit homes to sit up with the sick all night as was the custom of the pioneers. He told me very decidedly, in German "Das glaube ich nicht" (I do not believe that), to 
which I replied somewhat testily that it did not alter the fact whether he believed it or not.

Those were the days when sulphur and molasses was given as a blood purifier, when asofoetida was placed in a little bag and hung around the neck to prevent contagious diseases; when bacon rind, or bread and milk poultice or possibly fresh warm cow manure as a poultice was used to "ripen" boils; when a red flannel, or kerosene soaked rag or fried onions was swathed around the throat for sore throat; when onion syrup was made for a cough and so on.

\section{FAMILY QUARREL BESIDE THE DYING- AUTHOR WRITES A WILL}

A young German farmer had shipped stock to the Omaha market and returning brought some candy for his brother-in-law's children whom he found ill with diphtheria. Sitting on the bed, he gave them candy and kissed them. The next day he descended to the bottom of his well to clean it, perspired at his work, became chilly and the following day felt ill and short of breath. After two days of home treatment I was called, found him with laryngeal diphtheria and in extremis. His aged father was at the bedside. I took him outdoors, told him Johannes was going to die and suggested that he talk to him about making a will if he so desired. The father had the commanding voice and mannerisms of the German autocrat. Approaching the bedside he blurted out in German: "Hannes, the Doktor says you are going to die and that you better put your house in order," meaning thereby, make a will. Johannes demurred, saying he felt some better after the medicine given him and asked me to say whether he might not get well. I told him the condition 
was very serious and that it would be a good thing to make a will anyway even if he were to recover. Whereupon it was agreed that he would make a will. Asked how he planned to divide the estate he suggested that inasmuch as the wife would have the five boys to bring up he would leave it all to her. The grandfather brusquely demurred and suggested to the wife that she might get married again.

On the instant the tigress within her was aroused and she exploded with the exclamation, "I get married again? I get married again? Have I not had troubles enough in my married life? I get married again? Have I not had trouble enough with one man? I want no more the rest of my life! Take your property and do with it what you please! I can make my own living and support the children besides! I have slaved here all these years and if it had not been for my work Johannes would not have anything today" - and some other expletives, unprintable. The matter was finally settled by her agreeing that she and the children should share equally.

A messenger was dispatched to town for a notary to draw the will, but pending his arrival it began to look as if he might not reach the bedside in time to get the will properly executed. I, therefore, took it upon myself to make a memorandum of the testator's wishes and had it signed and witnessed by the father and myself shortly before coma supervened. This was afterward offered in probate court and although irregular, was admitted as the last will and testament. Johannes died during the afternoon. Nine months afterward the widow married the hired man! 
SOME MEMORIES OF EARLY DAY CONTACTS

SURFACE WATER-TYPHOID

The early settlers followed the water courses. Where streams were not near at hand they dug open wells of a few feet depth for water. Those who came a little later had to take the upland prairie and their wells also tapped the upper or surface streams of water. Typhoid fever, being for the most part a water-borne disease, became very prevalent. The

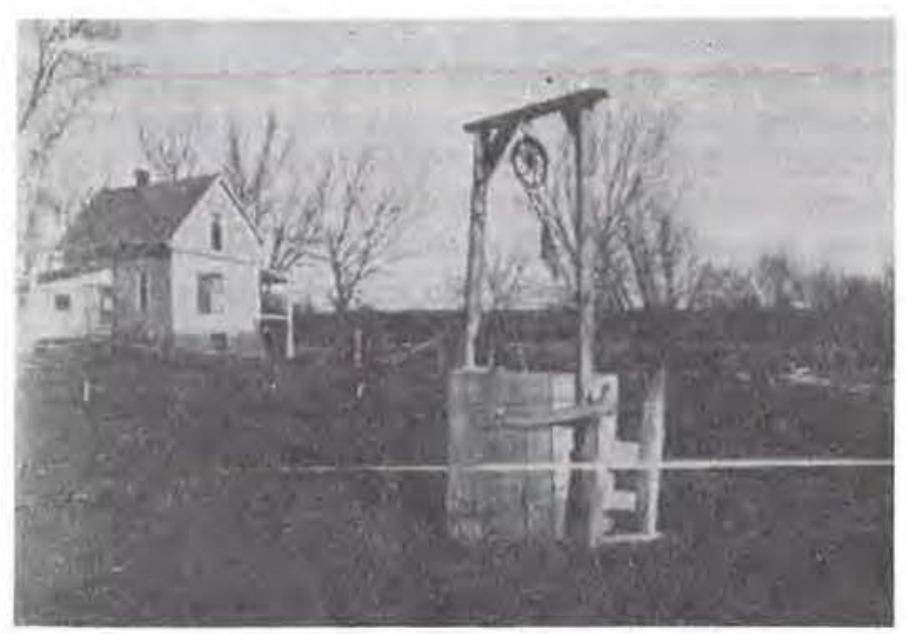

A homesteader's well.

cattle yards were close to the open wells for convenience and surface contamination was, therefore, inevitable.

In the later eighties the two physicians then occupying the field must have had seventy-five cases of typhoid to treat one fall. Whole families were stricken, one after another. I was in charge of one family consisting of father, mother and ten children all of whom contracted the fever except the mother and nursing babe. The father was one of the last 
SOME MEMORIES OF EARLY DAY CONTACTS

to develop the fever and as his was a mild case he had much time for reflection and speculation as to the cause of the epidemic. He was one of the brightest and most conscientious men in the settlement as well as one of the most prosperous-and the soul of honor.

He was a deeply religious man and wondered why the Lord had visited this scourge upon his family. He asked me what could have caused this plague. I told him it was well known that typhoid was a waterborne disease resulting from surface contamination and that therefore his open well located by the cattle yard must be at fault. He told me he could not believe it-it could not be so. He reflected upon my suggestion, however, and after he had recovered he thought to test the doctor's assertion, so they cleaned out the well bringing up rotten corn cobs and corn husks, dead rats and mice and a dead rabbit! He came to town to tell the doctor he now believed in the theory of water contamination. Within a few years, with a measure of prosperity, windows and doors were screened and with a greater need for more water for the growing herds, the deeper, driven, or bored wells-and wind-mills, came into use and typhoid fever practically disappeared.

In those days we had no quarantine laws and regulations and the public knew almost nothing about contagion and infection. It was the custom of pioneers to go to the assistance of their sick neighbors. This may have been particularly true of the foreigners, but I suspect it was true of all. I do know that in the eighties the Odd Fellows had a provision in their by-laws that members, listed alphabetically, were called in turn to "sit up" with sick members. Thus a person ill with typhoid and perhaps in delir- 


\section{SOME MEMORIES OF EARLY DAY CONTACT'S}

ium, had a different person "sit up" with him each succeeding night. A worse method of providing nursing care for the sick could not have been devised.

\section{NIGHT TRIPS ON TRAILS}

Fifty and more years ago the farmer and his boys worked in the field all day and in the evening, at his convenience, he put a boy on a pony and sent him after the doctor. The doctor saddled his pony or hitched his team and went ten or fifteen miles on the trails to visit the patient and returned home about daylight, having spent the whole night on the trip.

WINTER CLOTHING-SHARP BARGAINS

In my early professional career I harbored the delusion that wearing heavy clothing in winter in the open country was a sign of effeminacy. I made several trips to a home 17 miles in the country on a slow pony when the temperature was 12 below zero, without leggings to protect my limbs and without a fur, or other heavy, overcoat. The bill amounted to $\$ 18.00$ to which the man strenuously objected. I told him I would throw off a dollar for cash. He made me wait a whole year and then demanded the discount I had offered!

When I had prospered enough to have a team of ponies and a buggy I offered my saddle and bridle for sale, A farmer bought it, but wished me to wait until he sold his hogs. I was desperately in need of cash but waited and waited, until the suckling pigs grew up and were sold, a full twelve months later!

\section{GET OVERPAII)}

Very few physicians ever get over-paid or receive more than they charge. I have always cherished one exception. A young man and wife acquired 1,000 


\section{SOME MEMORIES OF EARLY DAY CONTACTS}

acres of land in the community, went there and improved it by the most extensive tree planting program ever undertaken in the county. I attended the young woman in confinement and when about to leave, the husband asked for the bill. I told him ten dollars which was then standard price. He said "That is not enough," wrote out a check which I stuck in my pocket without looking at it. When, later, at home. I looked at it, it read "Fifteen" dollars. This is perhaps a small thing to publish but it made a lasting impression on me.

WILL LET YOU KNOW

When a doctor was called to a patient, even though it was diphtheria, pneumonia or typhoid, many persons expected the doctor to leave enough medicine to last for the cure. They would tell the doctor "We will let you know how we get along." It took some argument to convince people that the patient needed daily attention.

FEE SCHEDULE

The fees in the early days were one dollar for town visits, day or night. Country calls were made on the basis of fifty cents a mile. Theoretically, one was supposed to charge something extra for visits but this was rarely done. Confinements were cared for at the flat rate of ten dollars whether in town or country; but instrumental or manual deliveries were charged extra. Physicians were rarely called to confinements in the country unless there was trouble in the delivery.

PIONEER CONFINEMENTS

The pioneers were a people inured to hardships and for the most part well developed muscularly. The pioneer mothers, because of their activity and mus- 
cular development had less trouble in labor than their more favored sisters of today. A neighbor woman usually was called to officiate at the birtls. In some neighborhoods there were women who professed to be midwives and made a business of attending births for a small fee, if obtainable. Labors occurred without the presence of a neighbor or midwife. Instances are known where the husband cut the cord and attended the mother and child. An instance occurred in this area when there was no one available but the twelve year old daughter. The labor was precipitate. The mother called the girl and told her what to do and together they managed to tie the cord, get the baby dressed and the mother's toilet arranged.

THE WAYS OF THE PIONEER

I was called to care for a fractured femur of a hired man who had slid from a load a grain and was run over. After placing a splint and extension dressing on the patient and making a second call, the family with whom the patient was living told me I need not come any more. I remonstrated, told them the limb needed daily care for a time and then the periods could be lengthened. They were insistent, told me they did not see that I did much to the limb on my daily visits - they could do that. I then drew up a release, reciting that inasmuch as they felt they could take care of the patient they would release me from blame if the results were not good in the end and after much argument they signed it. The man acquired a permanent deformity and lameness.

MEALS IN THE COUNTRY

I attended a confinement case 12 miles from home on an early fall morning and was through with my 
SOME MEMORIES OF EARLY DAY CONTACTS

work at six a. m. The neighbor woman present asked me if I would have breakfast to which I assented, since I wanted to feed the horses before returning and breakfast after several hours work was always welcome. It was some time before I realized what was happening. The neighbor woman caught and killed a chicken after she had asked me if I wanted breakfast. Then she baked biscuits and made the gravy famous among the Virginia people as "big sop." It was an excellent breakfast, but I had to wait longer than was my wont for I was always in a hurry, and did not like to cause people extra work.

In contrast to the usual hospitality of farmers, I was called to treat a patient in a Jewish family out of my immediate territory, about an eight hour round trip from my office in those slow going horse and buggy days. A relative begged to accompany me to the home of the patient. We reached the house at high noon. The relative was given his noonday meal, but I was not offered anything!

I early developed the theory that a reputation for promptness would be a valuable asset and cultivated the habit all my active years. After five o'clock one afternoon I received a call four miles in the country. I did not like to miss the evening meal so asked my wife to prepare me a hurried lunch while I fed the horses. When I got to the house I found the patient suffering rather more than I had anticipated and my conscience hurt at the delay I had caused. The rather large family was at the supper table. The housewife asked whether I would have supper. Not wishing to confess that I had eaten I said I would take "pot luck" with the boys when I got the patient relieved. "Oh, no," she said, "we will serve your supper on the parlor table in the other room," and 
she proceeded to prepare such a spread as they might offer the priest! That evening I had to eat two meals to conceal my guilt.

\section{A PUGNACIOUS MINISTER}

A minister called me to the bedside of his wife who was hysterical and sleepless, so it was reported. On close inquiry the minister admitted that in a heated argument he had knocked her down. He never offered to pay for the visit. 


\section{SOME MEMORIES OF EARLY DAY PROFESSION CONTACTS}

(Continued)

"Aritake When I Die." "He Might Kill Mother," The Pot of Gold. Coffee Bean in Bronchus. Cholera Infantum. Dental Surgeon. Hold-Up. Freak Reaclions. Paralysis of the Pncumogastric Nerve. "Snow Bird Soup." Rattlesnake Bites. Strychnia Poisoning. Hydrotherapy. Antiseptic Washing. "Like IVeelum McClure."

"AWAKE WHEN I DIE"

A German friend and patron with the good Irish name of "Denis" went through an attack of pneumonia, became sleepless and asked for something special for relief. I prescribed a bromide mixture for him. On my call the following morning I asked whether he had rested any better; he replied in the negative but added that he had not taken the medicine. I insisted that he must take it the following night. On my visit the third morning I again inquired whether he had slept to which he replied he had not. Looking at the vial convinced me he had not taken a drop. I rather insistently told him he could not expect results unless he followed directions, whereupon he explained that the reason he had not taken it was that he was afaid he was going to die and he wanted to be awake when he died!

"HE MIGHT KILL MOTHER"

There lived in our community a German farmer, an ignorant, brutal man who, so it was said, in prehomestead days had served a term in the Joliet penitentiary for killing a man. The entire family was illiterate, although possessed of ennugh native shrewdness to acquire considerable property. On Thanksgiving evening he dropped dead at the sup- 
SOME MEMORIES OF EARLY DAY CONTACTS

per table. A neighbor was called, the body bathed and dressed and placed in a cold room and the windows opened to cool the body. Following this, one of the boys drove to my office and asked me to go eight miles to see whether father was really dead. I declined to go.

The funeral occurred on a very stormy day and the widow became ill after the exposure and developed pneumonia. One of the grown sons came for me on horse-back. I had been called away in consultation and would not return until night. He asked my wife what he should do. She told him to get one of the other physicians and mentioned one by name. Now, shortly before this episode a young woman in that neighborhood had died of puerperal sepsis, childbed fever, under the care of the other physician, and there had been plenty of neighborhood talk about the sad event. He replied: "But he might kill mother." Reassured, he called the other physician who drove an open buggy. The son asked to ride with the physician and lead his horse, which was granted. On the way home, which was more than an hour's ride, the son talked of nothing but his father-what a good father he had been, how kind, and how they would miss him. When they were driving into the farmyard, as a grand finale he said - "Vell, if Fader, he was life, he vould not be det!"

\section{THE POT OF GOLD}

Hansen was an illiterate but shrewd and wily German homesteader and his wife was mildly confused mentally. They had a number of children, only one of whom was of normal mentality and two of them were at different times confined in the state hospital for the insane. One of these was Pete. Pete liked 
SOME MEMORIES OF EARLY DAY CONTACTS

machinery and was apt at repairing it. Hansen accumulated much property and cautiously handled it himself. None of the boys of whatever age handled any money and none was paid wages. If they needed shoes or clothing the father purchased it and paid for it.

He was a feeder of cattle and hogs and profited thereby. He conceived the idea of hoarding some of the profits in a secret cache rather than trust it all to the banks. This was 25 years before the recent multiple bank "explusions." For several years, when his remittances came, he asked his banker to give him a certain portion of it in twenty-dollar gold pieces. In this way he accumulated a hoard of \$5,000 at home. A new house had been built to replace the pioneer frame one. The gold pieces were placed in an old cooking pot and buried under the floor of the old house, presumably with the knowledge of the parents only.

The automobile age came along and the auto appealed very strongly to Pete's mechanical inclinations. The father would not buy one. One morning Pete was missing from home. He appeared in town early in the morning, purchased a collar and handkerchief from a clothier and paid with a twenty dollar gold piece. He purchased a ticket for Omaha using another twenty dollar gold piece. Toward the end of the week he appeared in town with a Fuller automobile. The father, always an admiring friend of mine, edged up to me and asked what such a car would cost. I told him at least $\$ 800$, so I thought. He shrugged his shoulders and remarked: "I'll never pay for it-I'll never pay for it." To which I replied that cars were only sold on a cash basis and that he had paid for the car or he would not have it. The 
SOME MEMORIES OF EARLY DAY CONTACTS

father said Pete did not have any money and could not have paid for it. I again asserted that only with money in hand could he have a car. The old gentleman became quiet and reflective. An inquiry in Omaha developed the fact that Pete had paid for the car with twenty dollar gold pieces.

The following day the father came to town with Pete as chauffeur, and filed a complaint against Pete for stealing his pot of gold. An uncle gave bond and Pete was released and went to live with his uncle. The charge was dropped after I suggested to the father that he probably could not make out a case against Pete, but that in making a will he might bequeath Pete $\$ 5,000$ less than to each of the other children.

The sequel to this episode was that a few years later the father came to his death bed from retention of urine and slowly developing uremia. This was before present prostatectomy days. He asked me to draw his will. Sensing what might become a lawsuit when the will was offered for probate, I suggested that it would be better for a lawyer to draw the will and offered, if he would tell me his wishes, to have the will drawn as directed. He stated he wanted the property divided equally with the exception that Pete should have $\$ 5,000$ less than the other children because of the money previously obtained.

\section{COFFEE BEAN IN BRONCHUS}

From another state recently came the story of a little boy who accidentally inspired a part of a roasted peanut. Noted specialists were called who performed three bronchoscopy operations on the child in a vain endeavor to get the offending fragment of 
SOME MEMORIES OF EARLY DAY CONTACTS

the peanut. I smiled as I recalled an experience of my own. Fifteen months old baby Mary got a half of a roasted coffee bean into the right bronchus and suffered greatly in breathing. In the absence of modern instruments and dearth of specialists what was a pioneer country doctor to do? I gave Mary enough paregoric to keep her pretty well narcotized continuously and also a little syrup of ipecac to stimluate the secretions. In twelve days Mary coughed up the bean. Now then, as between paregoric and the bronchoscope-!

\section{CHOLERA INFANTUM}

Until very recent years cholera infantum was the scourge of infancy. Better sanitation and better understanding of infant feeding has almost eliminated the diarrheal diseases from the catalogue of diseases of infancy. In the early years, one very hot, dry dusty September when a high south wind had raged for days upon days, I was called to minister to an infant of about nine months suffering from cholera infantum, and who in rapid succession developed not only vomiting and purging, but a temperature above 104 and meningitis with convulsions. The nights were so hot that any cover, however light, was almost intolerable and the daytime temperature reached above 100 in the shade. The hot, dust-laden windswept atmosphere forbade opening windows. The father of the child was a saloon keeper. I asked him to bring the largest chunk of ice he could get from his beer vault and place it in a tub in the middle of the sitting room, which we had commandeered as an infirmary. The temperature was reduced several degrees and added much to the patient's comfort. This was continued for a week until the outside lem- 
SOME MEMORIES OF EARLY DAY CONTACTS

perature became seasonably normal. But our troubles were not over for occasional convulsions and continued head movements made every one concerned almost frantic. It appeared the child could neither get well, nor die an early death. It occurred to me that I had, in medical colllege, heard Professor Farnsworth make the statement that, in spite of the accepted teaching at that time that opiates had no place in the treatment of meningitis, he had proven to his satisfaction that minute doses might be given with benefit; that rest was induced and it seemed to have a beneficial affect on the meningeal inflammation. Following the lead of this beloved teacher, I gave 1/36 grain morphine by subcutaneous injection. The quiet that followed and the apparent benefit induced me to repeat the dose a number of times. The child eventually recovered.

\section{DENTAL SURGEON}

Among the early settlers the physician was also the dental surgeon, for resident dentists were scarce and the smaller communities did not afford enough work to support dentists. In medical school we received no instruction in dentistry of any kind whatever. When the first patient came to have a tooth extraction I did not know enough to take the armhold the dentist takes around the head and face of the patient. I made a sorry mess of it, but I got the tooth. I soon learned better and for many years did some extracting. When dentists did come to our town they followed publicity given through the press and remained perhaps a week and returned possibly twice a year. As the country grew in population several dentists made appointments in town at different periods and finally resident dentists appeared. 
SOME MEMORIES OF EARLY DAY CONTACTS

I recall one of the first, a large, pompous old fellow with a shabby silk hat and a white vest spattered with tobacco juice. Within a few years competent resident dentists came along.

\section{HOLD-UP}

One night I was the potential victim of a hold-up. My little daughter had gone with me to a distant place and we were returning in the night. When crossing a river bridge, we were hailed by a man swinging a lantern. Not impressed by the signal I used the buggy whip vigorously on the horses and succeeded in escaping the men, of whom there were two, one on each side of the bridge, each of whom tried to grab the horses' reins.

\section{FREAK REACTION}

Freak reactions sometimes occur among otherwise sensible people. A family lost a child from scarlet fever. It was but natural for them to blame the doctor for the unhappy result. The father came to town and expressed his displeasure and grief and wound up by saying, "Just think, it cost me fifty dollars to pay the doctor and bury the child."

PARALYSIS OF THE PNEUMOGASTRIC NERVE

A brilliant but erratic physician at one time practiced in the town from which I write. In addition to his practice he at one time published a weekly newspaper. His foreman's young wife was seized one night with a sudden illness from which she died in about thirty hours. Rumors that came from the sick chamber led one to think. the sudden illness might have been a ruptured tubal pregnancy. The weekly paper announced the death as due to "paralysis of the pneumogastric nerve!" 
SOME MEMORIES OF EARLY DAY CONTACTS

"SNOW BIRD SOUP"

Once I was called five miles in the country to treat a baby ill with pneumonia. I was told that because the baby would take no nourishment they had shot a snow bird and made "snow bird soup" of which the baby partook. I never did know whether my treatment or the "snow bird soup" cured the child.

\section{RATTLESNAKE BITES}

The prairie rattlesnake was a menace to the homesteader. Small animals, when bitten, always perished; grown animals, like horses or cattle, usually survived. It was always an alarming matter when a human being was bitten by a rattlesnake. Early in my career I had the care of two cases. One was a four year old child who was bitten on the leg. She was brought to my office where I had her under my immediate care for some hours. The approved treatment at that time consisted of cauterizing the wound with nitrate of silver and the administration of aromatic spirits of ammonia and whiskey. The child died in about twenty-four hours. The other was an adult farm hand who, after being bitten was, very unwisely, put on a pony by the farmer for whom he was working and sent eight miles to my office, alone. He took kindly to the whiskey and recovered in spite of it!

\section{STRYCHNINE POISONING}

Several cases of strychnine poisoning came under my notice. Called to a lady in the country who was a sufferer from severe headaches and was somewhat of a burden to her husband, I gave her a bromide and chloral mixture. Her sister-in-law, who was known as a treacherous person, was, supposedly, taking care of her. Between my visits the patient 
SOME MEMORIES OF EARLY DAY CONTACTS

developed strychnine convulsions and died. The case was never investigated, but the inference was plain, particularly so, after the following occurrence: The sister-in-law's own husband became ill and his physician noticed symptoms he believed were symploms of strychnine poisoning. He had a consultant called who told the wife the symptoms were those of strychnine poisoning and "it would make an awfui bad mess if he should die." The husband had no more convulsions.

A German-Russian had Bright's disease and concluding he could not get well he decided to take it dose of strychnine and pass out. I was called to his farm home five miles in the country and feeling sure that there was nothing to do but relieve his suffering (he had violent convulsions and his body was so arched that it rested on the back of the head and the heels), for I was certain he would die, I administered a half grain of -morphine hypodermically. Not getting relief I soon repeated the dose. Still not getting results I repeated the injections until he had been given two and one-half grains in two and onehalf hours, hypodermically. Not wishing to be tempted to give any more and my services being needed elsewhere I left the patient for a time, to find on my return that he was recovering!

\section{HYDROTHERAPY}

One of the practices somewhat in vogue in early days was a modified hydrotherapy. I hung sheets wrung out of water in rooms to humidify the air. I used sheets wrung out of water wrapped around the person to reduce high fever in patients who were unresponsive to other treatment, with happy results. My own daughter of nine years had scarlet fever 
SOME MEMORIES OF EARLY DAY CONTACTS

with a very high temperature. I wrapped her into a cool water sheet and after she had been wrapped for a few minutes she volunteered the information that she felt much better. I was called in consultation in a case of puerperal sepsis with a high temperature and delirium. I suggested a wet pack. The family physician agreed, but the father said he did not think much of that way of treating a patient for she might "take cold." Reassured, he subsided and the pack was applied with pleasing result. The patient recovered and the father later told me he gave me half of the credit for suggesting the wet sheets and to his family physician the other half for giving her every attention.

\section{ANTISEPTIC WASHING}

Convinced that a physician should take precautions against carrying contagion and infection from one patient to another, I had a closet built in my barn in which I kept a linen duster to wear into homes with contagious diseases. I also kept in this closet a special basin, sublimate tablets, carbolic acid and soap and towels. I always washed on returning from such cases before entering my office or home, a precaution which I believed very important and which it might be well to stress today.

\section{"LIKE WEELUM MCCLURE"}

The practice of medicine in a pioneer community had many compensations in pleasant memories of appreciation of the efforts made by the physician. The following is a notable instance of such an outburst of apparent appreciation: The head of a family for whom I had done a great deal of work (and I have every reason to believe I stood very high in 
SOME MEMORIES OF EARLY DAY CONTACTS

their esteem) told me after the family returned from a trip to relatives in Ireland that after telling all of the different accidents and operations they had experienced in past years, the hosts asked what kind of a family physician they had. He told them the nearest he could come to telling them was that he reminded him much of Weelum McClure of the Bonnie Brier Bush! 
EMERGENCY SURGERY IN PIONEER HOMES: FIRST APPENDECTOMY IN NORTH NEBRASKA

Removing Bullet-Operation in Round House. Depressed Fractures of Skull. Scalped. First Appendectomy in North Nebraska. Boiled Water. Mastoid Disease, First Contact With Hospital and Nurse. Extra Uterine Pregnancy. Vesico-Vaginal Fistula. Si.r Day Trip to Patient. Osteomyelitis. An Enucleation of Eye. Enpycma-Gastro Pleural Fistula. Early Hospitals.

REMOVING BULLET-OPERATION IN ROUND HOUSE

Rural Nebraska, like the rest of the nation, had not become hospital conscious when I came to the state to practice.

The physician of the eighties had to be truly an all-around man. Accidents happened then as now and called for the very best there was in the local doctor. If he failed he failed miserably. I remember the case of a man who was accidentally shot. The bullet entered above and to the outer side of the knee and lodged below the knee in the soft tissues of the posterior surface of the leg. The near-by physician first called was afraid to attempt removel of the bullet and advised leaving it. Not satisfied the patient had me called to go some twenty miles to remove the bullet, an operation easily accomplished. The first physician merely lacked nerve.

About 1883 or 1884 , I assisted a railroad surgeon in a neighboring town in amputating a trainman's foot in the roundhouse. The brakeman had a bunk in the roundhouse, so it was his abode. A table was improvised by using a door laid on blocks. Hot water was obtained from the engine boiler. The foot which had been caught under a car wheel was ampu- 


\section{EMERGENCY SURGERY IN PIONEER HOMES}

tated. The next day the surgeon put the patient on the train and took him to the home of his parents, at the other end of the run.

\section{DEPRESSED FRACTURE OF SKULL}

A sixteen-year-old boy was kicked on the right temple by a horse, producing a depressed fracture of the skull which rendered him unconscious. With the assistance of a confrere, the patient was placed on a kitchen table in a slovenly kept home, the head shaved, and the fragments elevated, several fragments being removed. He made a good recovery.

A physician-friend in a neighboring county told me he elevated a depressed fracture of the skull with a metallic husking peg (of a type then in use) which he saw hanging on the wall, after the attending physician, lamentingly, had said, "If only we had a trephine or some other surgical instrument to raise it up."

I am reminded of an incident in a recent book Deep Water, by C. A. Mitchell, a retired sea captain, who relates, how, when a petty officer, he did his first "surgery" when a big Russian Finn fell striking on his head, denting his skull on top, as if he had landed on a ring bolt, but not breaking the skin. The dent was 3 inches in diameter and half an inch deep. The man remained unconscious for hours. As the sailing vessel was 12 days out of Melbourne the author asked the captain's permission to try to relieve the patient. With a crude, but ingenious contrivance, space forbids describing, the petty officer "surgeon" succeeded in bringing the depressed portion flush with the rest of the skull. The work was so all-absorbing that the operator was startled when a voice said, "Vat the 'ell you do mit 
EMERGENCY SURGERY IN PIONEER HOMFS

mein yed?"-The patient had regained consciousness!

All of which tends to show that when confronted with a desperate condition we cannot unload on other shoulders, we must rise to the occasion.

SCALPED

Three cases of accidental scalping from ear to ear, from the eye brows backward fell to my lot for surgical care. One had, in addition, a depressed fracture of the skull and a separation of the skull at the fronto-parietal suture. The patient, a four-year-old boy, was brought to my office, where I trephined the skull, elevated the depression, crowded the interdigitations of the frontal and parietal bones together as well as possible, brought the scalp forward with about thirty-five sutures and established stab-wound drainage over the occiput. The father rented a room in town and personally did all the nursing. The boy was delirious for several days. A wet skull-cap was applied to the entire head and was kept wet with boric acid solution. After four stormy days and nights, recovery was uneventful.

FIRST APPENDECTOMY IN NORTH NEBRASKA

Without a doubt the very first operation for the removal of the appendix ever performed in North Nebraska, was done by Dr. F. L. Frink of Newman Grove, Nebr., and myself on December 18, 1892, at a farm home 16 miles in the country. I was called to see the patient, a sixteen-year-old girl, in consultation; a previously made diagnosis of appendicitis was confirmed and operation advised and agreed upon.

The kitchen table was requisitioned for an operating table. Basins were scarce at the home but sev- 
eral earthenware milk crocks were sterilized by boiling in a wash boiler. The instruments were slerilized by boiling. Sheets, towels and gowns were sterilized by dry heat in the oven of the kitchen

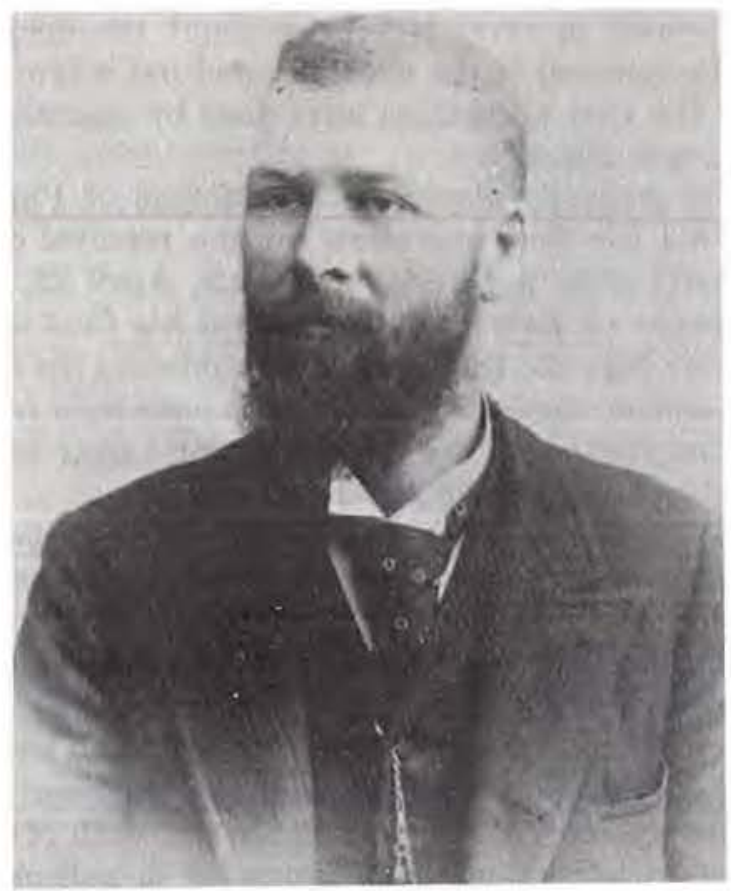

A Busy Prairie Doctor at 33.

stove. Dr. Frink had been gold medalist in surgery in medical school and naturally, I supposed he would do the operation; but he insisted (no doubt in deference to my seniority in years), that I do the operation. He gave the anaesthetic and also assisted. The appendix lay under the incision made when the abdomen was opened-and this may have saved us some embarrassing moments, for, has not one heard 


\section{EMERGENCY SURGERY IN PIONEER HOMES}

of cases of young surgeons hunting for the appendix in vain? The operation was "fearfully and wonderfully" done. The patient lived to bear ten children.

This case demonstrates a bit of courage of two frontier general practitioners at a time when little was known in rural Nebraska about the operation for the removal of the appendix and but a few years after the first operations were done by specialists in the larger cities.

It is generally conceded that Morton of Philadelphia did the first operation for the removal of the appendix after a definite diagnosis, April 23, 1887. McBurney of New York, performed his first appendectomy May 23, 1888, and later published his classical paper on appendicitis which at once took hold of the imagination of surgeons the world over and resulted in popularizing appendectomy.

During the nineties we did numerous appendectomies and appendicotomies (draining abscesses of the appendix) at the homes of patients with satisfactory results and so have other, older, general practitioners.

Emergency surgery had to be done in all kinds of homes, including sod houses, many of them under the most unsanitary conditions. But with it all, if operators were fairly well grounded in pathological anatomy and had some manual dexterity, the results were satisfactory-particularly when practical antisepsis was employed. This leads me to relate what a noted surgeon-friend of my own years of service and who has had a vast experience in emergency surgery in all kinds of homes, says:

"The modern surgeon is in reality a hot-house plant, also the trained nurse; they would be hopelessly useless were they called upon to do some of 


\section{EMERGENCY SURGERY IN PIONEER HOMES}

the emergency work that you and I have done in private homes, many of them under the most unfavorable surroundings. And they were successful too!"

\section{BOILED WATER}

This is strong language, not fully intending what it says, we may well believe; but it does call attention to the contrast of working in a modern hospital with every convenience and operating in pioneer homes with no conveniences at all. It does another thing: it emphasizes the fact that where boiled water can be obtained it is possible to do an operation with reasonable probability of a successful result.

\section{MASTOID DISEASE}

It fell to my lot quite early in my professional career to have a number of cases of mastoid disease to treat. In the first case, a half grown boy some miles in the country, I made an incision over the most prominent part of the mastoid process and drilled through the bone. This was an approved method at that time. Pus flowed freely and the patient recovered in a reasonable time. I met this patient a year ago and he told me "You certainly did a good job!" These little reactions coming to one in later life are very pleasing. Later I used the chisel, gouge and bone scoop in such cases. One case I was called to treat was that of a close friend, who after suffering for some days and nights agreed to operation, but after arrangements had been made to do it on the following morning, he recalled me to his home and said in effect, "You are all right and I believe you can do this; but this is my head and I would rather have an expert do it. I have decided to have you take me to Omaha in the morning to a 


\section{EMERGENCY SURGERY IN PIONEER HOMES}

specialist." I accompanied him to Omaha to the original Methodist Hospital (a square frame building of two stories and an attic, originally built for a home) and gave the anaesthetic for the operation. This was my first contact with a hospital and nurses. This was before 1890 .

\section{RUPTURED TUBAL PREGNANCY}

I have no recollection of ever hearing anything about extra-uterine pregnancy while in medical school. If a lecture was given on that subject it failed to register for me. I had however read Lusk's description in his Midwifery and had no doubt read references to the subject in medical journals. Lawson Tait did the first operation for ruptured tubal pregnancy in 1883 . When, therefore, confronted with this condition quite unexpectedly not many years after engaging in practice, I am proud even at this day to realize that I rose to the occasion in a few minutes after being called. I am confident the general practitioner in the pioneer west, perhaps everywhere, knew very little about the condition at that time. I had never heard any physician mention it.

I was called in the early morning to the bedside of a lady who was found by her husband in great agony and unable to tell what had happened. I at once gave her a hypodermic of morphine for relief, then proceeded to make a systematic examination. Finding blood stains on her gown I at first jumped to the conclusion that she was having a miscarriage, something that had happened several times. By bimanual examination I felt a boggy mass in the culde-sac, but no softened or dilated os. Repeating the examination in half an hour, the mass in the cul-de- 
sac felt more decidedly boggy. I told the husband something very distressing had happened-that she had had an internal hemorrhage from a ruptured extra-uterine pregnancy. By this time the patient was unconscious and almost pulseless at the wrist and the husband suggested I might have given her too much morphine. I explained that the internal bleeding was accountable for the collapse. Hot applications, hypodermics of heart stimulants, raising the foot of the bed, all were used during a long six hours before the radial pulse reappeared. I then suggested that an Omaha surgeon be called. Arrangements were made to bring him and a nurse by special locomotive. By the time he arrived at the home the patient was rallying well. The operation done 12 hours later, proved successful, the patient making a prompt recovery.

This was my first contact with a trained nurse in a home. The surgeon had brought her along as assistant for the operation, but we insisted on her remaining to care for the patient.

The systematic care, the systematic record of pulse and temperature, the systematic care of bodily functions and the innumerable little attentions the trained nurse gave the patient to add to her comfort made a deep impression on me.

Before the end of the nineties I saw perhaps a dozen cases of ruptured extra-uterine pregnancy several of them in consultation. All these cases were operated on at home, most of them by local surgeons and all recovered.

\section{VESICO-VAGINAL FISTULA}

A farmer's wife twelve miles in the country was in labor twenty-six hours before I was called to attend 


\section{EMERGENCY SURGERY IN PIONEER HOMES}

her. The fetus was dead, macerated and bloated out of all semblance of normality and weighed 18 pounds. The head had no doubt rested against the pubic bone for many hours before I was called to deliver her. A urinary examination showed sugar. On a restricted diet she became sugar free, but began to complain of an indefinite pain in the vagina. Examination disclosed a sloughing vaginal vault, and after a number of days, leakage of urine occurred through a fistulous tract in the center of the sloughing area-a vesico-vaginal fistula. The matter was explained, a nurse was put on the case and after the slough had separated, with the assistance of two neighborhood physicians I did an operation for the repair of the fistula, with much fear and trembling, remembering the dictum to draw the ligatures "just tight enough, but not too tight!" Fortunately the repair was a success. Later it fell to my lot to have another such case which I also repaired and with good result.

In a neighboring community thirty miles distant, a young practitioner with an interest in surgery, was called to a nine-year-old boy who had been accidentally shot through the abdomen with a 22 bullet. It was early summer. The home had burned a week before and the people were temporarily living in the chicken house. The physician had as helpers a pharmacist and young bank clerk. Water was boiled, an operating table improvised under a blooming cherry tree, the child anaesthetized, the abdomen opened, eight perforations of the bowels found and sutured and the boy recovered without any special postoperative incidents. 


\section{EMERGENCY SURGERY IN PIONEER HOMES}

\section{SIX DAY TRIP TO PATIENT}

A friend who was division railroad surgeon for about forty-five years relates an interesting experience in pioneer surgery. A physician a hundred miles up the line telegraphed him to come on the evening train prepared to amputate. Reaching the physician's home he was told the patient lived in the Dakota Indian country two days' pony drive away. They started early in the morning, drove all that day and all the next before reaching the ranch home of the patient who had gangrene of the leg following exposure and freezing of the foot and leg. After a night spent at the patient's home they amputated above the knee and remained with the patient the rest of that day and the following night. Necessary dressings were left with the family-there was no nurse. The physicians were two days in returning, having spent six days on the trip. The patient recovered.

\section{OSTEOMYELITIS}

A German boy some miles from town developed a pain in his thigh referable to the region of the prominence or greater trochanter. As a child he had had osteomyelitis of the tibia. I thought it a pain in the bone and told the family. He always suffered at night and was fairly comfortable during the daytime. No permanent relief followed my treatment so they employed several other physicians, received various diagnoses, but no relief. They betook themselves to a somewhat noted German physician in Omaha who told them it was sciatica. No relief followed the German physician's treatment; so one night they again called me. I again told them I believed it was bone disease and asked to have a friend called in consultation. The consultant wanted to try a new 


\section{EMERGENCY SURGERY IN PIONEER HOMES}

remedy which he had read for sciatica. We came to an understanding that the consultant's remedy should be tried for three days and nights and if no relief followed, I was to have the privilege of opening the thigh in search for dead bone. When his remedy failed I opened the thigh over the painitul spot which was the greater trochanter and found the dead bone. It was cleaned out, recovery followed.

ENUCLEATION OF EYE

A farm hand was kicked by a horse, the resulting injury being an impacted fracture of the malar bone - the prominence of the cheek - and the outer border of the orbit and the rupture of the eye ball with escape of the lens. The patient was given emergency care, for he was in shock. After a few days I enucleated the eyeball at his home. He made a good recovery and was fitted with an artificial eye.

EMPYEMA-GASTRO-PLEURAL FISTULA

A family from lowa moved into the community with a four-year-old child who had recently had an attack of pleuro-pneumonia. The child was not convalescing satisfactorily. She carried a variable abnormal temperature, rapid pulse, etc. My first impression was that resolution had not taken place, but later bulging between the ribs was noticeable. I suspected empyema, (something I had never encountered) and told the family. They were not impressed so the matter drifted until there was bulging below the scapula pointing as an abscess. I was allowed to open this. Drainage continued indefinitely. Finally they took the child to a well known Omaha internist who called an equally well known surgeon who did a pleurotomy, (an incision between the ribs 


\section{EMERGENCY SURGERY IN PIONEER HOMES}

to drain the pus from the chest cavity). The child was returned to my care and in time the incision closed. The child again became ill and the incision reopened. Following the later procedure the child gained appreciably and developed an appetite but continued to have an evening rise of temperature. The season had advanced to the period when spring radishes were available. The patient drank much milk and with other foodstuffs, ate some radishes. One day after eating radishes and drinking a lot of milk she complained that something was running down her back.

On opening the dressings it was at once apparent that milk had run out of the drainage tract and there were unmistakable pink radish skin particles scattered over the dressings: the poor child had developed a gastro-pleural fistula, an opening between the chest cavity and the stomach. This raised a question that solved itself, for in time the fistula closed and the empyema also cleared up. I saw that girl after she had grown to womanhood-a sturdy, buxom lady.

The purpose of this chapter is to show how the pioneer physician was handicapped in his work and how he had to handle the emergencies before him. The experiences were not outstanding, they were a part of the early physician's daily grind. If a man of parts, he rose to the occasion.

If we pioneer country doctors struggled along performing our surgery in the homes it should be renembered that even the larger cities had only meagre hospital facilities at this time.

St. Joseph's in Omaha, dates from 1880, although another Order had furnished some hospital facilities earlier. Of other Omaha hospitals, Clarkson Memo- 
rial, established as a child's hospital in 1881, did not admit adults until 1885. The Omaha Eye and Ear Infirmary established in the middle eighties by Dr. Lynn B. Graddy and Dr. Harold Gifford, in a two story house became the nucleus, in 1891, of the present Methodist Hospital.

Immanual Hospital was established in 1890; the "Presbyterian" Hospital (later abandoned) was established in 1893, and the Wise Memorial (now the Lutheran), in 1899. St. Elizabeth Hospital, Lincoln, was founded by four Franciscan sisters and Bishop Bonacum in 1889 by the purchase of a private residence for $\$ 20,000$. It has grown through many viscisitudes into a hospital of 200 beds.

St. Mary's Hospital, Columbus, for many years the only hospital in all North Nebraska, was founded in 1879 , largely at first for the accommodation of the Union Pacific railroad and for many years remained a small institution although now it has 218 beds.

Not only had the laity not become hospital conscious, but early-day surgeons did not feel the need of hospitalization. That is a development which has come largely since the turn of the century. 
PIONEER OBSTETRICS

First Instrumental Delivery. Mrs. "Pants' Bed Breaks

Down. A Long Term Pregnancy (?). The Doctors'

Mistakes. Podalic Version. A Mole? Acephalous

Monster. Delivering a Placenta. Two Headed Monster.

FIRST INSTRUMENTAL DELIVERY

My first case of instrumental delivery occurred during my first year of practice. It was in a sod house eight miles in the county. I rode there on a pony carrying my instruments wrapped in a bundle. The woman had been in labor twenty-seven hours. (In pioneer homesteader days, as stated in a previous chapter, physicians were called only when a woman could not deliver herself.) The external parts were swollen black and blue and a part of the child's head, the caput succedaneum, presenting, looked black and lifeless. I had no difficulty introducing the instruments - thanks to splendid instruction given in medical school on a manikin. The delivery was not easy, but was readily enough accomplished and brought forth a dead and macerated fetus. My fee was fifteen dollars - this was in 1882 - and I am still waiting for it.

MRS. "PANTS" "BED BREAKS DOWN

There lived in our town a man with a perfectly good name, but whose trousers were always bagging, the seat hanging down toward the knees, which suggested for him the cognomen "Pants." Mrs. "Pants" was a stupid woman, the mother of a number of children. He was a laborer and the family always lived in filth and abject poverty.

One day she went into labor and sent one of the children for a neighbor lady. When this lady arrived the child had been born and she at once de- 


\section{PIONEER OBSTETRICS}

cided that this was a case to share with the doctor who lived nearby. Arriving I found the bed broken down in the middle, dropped on the floor and the mother literally swimming in a pool of blood, waters, baby and secundines. She wore her everyday dress and on being questioned she stated that she had no change of clothing or bedding nor any baby clothes. The neighbor-lady and the doctor's wife became the good samaritans, rustled outfits of baby clothes, bedding and clothing for the mother. The wash basin had a hole in the bottom with a rag stuck in it. I brought basin, gauze, antiseptics and cotton from my office and did my duty by the mother. All went well afterward.

\section{A LONG TERM PREGNANCY (?)}

I had been in practice eleven years and had a large clientele, including confinement cases. I wanted to go to the World's Columbian Exposition but business kept me home all summer. The first days of October I had a series of confinements and I decided rather suddenly that when this series was cared for, I would slip to Chicago.

A husband came in one evening and said-"Are you going to Chicago?" I told him I wanted to go and time was getting short as the Fair would close early in November. He said his wife would be very much disappointed for they expected an heir any time. I questioned him as to time, but could elicit nothing definite. A neighbor lady who did some nursing had previously told me of the case but suggested appearances did not justify the expectations.

I slipped off to the Fair about the sixth of October. Upon my return nine days later I asked my wife if the "Jones'" had a new baby. She had not heard 


\section{PIONEER OBSTETRICS}

of any. The expected baby arrived the following Fourth of July!

\section{'THE DOCTORS' MISTAKES}

A rather plump, slightly obese young woman, mother of several children, called me to her farm home to attend her in confinement, her regular physician, resident of a neighboring town, being ill. After the usual formalities and questions as to case history, I made a bimanual examination and was surprised to find a small non-pregnant uterus. Questioned what I thought about the prospects I told her that there was no evidence of pregnancy which apparently made her angry at me. She told me Dr. "Blank" had told her she was pregnant and when she might expect the birth of the child. I could not help it; neither could she. She never after was confined.

A husband brought his wife from a neighboring town to consult me because they knew my parents in another part of the state. The woman was sure she was pregnant, could feel fetal movements; but her home doctor told her it was imagination. Not satisfied and hardly knowing what to do they decided to consult the doctor whose parents they knew. Binanual examination proved the family doctor right. The periodic waves in the abdominal muscles could be seen by a novice and she was unconvinced. I then told her that a way to prove the case was to give an anaesthetic and, if pregnant, the waves would continue; if non-pregnant they would subside. She consented and the waves subsided.

One Wednesday morning-remember the day of the week - a physician from a neighboring town called me to meet him at a confinement case some 


\section{PIONEER OBSTETRICS}

miles in the country. Arriving he told me the trouble was that "it" would not come down. He said that he had been called on Sunday morning, early, and had been at the bedside constantly since that time and "it" had made no progress. He had been in constant attendance over three days and nights. Examining, bimanually, I found it to be a case of early, incomplete, miscarriage. With a dull curette we cleaned out the uterus, after which she promptly recovered.

\section{PODALIC VERSION}

Before the advent of telephones and automobiles a confrere called at my house one night after the zero hour and asked me to go several miles in the country to assist him in a transverse presentation. He told me he had worked for hours but could not deliver because his hand became cramped. $\mathrm{He}$ also said that in an effort to deliver he had amputated the arm of the child which presented, in an endeavor to right the position! Further he stated that his chloroform gave out. He had left the woman lying there in labor with a mutilated child and had driven to town to get me and some chloroform.

Arriving at the house I said "Doctor, what do you want me to do?" He replied that his hand was now better and if I would give the chloroform, he would again try to deliver. I administered the anaesthetic while he, with the woman across the bed, but not at the edge of the bed, made an effort to deliver. Soon, he said "My hand is cramping again, you may try it." I brought the woman's hips to the edge of the bed, scrubbed my hands and arms in lysol solution, introduced a hand, grasped a leg, did a podalic version (turned the child) and in ten minutes had the dead child delivered. I then irrigated the uterus, 


\section{PIONEER OBSTETRICS}

for it needed some attention and cleaned up the mess as best I could.

Some time later the husband came to pay the bill. I charged him twenty dollars. He objected, saying that in proportion to what the other doctor who was there all night, charged him, this was too much. Irritated, I said if I could do in fifteen minutes what he had not succeeded in doing all night, I thought I was entitled to the amount asked. He paid and always after patronized the doctor of the first choice. I had not made a hit.

\section{A MOLE?}

A couple desired to make a trip to "the auld sod" and thinking foresight a virtue, the wife had her physician give her a course of "blood purifiers" to prevent seasickness and to put her in generally good condition. Later she consulted the professor at the medical college at Belfast because of suppression. He treated her for several weeks by local applications for what he is said to have called an erosion. After a visit of several months they returned to their Nebraska home with the wife not feeling well. The former family physician having meanwhile moved to the Pacific coast I was called to her bedside on account of a hemorrhage and pain. Examination at once revealed a prospective miscarriage or premature birth. The husband was not convinced that the new doctor knew his business. He asked "Could it be a mole?" and later while I was temporarily away from the home he consulted his Encyclopedia Brittanica for information on the matter. The final result was twins, both viable, but they died within half an hour. The mother-in-law ever after enjoyed her son-in-law's discomfiture. 


\section{PIONEER OBSTE'TRICS}

\section{ACEPHALOUS MONSTER}

I was called to attend a lady in a neighboring territory because of the illness of the family physician. She was a large woman and examination told me I had an unusual case, but I could not determine its exact nature. An unusual head presented and time showed no progress. I determined to apply forceps. There was a two-year-old child in the room and no amount of suggesting and ordering the child to be taken out of the room, availed. I had to administer the chloroform. The child ran around to get to the mother repeatedly and finally knocked the chloroform bottle from the chair and broke it. I was out of chloroform! I applied forceps and they slipped, no matter how I applied them. I then determined to turn and deliver, which I did without any anaesthetic, harsh though it seemed. The child was a microcephalous monster and of course, dead.

\section{DELIVERING A PLACENTA}

A boy on horseback came to my home early one morning with a message for me to go twelve miles in the country to assist a young physician from a neighboring town in a confinement case. The child had been born early in the evening, but the placenta, "the after-birth," would not come away. The patient was a powerfully built young woman. Everytime the attending physician attempted to introdice his hand to do a manual extraction of the afterbirth the patient flinched and he evidently lacked the courage to persist in his efforts. Sensing the situation and to save his face $I$ had him administer some chloroform to the patient while I delivered the placenta which was accomplished without difficulty. After the patient's toilet had been attended to, the 


\section{PIONEER OBSTETRICS}

young physician followed me outside and around the corner of the house and addressing me said, "Say, I made a d-n fool of myself, didn't I?" This erstwhile young physician is now one of the foremost surgeons of northern Iowa.

TWO HEADED MONSTER

I was called to a labor case and on arrival found the prospective mother laboring very hard. The head was emerging from the outlet when I made an examination and was soon born. Severe pains continued and no further progress seemed to be made. A light traction did not help the shoulders to engage. A sweeping examination with my finger around the child gave me only bewildering information. I felt something I could not describe or visualize because of its indefiniteness. After many more hard labor pains I felt another head engaging and after a number of terrific pains it was born and was immediately followed by the body of the fetus. There were two well formed heads on one pair of shoulders, but between the two heads and back of them a cartilaginous formation stuck up, somewhat crestlike, somewhat like the breastbone of a chicken, but perhaps $31 / 2$ inches long. It may have been a supernumerary scapula. I was not permitted a camera exposure, postmortem, or a studious palpation and have no definite idea at this time what the cartilaginous formation was. I only know it was queer!

The teaching in medical school in 1880-1882, in obstetric cleanliness was almost nil. It was suggested that one should wash his hands with soap and water before making an examination or any obstetric procedure and should lubricate the examining hand with soap, unsalted lard or vaseline. We were told the 


\section{PIONEER OBSTETRICS}

forceps before using should be immersed in warm water and lubricated with unsalted lard or vaseline. I do not recall that any suggestion was made of any surgical cleansing of the patient. Those refinements of surgical cleanliness came a little later as the Listerian theory became accepted by the profession. Years passed before childbirth was thought a surgical procedure by the profession. Fortunately pathogenic germs were probably not abundant in the new West in pioneer days and the pioneer mothers had been inured to hardships and probably had greater resistance to infections.

We may smile at the shortcomings and vagaries of others, but let us not forget that we, all, lack perfection. 


\section{THE PHYSICIAN AS FATHER-CONFESSOR}

Sacred Relationship of Patient and Physician. Doing the Right Thing. Love Powders. The Wooing and Winning of Kyriss. Physician's Duty and Privilege.

\section{SACRED RELATIONSHIP OF PATIENT AND PHYSICIAN}

There is an almost sacred relationship between patient and physician that is akin to the relationship of communicant and clergy. The law and the decisions of the courts uphold the principle of the sacredness of privileged communications between patient and physician. The physician is the good genius at birth, ministers to the suffering during life and tenderly cares for the dying. His relation to the family is closer than any other, barring blood relationship.

It was therefore fitting that less than a generdtion ago, the physician should have been called upon to draw the wills of persons about to depart for the great unknown, as mentioned elsewhere in this book. It is not to be wondered at that he should be consulted on matters of policy, domestic, political and economic. Wife or husband may consult him about intimate domestic difficulties real or imaginary. The erring swain and the unfortunate girl who loved and trusted "not wisely but too well" go to him for help out of their difficulties. It is in these situations that the physician can show his generalship, his moral stamina and his sense of justice.

A young man approaches a doctor for something to help his trusting, girl lover "come around." The physician at once knows what is wanted. If the physician is true to his profession, as nearly all are, he will quietly talk the matter over with the young 


\section{THE PHYSICIAN AS FATHER-CONFESSOI?}

man or young woman and suggest that a marriage be arranged, as that will make it as nearly right as it can be made. In most cases the advice will be followed, shortly. Instances like the following, none of which refers to persons now living, are common enough.

DOING THE RIGHT THING

A young man came with the story that he and a young woman whom he expected to marry were in trouble. They were not in a financial position to marry, although they expected to be married as soon as he could afford it. He seemed a sensible, quiet young man of honest intentions. Talking the matter over from several angles, I advised him to go to the young woman's father and lay the case before him, telling him he was willing and anxious to do the right thing, but had no immediate prospects of being able to support a family. He took my advice "laid his cards on the table," the marriage took place and the father helped them to farming equipment and they got along very nicely.

A girl of German parentage, boisterous and somewhat spoiled by her many brothers, a girl whom 1 knew very well and whose family was close to me professionally came with a story of having missed several periods. Questioned she admitted that a lover had taken advantage of her, but stressed a story that she had been forced. I told her that was an unlikely story and that she could have protected herself but she pleaded that she fought until overcome, which I also told her was unlikely. I suggested that abortion was impossible to consider, that she must have the young man marry her, that she needed a husband and her prospective child a father. She blurted out that she did not want him, would not 


\section{THE PHYSICIAN AS FATHER-CONFESSOR}

marry him. I again insisted that the child needed a father and she a husband, that she was in no position to choose - an attitude she had, apparently, assumed. I offered to talk to the young man if she wished me to do so. This she declined, but she promised me she would see him and report to me later. She returned with the report that the young man had said he would marry her if she would talk to her father and make him "come down handsomely." To this astounding proposition she told him to "Go to h-ll," she would do nothing of the kind. Eventually, however, they were married and her father outfitted them on a farm.

A young woman came to me to find out if she were pregnant. Examination revealed a pregnancy of probably five months. She said a marriage had been planned but postponed on account of financial conditions. Feeling a fatherly interest I ventured to suggest that a wedding take place very shortly, quietly, without waiting for a special trousseau and suggested that by the time the baby came the community would think nothing of it. A full month later there was a church wedding.

A fond mother brought her beautiful daughter to consult me because of missed catamenia. Placing: her on the examining-table a prominence of the abdomen in the mid-line was at once noticeable. I then asked her if she had been true to herself to which she replied in the affirmative. I then more insistently asked her whether her lover had taken advantage of her, which she denied with an insulted air. I then said we would make an internal examination to find whether she had a tumor. To this she demurred. Her mother came to my assistance by asking the girl some pointed questions. Finally the girl burst 


\section{THE PHYSICIAN AS FATHER-CONFESSOR}

out weeping and said "Let's go home," A wedding followed, shortly.

A girl from a neighboring community worked in a cafe and came under my care on account of painful flooding. Questioned, she readily admitted indiscretions with a lover who had departed. I had her moved to the home of her parents who were unsuspecting Germans, told them she had had an internal hemorrhage and needed surgical attention, and with the assistance of another physician, who administered an anaesthetic, I cleaned out the debris with a dull curette.

A teacher came to me with the story of indiscretions with her lover in a moment of forgetfulness for which she blamed herself as much as she did the lover, and wondered if she might be pregnant. She thought there had been no penetration. I encouraged her to think nothing serious had happenedand events proved my statement correct. They later married and raised a fine family.

\section{LOVE POWDERS}

Perhaps the poorest couple it was my pioneer privilege to know was Jimmy and his wife, young people barely of age, renters, who occasionally came to town on their rickety lumber wagon pulled by two skinny ponies. Jimmy and his wife did not live altogether agreeably it appears, for one day he came into my office and asked me whether I could give him some "love powders" for his wife. He explained that she did not seem to care for him anymore and he had heard that there was such a thing as love powders. I had to explain to him that there was no such medicine and ventured the suggestions that perhaps 


\section{THE PHYSICIAN AS FATHER-CONFESSOR}

if he made quite an effort to be agreeable, it might affect the home life of both.

THE WOOING AND WINNING OF KYRISS

Kyriss was a German bachelor who lived on his own farm and wanted a wife. He was stolid, about forty and unsophisticated. He was told he might be able to induce a certain young woman whom we will call Henrietta to marry him. He called on her several times but she repelled him for he was too slow to suit her disposition. Henrietta had other admirers more to her fancy. In the course of time Henrietta discovered herself with prospects of motherhood and without anyone willing to assume paternal responsibility. A family council was held and it occurred to someone in the group that simple minded Kyriss might be won over. Father interviewed Kyriss with the story that Henrietta wanted to see him; that she was very sorry for having repelled his previous advances-would he come over to their home? Kyriss would. A prompt wedding was arranged.

In ten weeks I was called to a confinement. A normal child of eight pounds was born. "A seven month's child," the grandmother exclaimed, "Don't you see the blueness of the finger nails?" I did not. A neighbor lady came in and ventured the suggestion that seven-months children never lived more than a few weeks. This disturbed Kyriss and he promptly came to see me about the matter. I told him not to worry that the child was fully developed and quite all right. I had not realized his stupidity nor her duplicity. He said that if it was a full term child, it wasn't his; that it could not be more than a three month child, if it was his. At this I sensed 
THE PHYSICIAN AS FATHER-CONFESSOR

the situation and changed my story, telling him that he must not for a minute let such thoughts trouble him, that it was a fine child and no matter whether it was seven months or three months it was physically perfect and he must not allow himself to thini of anything else but that it was his child. This seemed to satisfy him and the matter quieted down.

PHYSICIAN'S DUTY AND PRIVILEGE

This may not pass as high class literature but it is a true representation of one phase of life seen by all physicians, during the passing years. It may prove a worth while object lesson to the young physician just beginning practice. The physician's opportunity to do good social service in such cases is undeniably great and he should consider it a duty as well as a privilege to use his influence for the good of such misguided and unfortunate persons. 


\section{FIFTY YEARS OF MEDICAL PROGRESS*}

The Shadow Moves. Tuberculosis, Then and Now. Pneumonia- "Taking Cold." Diphtheria in Pre-Antitoxin Days. Cocaine. Typhoid Fever-Riding the Circuit. Typhlitis-Perityphlitic Abscess- "Appendicotomy."

\section{THE SHADOW MOVES}

"We perceived the shadow to have moved, but did not see it moving." It would take a keen analyst to tabulate all the advances made in medicine in fifty years so that "he who runs may read" of the progress made; yet all of us know that tremendous progress has been and is being made in all lines of medical endeavor. Rome was not built in a day, but became a city magnificent in proportions and in influence on the world. Medicine is making steady progress; it has been so from the beginning, but more has been accomplished in the past sixty years than in all the years that have gone before.

\section{TUBERCULOSIS, THEN AND NOW}

I began the practice of medicine the year of Koch's epochal discovery. Called upon at that time to treat a patient with tuberculosis was not so much different from being asked to attend a funeral; there was almost nothing one could do except stand by and watch the patient sinking. It is however true that in some cases the disease was arrested. Cod liver oil, phosphate of lime and the hypophosphites were highly extolled in those days. A generous diet of meats, milk and farinaceous articles and the different vegetables were highly recommended. Tonics, such as quinine, were used. The outdoor life and travel under favorable conditions were advised.

\footnotetext{
- See Appendix A for Chronology of Medical Progress.
} 
FIFTY YEARS OF MEDICAL PROGRESS

In 1881, Dr. Austin Flint, than whom there was no higher authority, believed tuberculosis to be "pre-eminently a diathetic disease," and also taught that "the general belief is in its non-communicability."

Koch's valuable discoveries came in $1882 . \mathrm{He}$, a simple country doctor, practicing at Wollstein, a small village in Germany varied the monotony of a country practice by microscopic studies of germ life. He discovered the tubercle bacillus and formulated rules for the identification of all disease germs. The White Plague has within recent years been taken from the catalogue of the scourge of the ages to one of the preventable diseases.

Following Koch's discovery of the Bacillus Tuberculosis, tuberculous persons were recognized as carriers and as a potential and actual menace to others in the same family. Recognition of this fact and a modified segregation of the afflicted from the well persons in the family has greatly limited the spread of the disease.

The discovery that absolute rest in bed during the active stage, fresh air, sunlight and generous feeding of highly nutritious foods, will arrest the disease and possibly cure many cases, has been one of the most important steps in modern medicine. Recent surgical procedures for collapse of one lung has added immensely to chances of recovery of this otherwise doomed class of patients.

\section{PNEUMONIA - "TAKING COLD"}

Pneumonia has always been fairly prevalent in the rural districts of Nebraska; but it has not been a particularly fatal disease. One usually expected lobar pneumonia cases to recover. A recent report 


\section{FIFTY YEARS OF MEDICAL PROGRESS}

from the Nebraska University Hospital(1) indicates a mortality rate for pneumonia for a ten year period of $29.6 \%$ which seems amazing in view of my personal observation and experience in over fifty years of private practice in a rural community. Without statistics to check my statement, I will hazard the the guess that the pneumonia mortality in rural Nebraska never reached $10 \%$ except during the Great Influenza epidemic. The same writer gives the mortality rate of ten per cent for Nebraska for a seven year period. This is no reflection: it is but stating a fact.

The early-day treatment of lobar pneumonia consisted of the application of moist heat to the affected side, usually of flax seed meal poultices or corn meal poultices (either one an abomination and burden to the patient). In the late eighties, oiled silk came into use as a chest dressing and still later the quilted pneumonia jacket. Aconite was the great antipyretic fifty years ago. So much were the praises of aconite as a febrifuge sung in my college days that I burst into rhyme and wrote the following on the fly leaf of one of my text books:

If skin is dry

And fever high,

Give aconite.

After a few years the coal tar derivatives came on the market as antipyretics and soporifics (sleep producers) and for a number of years were much used in all kinds of fevers.

The theory concerning febrifuges was that if one reduced the fever and brought on sweating, he relieved the disease. The patient's expressions of re-

1. Dr. Frank Conlin "Etiology of Pneumonia" in Nebr. State Med. J., Vol, 19 , page 48 . 


\section{FIFTY YEARS OF MEDICAL PROGRESS}

lief seemed to bear out that theory. We now believe that a rise of temperature is the essential expression of the disease-the infection-and must not be tampered with except by way of sponging, and by drainage where the latter procedure is indicated.

Pain was relieved by small doses of an opiate. Paregoric often sufficed for the double purpose of relieving the pain and controlling the cough.

Ever since my very early years in practice I have been impressed with what a wonderfully efficient medicine simple paregoric is! A Civil War veteran had attended a reunion of his regiment at Iowa City. He reached his Nebraska home, ill. His family physician was away, so I was called to attend him. He had a very annoying dry cough with light stitches in his side-he was developing lobar pneumonia - and what he wanted most of all was relief from that cough. It occurred to me to give him paregoric which gave immediate relief. This little incident was worth many dollars to me in the succeeding months through kind words spoken for the "young doctor" who gave relief with that pleasant medicine.

Muriate or carbonate of ammonia was much given in flavored syrup to promote expectoration. The once-upon-a-time practice of blood letting in sthenic (full-blooded) cases - those having a strong bounding pulse, high fever, delirium-of pneumonia had passed when I came on the medical arena. Tonics and sedatives were given as indicated.

The fear of "taking cold" in pneumonia as in other febrile affections gripped the popular imagination in pioneer days as it does now. The axiom, well known to all physicians that "catching cold" in the 
FIFTY YEARS OF MEDICAL PROGRESS

febrile state is impossible, has never caught the popular fancy. Well ventilated sickrooms were hard to attain in pioneer homes, not only because these homes were makeshifts, crowded and without proper facilities for both warmth and ventilation but because of the almost fanatical belief in "catching cold."

The bacteriology of pneumonia has been well worked out in recent years, the disease germs typed and anti-sera are produced to counteract the disease. Creosote and other supposed relatively nonpoisonous antiseptics are being used in the treatment of the pneumonia of today. With it all it is doubtful if medical science has made any substantial advance in the treatment of pneumonia in the past fifty years. Statistics do not indicate it.

Lobar pneumonia is a self limited disease, requiring, perhaps, only symptomatic treatment. Perhaps the old saying: "Physic is the art of amusing the patient, while nature cures the disease" applies here.

\section{DIPHTHERIA IN PRE-ANTITOXIN DAYS}

In another place I have given some of my observations and experiences with diphtheria. I purpose here to touch more particularly on the treatment in pre-antitoxin days. Diphtheria was epidemic every year, mostly in late fall and early winter. In the crowded pioneer homes perfect isolation was almost impossible. Diphtheria was always known as a constitutional disease with a local manifestation in the throat and often in nasopharyx and trachea. Much attention was always given to the local throat membrane. Soiution of nitrate of silver was applied to the throat. By some this was varied by using tincture of iodine applied on a swab. 
FIFTY YEARS OF MEDICAL PROGRESS

A solution of chlorate of potassium was almost universally used as a gargle. If the patient could not gargle the remedy was sprayed on the throat. Weak carbolic acid solutions were sometimes used as a spray. The local treatment was varied from time to time by inhaling the steam generated by slacking lime and by the fumes of pine tar placed on boiling water. Chloride of lime in water was placed under the bed as deodorizer and disinfectant. When peroxide of hydrogen appeared in the late eighties or early nineties it at once sprang into favor as a gargle because of the cleansing virtues and deodorant and antiseptic effect. For constitutional effect tincture of iron in syrup and water was used almost altogether. A confere, much taken up with the products of the Tilden company, prominent manufacturing pharmacists of that day, used a product known as "Elixir Iodo-Bromide of Calcium Compound." The name sounded good.

The early texts described as a separate and distinct disease "Membranous Croup," which caused much confusion. Flint in 1881 described membranous croup as "fibrinous inflammation of the upper air passages; diphtheria, a general constitutional disease, with, in certain cases a similar localization of fibrinous exudation." In the early quarantine regulations provision was made for the quarantining of diphtheria, but not for membranous croup. By the nineties membranous croup and laryngeal diphtheria were considered identical, at least for all practical purposes, although it is conceded today, I believe, that a streptococcic laryngitis is possible.

In 1883 Klebs discovered the diphtheria bacillus and in 1884 Loeffler demonstrated that it is the cause of diphtheria. In 1889 von Behring and Roux, 


\section{FIFTY YEARS OF MEDICAL PROGRESS}

coincidentally, discovered diphtheria antitoxin and by 1894 it was placed on the market on a large scale. Since that time mortality from diphtheria has been reduced from over fifty percent to a bare $10 \%$, which is still too high.

My earlier experiences with diphtheria made such a profound impression on me that when Behring's antitoxin was announced I at once obtained some and administered it first in January, 1895; probably the first antitoxin used in all north Nebraska,certainly the first in the county.

Antitoxin did not at once become universally popular. Eclectics and Homeopaths did not take to it kindly and some other practitioners refused to use the new remedy. Locally, we had some difficulty about antitoxin. A girl on whom the antitoxin had been used developed a partial paralysis which remained permanent. A meddling physician told the people it was due to the antitoxin. He forgot to tell them that diphtheritic paralysis occurred before antitoxin was known. This meddling and opposing physician finally began to give antitoxin under protest, and later gave it as a routine in diphtheria, as others were doing.

\section{COCAINE}

Local anaesthetics were not available in my early practice. Koller of Vienna in 1884 demonstrated the use of cocaine in eye surgery, but it was some years before cocaine became generally available. This discovery signalled the birth later of local anaesthetics by synthetic products, which has now all but covered the entire field of surgery,-nerve block, spinal and sacral anaesthesia. 


\section{FIFTY YEARS OF MEDICAL PROGRESS}

TYPHOID FEVER-RIDING THE CIRCUIT

The great prevalence of typhoid fever in pioneer days was a source of considerable income to the general practitioner. A case of typhoid some miles in the country called for daily or almost daily visits on the part of the attending physician for from several weeks to a month. Occasionally there would be several cases in the same community or in the same general direction from town, necessitating circuit riding to the several patients. There was then no method of prevention, except that of boiling the drinking water, and this people would not do.

The early treatment in the eighties consisted of giving broken doses of calomel to stimulate the secretions, the administration of dilute mineral acids, preferably dilute sulphuric acid, and cold sponging to keep the fever down and for the comfort of the patient. Quinine was given to some extent, in large doses to reduce the fever and in small doses as a general tonic. When the coal-tar products came on the market they were used considerably as antipyretics and soporifics-fever reducing and sleep producing agents. When the sulphocarbolates became available, they, too, were much used. A liquid diet was thought absolutely essential. Milk and meat broths were the stand-bys. The need for intelligent nursing was ever present and rarely supplied. The typhoid patient in the earliest years was lucky if not pestered by flies. In those days no one recognized the fly as the possible carrier of the disease. That recognition came during the SpanishAmerican War.

Briefly told, the story of the recognition of the common house fly-Musca domesticus-as the cause of the outbreak and spread of a violent form of 


\section{FIFTY YEARS OF MEDICAL PROGRESS}

typhoid fever was the scandal of the mobilization camp at Chickamauga where enlisted men were being prepared for the expedition into Cuba in 1898.

Open latrines in close proximity to the open and unscreened dining halls allowed flies access to both latrines and the unprotected food on the tables. Contamination resulted carrying the typhoid germs from the typhoid infected latrines to the food the soldiers consumed. Shallow wells below the level of the camp and below the level of the latrines resulted in typhoid germ infected drinking water.

Here, then, were two sources of infection. One soldier coming into camp infected with typhoid germs, using the latrines could be and was, the potential and actual source of an epidemic of typhoid that became a national scandal and resulted in the discovery by army surgeons that the common house fly is a carrier of the germs of typhoid fever and prevention is possible by sanitation.

Inoculation with anti-typhoid serum as a preventive was begun in 1897. Tried in the armies it has all but wiped out typhoid. Luckily typhoid fever is now rarely seen in the rural districts, thanks to pure, deep well water supply and the careful screening of houses against fly contamination of food supplies.

\section{TYPHLITIS-PERI-TYPHLITIC ABSCESS- APPENDICOTOMY}

Ashurst's Principles and Practice of Surgery, published in 1878, and used as a text book in my college days 1880-81-82, did not mention the word appendicitis; but referred to "Perityphlitic Abscess" and disposed of the subject in just fifteen lines. Flint's Practice of Medicine (1881) mentions two disease entities-"Inflammation of the Caecum, or Typh- 
FIFTY YEARS OF MEDICAL PROGRESS

litis" and "Inflammation of the Vermiform Appendix." In common parlance the condition we now know as appendicitis, was known in the early eighties as inflammation of the bowels. Inflammation and perforation of the caecum and of the appendix was recognized as a possibility. The formation of abscess was noted and the possibility of the abscess perforating into the lumen of the gut and discharging per rectum, with eventual recovery of the patient, is noted in the text. Perforation into the peritoneal cavity, peritonitis and death occurred frequently. Drainage was advised as soon as the presence of pus was recognized.

The medical treatment of "inflammation of the bowels" during the decade of the eighties was first of all to relieve the pain in the abdomen and incidentally lock the bowels to prevent the worm-like motion of the bowels which physicians call peristalsis. This was done with an opiate. Hot applications, dry or moist, according to the notion of the physician were always used. If the patient after a number of days showed signs of improvement by a lessening of the pain, slower pulse, lowered fever, less tenderness and the absenee of a frank abscess, it was the custom to give small doses of "salts," magnesium sulphate, at hourly intervals every forenoon until the bowels moved. This treatment was usually supplemented with enemas. Such patients were often bedfast for as many weeks as a typhoid fever patient. Not infrequently the severer cases eventually passed pus from the rectum, indicating perforation of the abscess into the lumen of the bowels. This event was always hailed as a favorable prognostic sign. I saw one case in consultation that burrowed into the lumbar muscles which we drained 


\section{FIFTY YEARS OF MEDICAL PROGRESS}

through the back. In the later eighties the formation of appendiceal abscess was hailed as a favorable omen and as physicians became more proficient in the recognition of the abscess formation, earlier drainage - appendicotomy* - became a recognized surgical procedure. The physician who had the courage to do an appendicotomy was looked upon by the laity as a good surgeon.

It is the belief of the author that the earlier, crude treatment by recumbency, relief of pain, locking of bowels to prevent peristalsis, and the application of heat, favored the early localization of abscess formation and saved many lives in pre-appendectomy days. Nowadays with the modern concept and practice we use ice packs to retard the inflammatory process, pending early operation for removal of the offending appendix.

The development of the modern appendectomy and the author's early connection therewith, is treated elsewhere in this volume.

Senn, in his "Practical Surgery," (1901), stated that European surgeons were slow in accepting the teachings and practice as developed in this country but suggested that in the near future they will have to submit to the most convincing proof-the results of clinical experience.

".Appendicotomy" was a perfectly good word a generation ago, although not now found in most medical dictionaries. Author. 


\section{FIFTY YEARS OF MEDICAL PROGRESS}

(Continued)

1/anasement of Scarlet Fever-Adenitis. Diabetes. Powders and Pills, Early X-ray-Secing Worms. Postgraduate Work. Complete Obstetric Armamentarium. Tonsillotomy-Tonsillectomy. Quarantine Laa's. IIlegal Practitioners. Physician Makes Bandages. Service, Not Wealth. Splints. Traveling at Night.

MANAGEMENT OF SCARLET FEVER-ADENITIS

Scarlet fever in the eighties among the Nebraska pioneers ranked with diphtheria as one of the most fatal of diseases. Its spread was more insidious and more rapid than that of diphtheria. The settlers called the malignant form "Black scarlet fever" by which they meant to convey the idea that the malignant cases were something apart from other scarlet fever. Malignant anything is but an overpowering infection, invariably fatal. It was a common experience to find cases of scarlet fever in which the glands of the neck were enormously swollen and painful, making swallowing almost, if not wholly, impossible. The tonsils and pharynx shared in the inflammatory process. Cases that survived the initial fever and eruption often suffered a breakdown of the glanòs of the neck. One occasionally saw patients in whom the glands and overlying structures down to the carotid artery had sloughed out, leaving a crater down which one could see the pulsating carotid.

The treatment of scarlet fever in pioneer days was purely symptomatic - as it is for the most part now. 'To relieve the dryness and burning sensation of the inflamed and erupted skin, bacon-rind was the remedy of the pioneer layman. Carbolized vaseline was used by the physician. Nourishment was, 


\section{FIFTY YEARS OF MEDICAL PROGRESS}

for the most part limited to milk. Small doses of calomel were given in the beginning to stimulate the secretions. Some aconite was given to control fever. After the coal tar derivatives came on the market, acetanilid, to which aspirin is related, was used for the same purpose. Soothing gargles were needed for the throat.

Scarlet fever, while today a disease to be feared, does not have anything like the mortality rate that accompanied it in the days of the homesteader. Better housing conditions and better nursing care must be the answer.

Scarlet fever antitoxin now available has done much to prevent the disease and to modify its course, although it is not yet either an ideal remedy or preventive because of the violent reaction that in some cases accompanies its use. It is believed that the objections will shortly be overcome.

\section{DIABETES}

Before we became vitamin conscious and before the discovery of insulin the adult diabetic was about the most miserable person living. The older the diabetic the better his prospects were of attaining average expectancy. Not so with growing children. Their expectancy was limited to months or weeks. A growing child must not only assimilate nourishment to live, but to grow and under the pre-insulin order this was impossible.

We were in the habit of telling people they must not eat bread, potatoes, sugar, fats, and other carbohydrates; they must eat lean meat and succulent vegetables. Nobody can live long without a relatively balanced diet and of course patients would not follow the directions laid down for them by physi- 


\section{FIFTY YEARS OF MEDICAL PROGRESS}

cians-and perhaps it was well that they did not. The von Noorden diet consisting essentially of albumin and fats was a standard for years and was modified and largely succeeded by the Allen diet which was an improvement; but eventually most patients ended in a diabetic death.

In 1923 Banting and Best produced Insulin, a preparation made from the pancreas of the ox, representing the activity of the islands of Langerhans, a part of the pancreas, (known to most people as sweetbreads), used in the treatment of diabetes, by the action of which the sugar content of the diabetic's blood is reduced to normal, the ability of the organism to reduce carbohydrate being increased. In the decade since insulin was introduced, millions of diabetics have been benefited. Growing children, who before the introduction of insulin were doomed to early deaths have, since insulin became available and by its use, been allowed to grow to maturity and usefulness.

\section{POWDERS AND PILLS}

Tablets triturates and compressed tablets did not come on the market, or were not generally available for some years after I began practice. It was the common thing to dish out powders of morphine, calomel, bismuth, Dover's powder and such remedies in powder papers. The doctor called for a piece of newspaper, cut it into the size wanted for powder papers and with his pocket knife dished out the powder into as nearly equal portions as possible and folded the paper over the powder. A little later a folding pocket spatula, not unlike a pocket knife, except that a spatula instead of a knife blade was fastened into the handle, became a part of the doc- 
FIFTY YEARS OF MEDICAL PROGRESS

tor's armamentarium. Powder papers, one could have made at the printing office with the paper cutter. Still later powder papers in packages of one thousand could be purchased from physician's supply houses.

Fifty years ago a drug store was still a pharmacy, the druggist a trained pharmacist who could and did compound prescriptions. He made pills, plasters, suppositories, fluid extracts, tinctures, syrups, vesicants, etc. Nowadays a drug store is a junk shop by crude comparison.

\section{EARLY X-RAY-SEEING WORMS}

The discovery in 1895 by Roentgen, of the properties of the $\mathrm{x}$-ray, revolutionized the diagnosis and treatment of disease. At first used only as an aid in the diagnosis and treatment of bone injuries, it soon developed into a diagnostic aid of first importance in gastro-intestinal diseases and later in chest and head and genito-urinary conditions. During the earlier period of the development of the possibilities of the x-ray much x-ray quackery was done. The laity believed then, as some do now, that the roentgen ray will show everything. A concrete example will illustrate this: About the turn of the century an adolescent boy under my care had pneumonia, and made a partial recovery, but resolution was slow. He was able to come to town but did not make the rapid recovery one should expect.

A priest at Epiphany, South Dakota, had acquired an x-ray machine, a Franklinic friction machine which had to be operated by a hand crank. Wonderful cures were reported from Epiphany and the faithful flocked there from all points of the compass. My patient went there accompanied by his father. 
FIFTY YEARS OF MEDICAL PROGRESS

The father later told me as soon as the "priestphysician" looked at the boy's chest through a hand fluoroscope, he exclaimed "the lungs are full of worms, I can see them crawling about!" Of course the boy recovered in time.

My first x-ray was a McIntosh Static machine, with hand crank, which I soon changed to a motor drive. It was not altogether satisfactory for x-ray use, but had some merit as an electrotherapeutic device. After a few years I gave it to one of my less fortunate brethren and put in a Meyer coil. Still later I owned an International unit, but my career as an x-ray man has not been brilliant.

The later development of the x-ray, the cost of which run into the thousands of dollars, made them better machines but financially impossible for the small town man, who can not command a sufficiently large clientele to pay the overhead of a machine. A portable x-ray unit recently placed on the market gives promise of meeting the needs of the general practitioner and is priced within the average doctor's capacity to pay.

It is a long cry from the hand driven static $x$-ray machine, which I first used, to the present day x-ray apparatus. In the early days it took several minutes to make an x-ray picture of the hand while today instantaneous exposures of the thickest parts of the body are possible.

This change came about gradually with about the following order: static, coil, mechanical interrupter and valve tube machines. The invention of the hot cathode x-ray tube, 1913, entirely supplanted the old gas filled tubes.

While these improvements were taking place in diagnostic x-ray apparatus equally great changes 


\section{FIFTY YEARS OF MEDICAL PROGRESS}

were occurring in therapeutic x-ray equipment. In the days of the static machine on through the coil days, only skin diseases could be treated by x-ray. The combination of the mechanically interrupted machine and the hot cathode (Coolidge) tube made possible the treatment of subcutaneous glands and growths. It was not until 1920 that growths located deep in the body could be successfully treated by $\mathrm{x}$-ray. At this time the era of deep x-ray therapy was born. At the present time (1937) still higher voltages are being used to produce $\mathrm{x}$-rays more nearly like the gamma rays of radium. It is yet too early to say just what change in clinical results the supervoltage $\mathrm{x}$-rays will produce. It is interesting to note in passing that today Nebraska has one of the most powerful constant potential x-ray machines in the world used for the treatment of patients,

\section{POSTGRADUATE WORK}

In spite of the teaching at medical school which was averse to Listerism, I early became imbued with the Listerian idea of antisepsis and used it in my work. In January and February, 1894, and again about $1901 \mathrm{I}$ attended postgraduate courses at the Chicago Post-Graduate School and Hospital and came under the tutelage of Dr. Franklin H. Martin and his co-workers who influenced my entire subsequent career, The most rigid sterilization of everything coming in contact with the patient was practiced.

The dull irrigating curette, since almost fallen into disuse, was much in use for incomplete miscarriages and abortions and also the sharp irrigating curette for removing the hypertrophied mucous lining of the uterus in cases of subinvolution, uterine decensus, (falling womb), etc. This appealed to me so strong- 


\section{FIFTY YEARS OF MEDICAL PROGRESS}

ly that I used the procedure for many years. It has now almost wholly fallen into disuse.

Following my first visit to Chieago I provided myself with gowns for obstetrical work and always gave the mother the best antiseptic care possible.

\section{OBSTETRIC ARMAMENTARIUM}

Modern obstetrics in the home requires some equipment and I determined to have the best. I obtained a large bag, 20 inches long, ten inches wide and twelve inches high, in which I could carry about all that was needed for proper care of any case, obstetric or other emergency. In this bag was packed a covered sterilizing tray, a Kelly pad, fountain syringe, five yard package of sterile gauze, a one yard package iodoform gauze, quarter pound carton cotton, one yard gutta percha tissue, half dozen bandages, leg holder, roll of gynecological instruments, obstetric forceps, razor, hypodermoclysis apparatus, sublimate tablets, cresol solution, liquid soap, hand brush, chloroform and mask, roll of adhesive plaster, heavy dilator, ergot, assortment of ligatures and of needles, collodion, operating gown, half a dozen sterile towels, sterile pads. Individual taste will suggest some changes. In addition I always carried 2 enameled basins and several small trays which latter could be used to sterilize needles, small forceps and scissors. One not so equipped cannot imagine the feeling of satisfaction the possession of such equipment gives the physician.

\section{TONSILLOTOMY-TONSILLECTOMY}

Unless my memory fails me we were not often consulted about tonsil affections in the early eighties, except in cases of tonsillar abscess or quinsy. The 


\section{FIFTY YEARS OF MEDICAL PROGRESS}

Fahnestock tonsillotome, an instrument for taking off a part of the tonsil was on the market. In the early nineties after the McKenzie tonsillotome was available tonsillotomy became an operation of some frequency. This instrument I have always thought was the most nearly perfect instrument ever invented. It did three things in one movement. On a handle having finger holds for the first and second fingers and thumb, is a ring shaped contrivance concealing a ring knife. The instrument was passed over the tonsil and as the fingers closed on the instrument, it first, speared the tonsil, second, pulled it toward the middle and third, cut it off, all in a jiffy. The general practitioner did tonsillotomies, on cases of enlarged tonsils and tonsils repeatedly prone to abscess. Tonsillotomy relieved the patient in only about one-half of the cases.

The focal infection concept belongs to the early years of the present century. With this concept came the operation for the complete removal of the tonsils in all cases of infected tonsils. Tonsillectomy has been a popular operation less than twenty-five years.

\section{QUARANTINE LAWS}

Quarantine and health laws and regulations for Nebraska are of comparatively recent development.

Nebraska was tardy in health regulations compared with other older and more populous states. Though larger than Pennsylvania, with less than $1,500,000$ population, Nebraska has always found enforcement of quarantine regulations difficult in rural districts and in villages. Lack of cooperation has been a serious handcap. The idea prevails among many lay people that it is quite right to quarantine the "other fellow;" but not "me." There is, today, 


\section{FIFTY YEARS OF MEDICAL PROGRESS}

a lack of funds for the stringent enforcement of the laws regarding quarantine and terminal disinfection. (See Appendix C.)

\section{ILLEGAL PRACTITIONERS}

In the early eighties many persons representing themselves as qualified physicians, registered at the county clerks' offices and engaged in practice. They were persons who had engaged in practice in other states and had been driven out by newer, stricter laws, and persons with forged diplomas. One of the latter located in the town from which this is written. He came heralded as a specialist in diseases of women. He "had been physician to the Queen of England"(?). He formed a partnership with our foremost physician. In course of time it became evident that he was a medical ignoramus of the first water. He did not know enough to introduce a pair of forceps, diagnose a plain case of pneumonia or properly dress a wound. It was later discovered that he had been a pharmacist in the east and lately had been fulminate mixer for the Union Metallic Cartridge Company at Bridgeport, Conn. He had not the slightest claim to being a physician. The reason it was so easy for such ilk to register and practice was that the law which provided for registration did not provide an adequate penalty for false registration.

PHYSICIAN MAKES BANDAGES

The early day physician had to make his own bandages. He purchased ten yards of muslin at a time and made it into bandages the width needed. To roll the bandages a clean apron was put on and they were rolled over the knee. 


\section{FIFTY YEARS OF MEDICAL PROGRESS}

Pioneer economy suggested that they be washed as they became soiled and used repeatedly. The laundry work of course was done at the physician's home. Plaster bandages also were homemade.

Before bandages became a merchantable commodity obtainable in rural sections, a little hand rolling device was invented. It was clamped to a table and turned by hand. This device could be used for ordinary roller bandages and also for making plaster bandages.

\section{SERVICE, NOT WEALTH}

The early day physician had much to contend against, but he was imbued with the spirit of service and answered calls in all kinds of weather and over all kinds of trails and roads to pay or no-pay patients, uncomplainingly. Wealth was not his objective in life: it was service. He was glad to be able to make a living for his dependents and himself. A physician who refused calls to the indigent and pauper class was usually frowned upon by the community and lost caste and the business of people who were able to pay. There were exceptional cases that never made an effort and were obliged to patronize every new doctor that came along.

The practice of passing non-paying customers off on the newly arrived physician no doubt dates back to ancient history. One such case was passed on to me. Manahan was known as a worthless, improvident individual. His family requisitioned the services of the physician on numerous unnecessary occasions, until the family physician tired of it. One night when a storm was brewing a messenger called me to go to Manahan, some miles from town. We hitched up hurriedly for the messenger thought Manahan was dying and drove out through a most 


\section{FIFTY YEARS OF MEDICAL PROGRESS}

violent thunder and rainstorm. When $I$ reached the patient's bedside and asked him his symptoms he said: "I feel all right now, but I had such queer feelings and sensations came all over me a while ago." That ended the case-and settled the bill!

\section{SPLINTS}

In the early days splints were made out of any convenient piece of board, sometimes taken from the pig pen or the siding from the house. I later conceived the idea of making splints out of tin and supplied myself with the sheets of tin and tin shears for the purpose.

Plaster of Paris bandages were known when I came into practice but were not used in acute cases; rather they served as a later dressing when the patient was able to be about and all danger of swelling of the part was over. The ready-made splints are a more recent invention and while a good thing are not altogether satisfactory in all cases. The Balkan frame, the bone pin extension, the airplane splint and a number of like improvements have come within very recent years.

TRAVELING AT NIGHT

Traveling country roads on very dark nights was a very difficult matter. It became necessary at times to carry a lantern. In the latter years of the buggy era, dash-board lanterns became available and were a valuable adjunct to the doctor's road equipment.

In my earlier years of practice buffalo robes were still obtainable and were generally used as a protection for one's feet and limbs. Later cattle and horse hide robes became available. The black galloway robe was the better one. To further protect the 
FIFTY YEARS OF MEDICAL PROGRESS

physician on cold drives a jug was sometimes filled with boiling water and placed between his feet. I had the experience of having one freeze solid and burst on a twenty mile drive.

Later charcoal footwarmers came into use-a little metallic compartment into which charcoal was placed and ignited. A lighted lantern was also used as a makeshift on occasions, but it had the disadvantage of being too tall for the best result.

No the life of the pioneer physician was not so comfortable as that of the physician who drives a heated automobile-covering as many miles in an hour as I drove in a day. Many a cold winter's day my country calls required the entire day and part of the night to complete the circuit. 
EARLY MEDICAL SOCIETY CONTACTS:

AUTHOR BECOMES PRESIDENT

Membership State Medical Society. Whiskers and Prince Albert Coats. Whiskey. "Typho-Malarial Fever." Organization, Elkhorn Valley Medical Society, Dr. George H. Simmons. Author Becomes President. Address "The Trained Nurse."

\section{MEMBERSHIP STATE SOCIETY}

It had been my intention from the date of my graduation to become affiliated with organized medicine as soon as I could. Six years elapsed, but in 1888 I was admitted to membership in the Nebraska State Medical society* at a meeting held in Lincoln in the Federal building-now the City Hall. About twenty-five were admitted to membership at this meeting, five of whom later made their impression on Nebraska medicine. Two became nationally known. During a morning recess one of the oldest medical men in Nebraska, Secretary A. S. von Mansfelde, came to the rear seats where most of the new members were congregated, saying: "I want to shake hands with all these new members," greeting us most cordially. This kindly gesture I have always remembered. It prompted me in my later associations in medical society work to make a good deal of effort to meet and greet members, new and old, and during my most active years I probably knew more physicians in the state than any other member. Unless one gets acquainted he gets little out of medical society work, for it is the personal contacts that count most; but the individual must make at least half the effort of approach. To meet and greet the other fellow, to get his viewpoint,

- On reorganization in 1901 the name was changed to Association. 
EARLY MEDICAL SOCIETY CONTACTS

to study his mannerisms and conceits, is worth all it costs in time and money.

WHISKERS AND PRINCE ALBERT COATS

The older physicians well remember that in their early days as practitioners, whiskers added dignity and a certain appearance of wisdom to the professional man. In those days few physicians would deign to appear in a sack business suit in everyday work. The Prince Albert and swallow tailed coats were much in vogue. A physician could then be spotted almost anywhere by his professional appearance. Nowadays in some cases it is hard to tell a physician from a horse jockey. With the coming of the ultra-scientific in aseptic surgery, whiskers were all but banished, and with the development of the more practical world, swallow tailed and Prince Albert coats gradually gave way to the more practical modern sack business suit. In the eighties and ear!y nineties, whiskers, silk hats and Prince Albert coats were almost universally worn at medical society meetings.

\section{WHISKEY}

While attending my first annual meeting of the State Medical society, the following incident happened: I had tired of sitting in the overheated assembly room so I stepped in the corridor to the head of the stairs to get fresh air. Presently out of the meeting-room, arm in arm, came two older physicians, now historic characters, whom I had previously met. When they approached me I asked "What is next?" meaning "What is next on the program?" One promptly replied "The next thing is a drink of whiskey, won't you go along?" I did not go.

The incident reminds me that there always were 
EARLY MEDICAL SOCIETY CONTACTS

some physicians in those earlier annual meetings who indulged too freely. I recall one particularly who had been state senator and was instrumental in passing the first board of health measure. He was on the program at the annual banquet and he was well saturated. He attempted to speak to the toast "The State Board of Health" and he talked and talked and talked until 35 minutes had elapsed. In desperation the orchestra was ordered to drown him out with music.

"TYPHO-MALARIAL FEVER"

During the early years of membership I read papers before several of the annual meetings. One of the earliest papers and perhaps the most important was on "The Continued Fevers of Rural Nebraska." Much was written and said about "typho-malarial" fever in the early eighties meaning thereby a distinct entity both typhoid and malarial in character. Malaria may occur in a typhoid patient, but is extremely rare, but we know now there is no such disease as typho-malaria. Occasionally typhoid fever at the onset may simulate malaria, but usually that is only in the first week of the disease and is atypical. The term typho-malaria was coined in malarial countries, and really was a term which did not mean very much. I endeavored to demonstrate that our continued fever in rural Nebraska was purely a typhoid fever; assuredly so, since we did not have any malaria in the state except perhaps in the extreme southeast corner.

This subject has always interested me and some time ago I undertook a further study which should be conclusive as to the existence of malaria in Nebraska. Addison Sheldon of the Nebraska State His- 


\section{EARLY MEDICAL SOCIETY CONTACTS}

torical Society told me that in his boyhood days in Seward county he had the real "shakes" and he knew of others who were similarly afflicted. Inquiry from a number of physicians in the southern part of the state leaves no doubt that occasional cases have been observed at Lincoln and along the Blue river near Beatrice. The malarial mosquito does exist in Nebraska.

The apparent absence of malaria over a large part of Nebraska cannot then be due to the absence of malarial mosquitoes but because, while the Anopheles genus does exist in Nebraska, it is not widely distributed, the number of individuals is relatively small and there were few hosts present in the State. (See Appendix D.)

\section{ORGANIZATION-ELKHORN VALLEY MEDICAL SOCIETY}

By 1896 a feeling had developed in the country tributary to the Elkhorn valley that there should be organized a medical society for the physicians of that section. Dr. P, H. Salter of Norfolk took the initiative and I became his close second in the work preceding organization on December 29, 1896.

Begun with the hope that the talent of the medical profession residing within a radius convenient to Norfolk could be organized into a strong and substantial working body, with great social, professional and financial benefit to the profession, the society from the first enjoyed uninterrupted growth. Eventually it became the foremost and strongest district medical society in the entire state. Its influence on the profession of northeastern Nebraska has been immeasurable and has extended over the state. Some of the best men of the state, specialists 
EARLY MEDICAL SOCIETY CONTACTS

and general practitioners, have shared in its councils and given to it their time and talent.

DR. GEORGE H. SIMMONS

I was elected the first secretary and became the third president. Later I served as secretary for

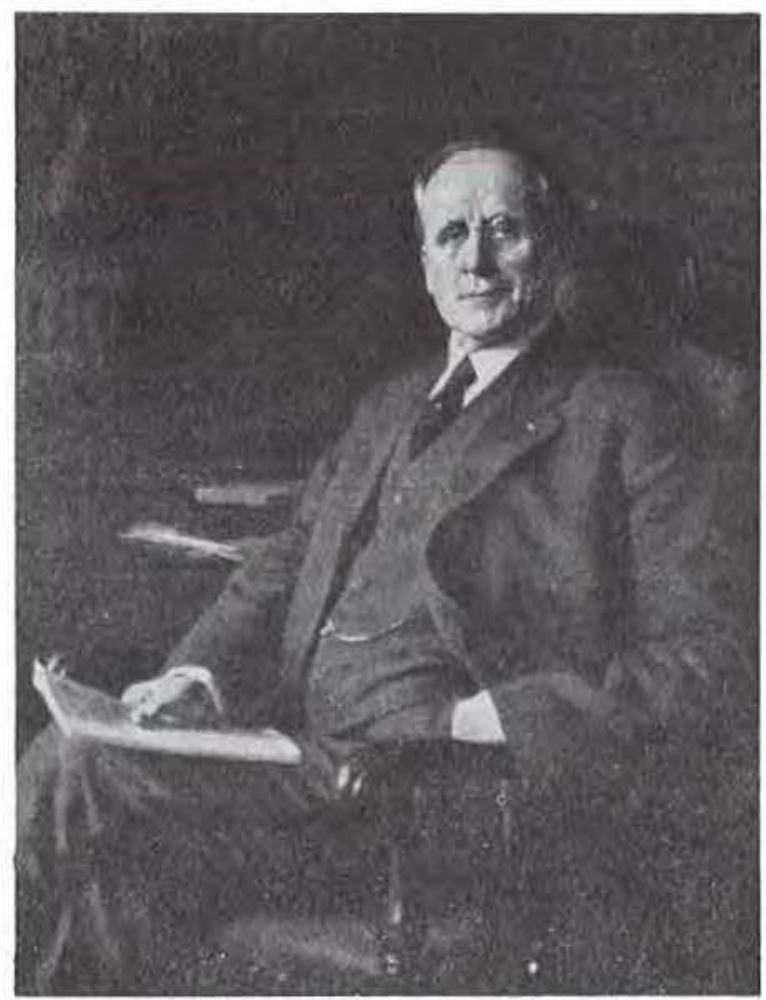

Dr. George H. Simmons, for twenty-five years, Editor of the Journal of the American Medical Association.

a number of years until I resigned on becoming president of the State Association. This developed into an active association and is still in existence 


\section{EARLY MEDICAL SOCIETY CONTACTS}

after forty years. My work in this society brought me into contact with state society officials and gave me a certain prominence among men who did things in the State society in those days. Among them was Dr. George H. Simmons, Lincoln, then secretary of the Nebraska State Medical Society and editor of the Western Medical Review. Later he served for twenty-five years as editor of the Journal of the American Medical Association. My reports of "Elkhorn Valley" meetings were published in the Review, under Simmons' editorship.

\section{AUTHOR BECOMES PRESIDENT}

I made it a practice whenever possible to attend annual meetings of the State association and missed but few. In 1897 I was made vice-president and at different times during the years, was appointed to important committees, the work of which I always took seriously. In time I became recognized as one of the active members of the society. In 1906 it fell to my lot to be again elected vice-president and when a few months later Dr. J. L. Greene, president, then superintendent of the Lincoln State hospital left the state, I succeeded to the presidency of the Nebraska State Medical Association.

When told that this was my fate, my first exclamation was "I don't know what I will do with it." I had never aspired to any position within the gift of the profession. Whatever preferment came to me, then and since, came unsolicited. After thinking it over for a time I visited the secretary of the Association, talked matters over with him, and came home determined to "buckle on my armor" and do my best. 
EARLY MEDICAL SOCIETY CONTACTS

"THE TRAINED NURSE"

Greatness(?) is not without its penalties. After I had "enjoyed" my high position a few months there came a request from Omaha that I give the address to the graduating class of nurses at the Omaha General Hospital. I had never given an address in my life, but it seemed that this was a command, not to be turned down. I consented, took the matter seriously, delved into the history of nursing, and produced an address on "The Trained Nurse" that when published in the Western Medical Review (Omaha), attracted the attention of the magazine The Trained Nurse (New York), which by permission republished it. It appears that up to that time very little had been published on that subject from the viewpoint of the general practitioner.

Thereafter for years requests came for reprints from points as far removed as Syracuse, N. Y., and Butte, Montana. Apparently I had said something that made a hit and that address became widely known. I am therefore constrained to give part of it here. My rural practice had afforded few opportunities for the employment of trained nurses; but these few had given me a deep appreciation of their value. In this graduating address, I first sketched briefly the history of the nursing profession then said in part:

1 bring you a message from the plodding country doctor, he who for five and twenty years, on the broad prairies of Nebraska, by day and by night, in sunshine and in storm, has ever heeded the sick call to duty, whether from prince or pauper, regardless of the pleasures of the day, or the needs or desires of home or family life. With but a few opportunities to have the valued assistance of trained 


\section{EARLY MEDICAL SOCIETY CONTACTS}

nurses, I have learned to appreciate their work perhaps better than my city brother to whom the assistance of a nurse is so common as to be taken as a matter of everyday necessity, and perhaps without full appreciation of the value of her services as an adjunct to his work.

Without taking too great liberties with the secrets of a professional life, I may add that in considerable more than a thousand births, at which I have been present as the good genius, I have not had the assistance of a trained nurse once, not once. Need I tell you that I have ever felt the need of trained nursing? Ah, you can imagine the disadvantages under which the country doctor labors.

Your professional life as private nurses will throw you in many situations akin to the everyday experiences of the country doctor. Let me admonish you to rise heroically, as does the true physician to every emergency.

Make the best of the opportunities with the material and facilities at hand and do not falter, because perchance, something needs doing not strictly in accord with preconceived notions of professional dignity. The nurse should not be a drudge but if something needs doing not strictly in the line with nursing, and there is none else to do it, do not shirk but like a good Samaritan do it ungrudgingly.

In my professional life, without the aid of trained nursing, I have ever considered it a duty to the newIy made mother, although not strictly a physician's work to see to it personally, that the bed and body linen were changed and her person rendered surgically clean.

I would as lief think of cutting and sawing off a man's leg, calling that a finished amputation, and 


\section{EARLY MEDICAL SOCIETY CONTACTS}

ask any bystander to wash and wrap it, as to leave the mother, without personally, first caring for her, trusting her toilet, instead, to the untrained and usually careless hands of the nearest neighbor.

Professional dignity is a good thing but it has limitations. I have little respect for the nurse who will consider her comfort paramount to that of the patient. Devotion to duty should be the watchword of every physician and nurse.

In great crises, sleep, out-door exercise and every comfort and pleasure of physician and nurse must be foregone for the patient's good.

Go where duty calls, whether to hovel or palace and regardless of the nature of the disease.

Do not misinterpret my lecture: Having consecrated yourself to this line of work heed every call to duty, and do it well even at the peril of your own constitution but take every opportunity that can be spared without risk to the patient to improve your physical well being, and in case of contagious diseases, neglect no opportunity to keep your bodily functions normal and to render the contagium from the patient, immediately innocuous.

To the physician or surgeon, and the patient, the intelligent assistance and co-operation of the trained nurse is half the battle. It is possible that in many cases the trained nurse saves the patient's life, and the doctor gets the praise-and the fee.

1 have thought that the favorable results shown by statistics of certain methods of treatment in certain diseases in hospitals, might be due not so much to the treatment employed by the doctor reporting, as to the thousand-and-one little things done for the patient's comfort by the nurse.

The nurse comes into the home during the great- 


\section{EARLY MEDICAL SOCIETY CONTACTS}

est crisis in the family's history and she is looked upon as a superior being. Her deportment as well as her work must be submitted to the crucial test of public opinion. Great things are expected from her and she should prove equal to every emergency.

From my observation and from the experience of patients I am led to believe that the greatest weakness of trained nurses is their want of ability to cook well. When a patient's nourishment is so very scant, it should be very tempting, so that the patient may relish every bit of it.

The nurse must be loyal to the attending physician and never speak of him disparagingly to the patient, or her advisers. She must carry out the physicians orders in the spirit of his intentions. She must not give a cold douche when a hot one is intended.

Cheerfulness, assurance and willingness count for much with the patient who must have absolute confidence in the nurse.

The ideal nurse would be perfect. "Trifles make perfection, but perfection is no trifle." To the patient, the average nurse seems almost perfect and she grows to have a genuine liking for the one who brings so much comfort and relief.

Her education and training entitle her to the respect which will everywhere be accorded to her. Her superior knowledge on matters pertaining to the public health, places her in a position where she can do much toward educating the family and community along hygienic and sanitary lines.

The impression made on a family by the short stay therein of a trained nurse marks a very distinct step in advance along the lines of surgical and 


\section{EARLY MEDICAL SOCIETY CONTACTS}

personal cleanliness, as I have repeatedly observed in isolated country homes.

Her short stay leaves bright memories, cherished for years. Her opportunity to do good in many ways is a grand one and she should avail herself of it, for it is a primal duty of all, to endeavor to uplift their less fortunate fellows.

I congratulate you most sincerely upon your graduation, and on behalf of the medical profession whom I have the honor to represent, I welcome you as helpmates of the physician and surgeon. Your star became ascendant with the dawn of Aseptic Surgery and you are a necessary part of it today, and ever will be.

Young ladies, you are standing this day upon the golden threshold of opportunity. A thousand homes are open to receive you; a thousand hearts are waiting for your kind and cheering word; a thousand bodies racked and tortured with pain await the touch of your deft fingers. You must be ready for every emergency.

To accomplish your aim and to attain to true success, you must be "as wise as serpents, and as harmless as doves."

Your fund of patience must exceed that of Job's, your wisdom that of Solomon's and your kindness that of the Good Samaritan.

The Good Book calls the angels "ministering spirits," but you are more-you are ministering angels.

Optimism must be written on your countenance, hope engraved in your heart, sympathy in your touch, and kindness in your speech.

Your reward for painstaking and conscientious service cannot be measured by a money standard, nor by the work done, but by Him who said-"In- 


\section{EARLY MEDICAL SOCIETY CONTACTS}

asmuch as ye have done it unto one of the least of these, my brethren, you have done it unto me."

And now Young Lady Nurses, I wish you all a brief but brilliant professional life, to be succeeded by a more brilliant home life, where and when you shall reign as the queen, and for which your training fits you as no other training can. 
THE PRESIDENCY, THE ANNUAL MEETING, MEDICAL EDITOR

Problcms of Organized Mcdicine. Founding of Ncbraska State Medical Journal. An Editor is "Born." Problems of Medical Journalism. Physicians' Ladies Home Journal.

\section{PROBLEMS OF ORGANIZED MEDICINE}

As president of the Nebraska State Medical Association I applied myself to the problems of organized medicine with no thought of provoking a revolution, but with the hope that in some small manner. I might be helpful in fostering the better things in medicine.

One of my first official acts was to circularize county society officers, asking for lists of names of such physicians in their respective counties who should, but did not, belong to the organization. In turn I then approached those whose names had been furnished me, presenting in a reproduced typewritten circular letter as best I could the objectives of organized medicine. For some reason the membership at the next annual meeting had increased by 144 over the previous year.

In my annual address I touched principally on the following major subjects: A State Medical Journal; Medical Organization; The Council on Pharmacy and Chemistry; Fee Splitting; Changing Location.

\section{FOUNDING OF NEBRASKA STATE MEDICAL JOURNAL}

I made a study of state medical journalism and at the annual meeting (1907) in my address gave the result of my survey of the 16 state medical journals then existing, stressed the need of a state journal and urged that the association look forward to the establishment in the near future of an association- 


\section{THE PRESIDENCY}

owned and conducted State Medical journal. This pronouncement was destined to bear fruit.

At a subsequent annual meeting a proposed ByLaw establishing the Nebraska State Medical Journal was offered and adopted.

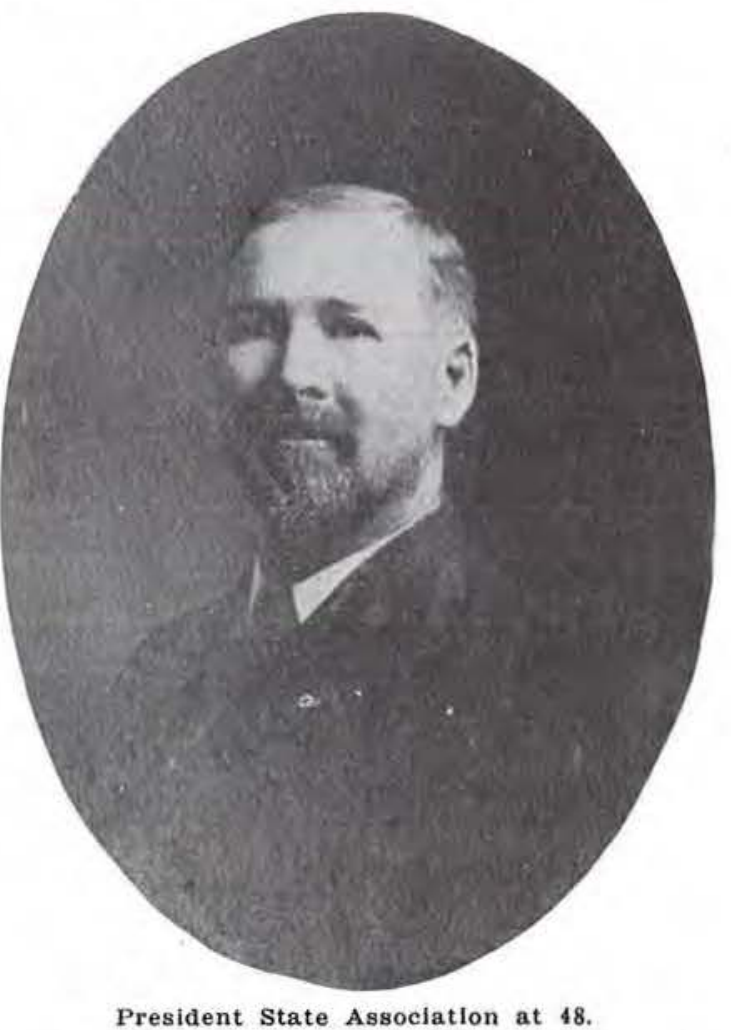

Thus, The Nebraska State Medical Journal was established by the House of Delegates with much enthusiasm at the annual meeting in Omaha in the spring of 1916. The first number appeared the following July, with Dr. Irving S. Cutter, then dean of 


\section{THE PRESIDENCY}

the Nebraska University College of Medicine, now dean of Northwestern University College of Medicine, Chicago, as the first editor. The publication board elected by the society, consisted of the three men who had served on the committees that brought.

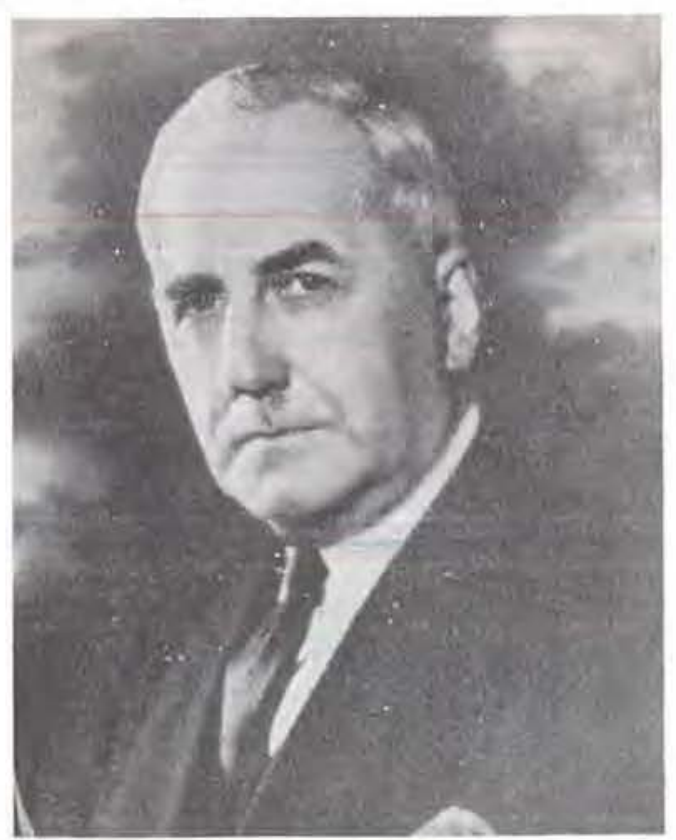

Dr, Irving S. Cutter, Dean of Northwestern University Medical School.

about the establishment of the Journal, Dr. W. O. Bridges, Dr. B. F. Bailey and Dr. F. A. Long. The last named has been chairman of the committee from its inception to date.

I had never even dreamed of becoming editor. It is true I took a deep interest in the Journal and cooperated with the editor by making occasional contributions. 


\section{THE PRESIDENCY}

\section{AN EDITOR IS BORN}

In November 1920, Dr. J. M. Aikin, then editor, died rather suddenly, following an operation. As chairman of the publication board, I stepped into the breach thus created, intending to carry on until

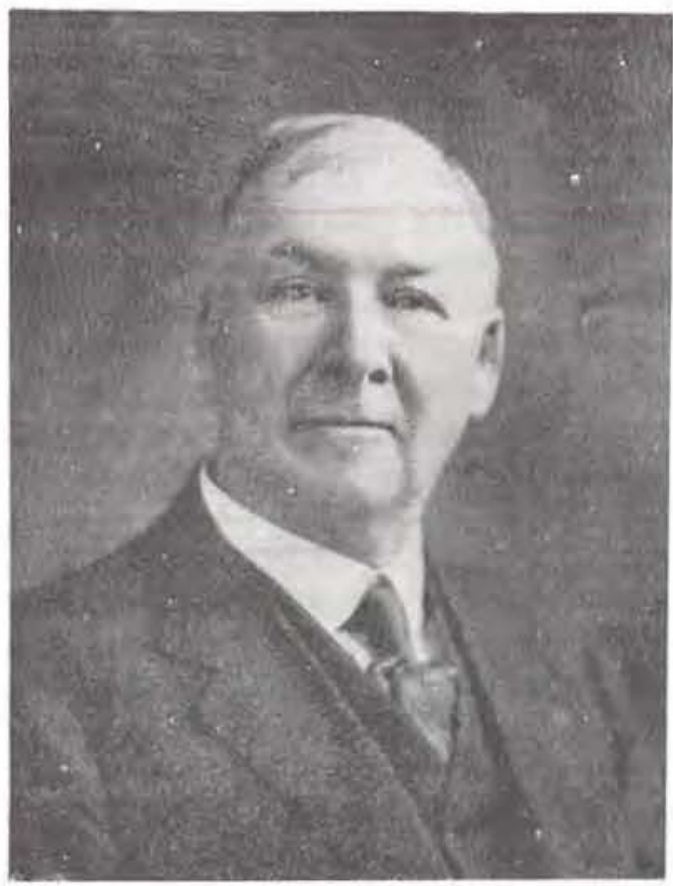

In the Serene 60's.

the next annual meeting, but never thinking of myself as editor. After doing the work on a few issues, I began to get interested in it, concluded I liked it and offered to carry it on if agreeable to the others on the board. Thus by the merest chance a medical editor was born. I have been editor since December 1920. 


\section{THE PRESIDENCY}

\section{PROBLEMS OF MEDICAL JOURNALISM}

I began to delve into the work seriously, doing the best I could while carrying on a laborious practice. After a few years I suffered a cardio-renal break, as a result of which I had to retire from the greater activities of a general practice and I determined to devote myself to the Journal as my contribution, if any, to organized medicine. The result, if any, is history.

Good editorial work on a state medical monthly journal requires the greater part of the time and energy of one person for about half of the time each month, somewhat depending upon the size of the magazine. The editor must take pride in his work. The work of a journal requires individual, personal attention. It cannot be well done by proxy. The better the editor knows the profession as individuals, the better he will get along with his work as editor.

Editorial service should be paid a compensatory sum to get the best results. With the best intentions any physician of average ability. cannot give one-half of his time, year after year, for the good of the cause and without compensation.

The editor should be a man who has earned his laurels by service in medical organization work, if he is to have a keen realization of the fundamentals of medical organization.

A state journal must reflect the expressed wishes of the organized profession of the state and of the American Medical Association and on matters on which there is some question of policy the journal must not go far afield. The state journal must discuss, editorially, the every-day problems of the profession from the various angles and much stress should be placed on these discussions. The editorial 


\section{THE PRESIDENCY}

pages should reflect the highest ideals of the profession and should so impress the reader as to be accepted as authoritative.

The state medical journal is perhaps the most cohesive thing in medical organization and its influence may be widened by catering to the human side of the physicians of the state. The physician is first of all a scientific personage; but he is also a human being with tastes for the lighter things pertaining to his professional life. The esprit de corps of the profession must be jealously guarded. This implies sympathy, devotion, enthusiasm and a jealous regard for the honor of the body as a whole.

I may be permitted to develop this topic by saying that county and district medical society meetings, from those of the highest excellence to those of relatively minor importance, should be featured in the journal as representing a cross-section of the work of the profession of that community. Unusual incidents connected with meetings, such as picnic meetings, banqiets by the local chambers of commerce, or by the local profession, dinners served by the physicians' wives, groups of physicians chartering auto busses to attend meetings at a distance in a body, are worth mentioning. They interest the physician reader.

I believe the editorial pages of a state medical journal should be an open forum for the frank discussion of the problems of the profession from all angles.

"Editorial Paragraphs," short comments on phases of medical economics and of various things related to medicine are of interest to the physician, and may find place in a state medical journal; they will be 
read with interest and profit by the local physician -and perchance by his wife.

PHYSICIANS' LADIES HOME JOURNAL

Many physicians' wives take an interest in the state medical journal. This is particularly true since the organization of the Women's Auxiliary. The State journal therefore becomes the physicians' ladies' home journal. This may seem a pleasantry, but it is a significant thing that the wives of physicians take enough interest in their husbands' profession to want to read the state medical journal. Physicians with such helpmates will succeed if feminine interest can compel success.

I have a theory that fillers, whether in the advertising pages or among the original reading matters should be abstracts of scientific or economic worth, or innocent pleasantries touching on the everyday routine or foibles of the physician.

The physical appearance of the medical journal counts for much. The mechanical execution and the general appearance should be dignified and should appeal to the aesthetic sense, but a journal should not be an artistic monstrosity.

Few would believe at first thought that it takes the greater part of the time and energy of a person for about half of each month to get into presentable form material that fills the Journal; but such is the case.

One of my valued critics stated that the foregoing constituted too much editorializing: that not conclusions, but what I did as editor, should be told. My reply is that I attempted to carry out the ideas about which I philosophized and which I advocated. 
MORE HONORS AND SOME TRAVEL

Delegate to A. M. A., etc. Good Roads Movement. Highrway Mission to City of Merico-President Obregon. Vice President International Meridian Highway. Going Abroad. "English-Not Scotch." Professor John Fraser. Hotel Dieu, Beaune. Fitting Climax to Career of Country Doctor.

DELEGATE TO A. M. A., ETC.

Following my term as president, I was elected delegate to the annual meetings of the American Medical Association and attended as delegate the meetings at Atlantic City in 1907, Chicago, 1908, and Los Angeles in 1911. My ambition was to do something, to be named on some committee where service could be rendered. It was no pleasure to sit through several annual meetings listening to dry reports of the reference committee on the reference committee's report! The supposed service, without service, did not appeal to me and although urged to do so, I declined to stand for election anymore.

Several successive presidents appointed me delegate to the Council on Medical Education and Medical Legislation in Chicago and I attended these meetings in 1909 and 1910, read a paper before one of the meetings and served on a reference committee. I represented the Nebraska State Medical Association at the Second Conservation Congress at St. Paul in 1910 when both Ex-President Roosevelt and President Taft spoke.

All of the above assignments came to me and I attended each one, before it became the policy of State associations to pay the expenses of delegates. Nowadays, delegates receive expense money, for what to each one amounts to a free jaunt and the representatives are willing to take a life tenure! 
MORE HONORS AND SOME TRAYEL

Early in 1914 a blank application for fellowship in the American College of Surgeons was sent me, anonymously. I did not feel qualified for fellowship although the matter appealed me. The application lay in my desk for nine months before I decided to fill it out, after first talking with some of my surgeon friends. Perhaps the stand I had always taken in regard to fee-splitting was taken into consideration in acting on the application more than my surgical experience. I was admitted to fellowship at the Boston meeting in October 1915, together with some hundreds of others, among whom was Dr. Willard Grenfel of Labrador fame. A Boston newspaper wag referred to the event as "The largest assembly of elderly cutups the world has even seen."

\section{GOOD ROADS MOVEMENT}

Because of an extensive country practice and my life on the road, I early became interested in the good roads movement. I was chosen several times to head the local community club and advanced the proposition that we could do more for our town and community by improving the roads leading into town than by any other thing we would undertake. As chairman of the roads committee I supervised the first demonstration of road dragging by the first split log drag made in the county about 1912 to 1914 . The next year the county commissioners of the county took up road dragging as an established practice and soon thereafter the same year the surrounding counties also inaugurated it.

HIGHWAY MISSION TO CITY OF MEXICOPRESIDENT OBREGON

When the Meridian Highway (now U. S. No. 81) was projected I was designated local representative 
MORE HONORS AND SOME TRAVEL

with power to designate the route through most of Madison county. When in 1921 a Meridian Highway Mission to Mexico City was undertaken by invitation of the Mexican government, I became the $\mathrm{Ne}$ braska representative. Returning home at noon one day my wife told me there was a telegram that the Mission would start from Laredo, Texas, four days later and asking me to come, or send a substitute if I could not go. I exclaimed I would not need a substitute and the next day I was off on what to me at that time was a great adventure.

Up to that time Mexico was without roads more than about three miles from any town. An exception to this was several paved roads leading from Mexico City to surrounding towns none over about forty miles away. So entirely true was this that two Mexican engineers with an auto made a scouting trip to Laredo in anticipation of our Mission and found it difficult though not impossible and recommended against the Mission undertaking the trip by autos.

Our mission was met at Laredo by Colonel Emilio Cirlos, a Major Moreno, of the Mexican Army and two engineers from the Department of Buildings and Communications, in an old type Pullman car, (purchased from the Pullman company by the Mexican government during the revolution for an officer's car), and a porter and cook.

The Mission was received and entertained by the chambers of commerce at Monterrey, Saltillo, San Luis Potosi and Queretero on the way to Mexico City.

At Queretero, (the city where the ill-fated Maximilian was executed), we were privileged to visit the palace of a Mexican millionaire. I recall it had 
MORE HONORS AND SOME TRAVEL

a very beautiful fountain in the patio, surrounding which was a lily pond with gold fish. With the ever watchful eyes of a physician for things medical I spied a bottle of Scott's Emulsion on the dining room table. Later, on the street cars in Mexico City I saw Lydia Pinkham's alluring poster in Spanish verbiage. Verily, suckers are sought in all nations and in all languages!

At Mexico City we were the guests of the government at the Regis hotel and were received in audience at the Department of Buildings and Communications, given a drive about the city and its environs and on a Sunday were taken across the mountains to Cuernavaca where we were banqueted in one of those quaint open-front hotel dining rooms, a feature of the semi-tropics. On our last evening in Mexico City we were received by President Obregon in the Palace of Chepultepec.

In every conference on our trip the fact was brought out that the Mexicans were interested but did not have any money. The net result of the Mission's contact was to interest the people of Mexico in real roads and the full fruition of that Mission is, that today there is a hard surfaced highway from Nuevo Laredo to Mexico City, a continuation of the Meridian Highway, or U. S. No. 81. This makes a continuous all weather highway from Winnepeg across the United States to Mexico City.

VICE-PRESIDENT INTERNATIONAL MERIDIAN HIGHWAY

At a meeting of the International Meridian Highway Association held at Salina, Kansas, in November, 1923, I was elected Vice President of the association and held the position until 1931, when I de- 
MORE HONORS AND SOME TRAVEL

clined re-election. During the nine years the Highway developed to an all-weather road across the entire United States. When the Federal Bureau of Roads designated the prospective primary highway system, the Meridian Highway was designated U. S. No. 81 across the entire United States, the only organized highway to be so designated throughout its entire length.

$$
\text { GOING ABROAD }
$$

In the spring of 1925 one of our daughters persuaded me to go overseas with her on a vacation trip. We sailed from Quebec to Liverpool in May wholly unattached to any conducted party although we came in contact with one of Peck's first clinical assembly tours at Montreal. We landed at Liverpool, went to Chester, made a motor trip through a part of Wales, spent several days in the English Lake region, then spent a week in Edinburgh, making side trips from Edinburgh to Glasgow, to Scott's home, a motor trip to Oban through the northern part of the Scotch lake region and the southern edge of the Trossachs-quite the traditional sightseer's trip.

"ENGLISH, NOT SCOTCH"

We went to a city near Edinburgh to have tea with some people to whom we had a letter of introduction. I was amused to find the gentleman remarking quite emphatically that he was not a Scotchman. He was an Englishman. Later when I made some pleasant remark about the Scotch people to his wife, she hastily remarked that she was not Scotch, she was Irish! A similar experience in a store confirmed us in the belief that no one but a Scotchman relished that appellation! In an Edinburgh store on a foggy morning, my daughter ventured "I wish you would 
MORE HONORS AND SOME TRAVEL

tell me what kind of weather you are going to give us today." The reply came sharply. "It is not my kind of weather, I am from England." It appears therefore that the Irish are glad they are not Scotch, the English are glad they are not Scotch and presumably the Scotch are glad they are neither Irish or English!

During our stay at Edinburgh I visited the medical school and hospital of the University.

The entrance requirements at Edinburgh, it was explained, are rather liberally construed. The equivalent of an A. M. or B. S. degree is required. There are 1,400 students. Two years are devoted to anatomy and physiology and three years to medicine, and the practical application is stressed.

\section{PROFESSOR JOHN FRASER}

In a lecture to a student body on Carcinoma of the Rectum, Professor John Fraser referred in favorable terms to the treatment by low degree heat "originated by an American surgeon named Percy," which rather pleased the writer, who accounts himself a personal friend of Doctor James F. Percy. Several abdominal operations were witnessed at the Royal Infirmary. Green drapes were used in the operating rooms because the color is thought to be more restful to the eyes. The Royal Infirmary has 900 beds and affords wonderful opportunities for medical study.

An invitation to luncheon with Professor Fraser furnished a delightful personal contact with a great man in British surgery. He expressed his appreciation of favors at the hands of American men of medicine on a trip to this country as a guest of the American College of Surgeons and said nothing he could 
MORE HONORS AND SOME TBAVEL

do for American physicians would ever repay the kindness he had received.

Incidental to a discussion of fee splitting in America he stated that it did not exist in Scotland, but added rather softly, that it was rumored it was a bit different in England!

St. Thomas' Hospital, London, dates back to the twelfth century and was named after Thomas a-Becket. The present plant contains 632 beds. The writer saw Sir Cuthbert Wallace do a gallbladder drainage and a gastro-enterostomy in an endeavor to lengthen the life of the patient suffering from carcinoma of pylorus and contiguous structures.

While not strictly modern in all respects these hospitals are well planned, well equipped and wonderfully well conducted.

HOTEL DIEU, BEAUNE

We also visited the usual tourist spots in Belgium, Holland, Germany, Switzerland and France. We stopped at Beaune, in the Cote d'Or region in France, to visit, because my daughter had been stationed there with the A. E. F. University in 1919. Here I saw one of the most interesting things on the whole trip, the old Hotel Dieu, founded in 1443 by Nicholas Rolin, Chancellor of Burgundy, and continuously in use as a hospital since that time. The unique Salle des Malades is a splendid great hall surrounded by ancient box beds, with heavy red and white draperies. At one end of the hall is a chapel, so that the sick may be present at a service without leaving their beds. The medieval costumes of the nuns add a picturesque touch to this ancient hospital.

The whole trip was a delightful experience for 
MORE HONORS AND SOME TRAVEL

one who had spent his life in medical practice on the Nebraska prairies.

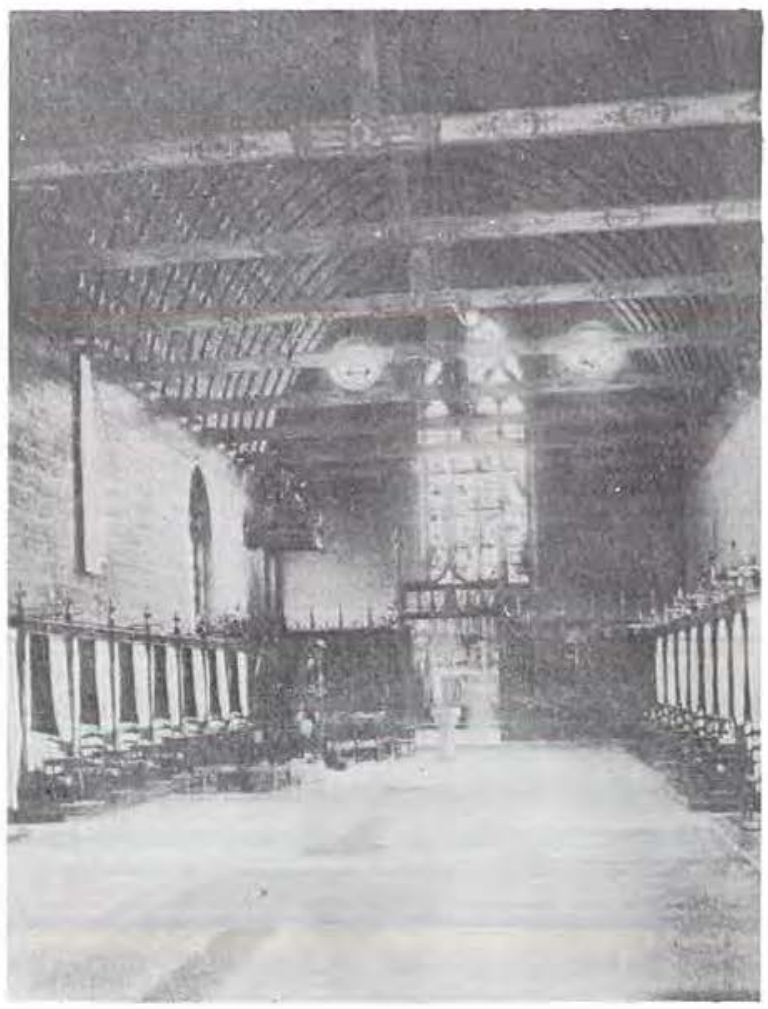

Salle des Malades. Hotel Dieu, Beaune, France. 


\section{CELEBRATING FIFTY YEARS OF SERVICE TO ONE COMMUNITY}

On April 15, 1932, representatives of the medical profession of Nebraska gathered at a dinner held in Norfolk, Nebraska, to honor the author's fifty years of service to one Nebraska community. One hundred forty-six were seated at the tables. Noted speakers from Omaha, Lincoln and outstate said many pleasant things suitable to the occasion. Human nature is so constituted that one likes to hear such things said although one knows they are not true!

At this time the celebrated Nebraska columnist "Doc" A. L. Bixby* of the State Journal (Lincoln) read the following verse written for the occasion and here printed by permission.

I am glad of this chance to unburden my thought, For that work is my very best hold, And to write, in the place of political rot,

A true story that's worth being told.

Fifty years have I toiled with the pencil and pen,

I have stood for the things I deemed right;

And my heart has been touched by the sorrows of men,

And made glad when they won in the fight.

For the same length of time has tonight's honored guest

Been as patient and plodding and strong,

And his labors have been most abundantly blessedAnd we honor you now, Doctor Long.

Yes, you traveled these wilds over trails that were blind,

- Since deceased. 
And you waded through drifts that were deep, Oft you rode like the devil to salvage mankind, And you went without vittles and sleep.

1 can see you today as you looked when at first $I$ beheld your kind features at rest;

I can vision you patiently doing your worst, Or when prudently doing your best.

The philosophers say that we all make mistakes-No one living but sometimes does wrong; As to medical practice, in getting the breaks, You're an offspring of luck, Doctor Long.

You have been a Samaritan all of the way, You are said to have played a square game, And a whole lot of people are living today

Who were mighty near dead when you came. You have contacted people with all sorts of ills,

Whom you never have sought to deceive, And your smile has been often more potent than pills,

As I think I may fairly believe.

Fifty years-I am glad to be with you tonight, And to pencil this rapturous song;

You have won a great race, you have fought a good fight,

So God bless you! man's friend, Doctor Long! 


\title{
THE PRAIRIE DOCTOR'S WIFE
}

\author{
By Herself*
}

The Pioncer Doctor. The Bride. The Babics. Christmas Candics. Church Bazaars. Pinching Poverty. Doctor's Wife as Office Girl and Entertainer, "Pink Pills." Neighborliness. Doclor's Wife as Cashier. Laundering the Surgical Linien. Consultations as Social Events. Short Order House.

THE PIONEER DOCTOR

The pioneer doctor in his frock coat and impressive beard, was usually a young man-as were most of the pioneer settlers. After graduation, he selected a location-hung out his sign with the hard won "M. D." attached, gave it an approving look and waited for business.

Of course he had a best girl by this time, and he convinced himself that if he could persuade her of the great future that lay ahead of him in his profession, she might be willing to get married at once and share with him this dream of the future.

THE BRIDE

The bride was either a teacher in the public schools, a music teacher or a dressmaker. These were the only vocations in which a woman could earn her own living at that time. She was easily persuaded for she too had great faith in the future of this young doctor. They were married in due time and she accepted the responsibilities as they came.

The bride of that day usually brought to her new home the bedding, linens, dishes, the little silver her friends gave her, good clothes, and perhaps a little money with which to buy furniture. This was fortu-

-Mrs, Long passed away May 11, 1937. 
THE PRAIRIE DOCTOR'S WIFE

nate, for in many cases the doctor had not been able to repay the money he borrowed to put himself through college. This is in striking contrast to the

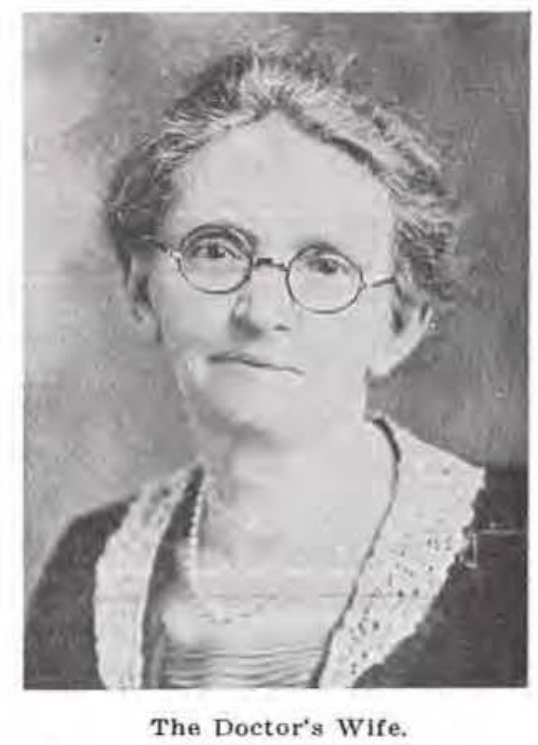

bride of today who looks forward to a furnished apartment, and to a husband who can supply the wherewithal to keep up the expenses of this apartment, a car, pretty clothes, and money to entertain.

THE BABIES

There were few families of means in those days and we shared what we had. We all had babies, took care of them ourselves, made their clothes, even hemstitched and crocheted the trimmings, washed, ironed, cooked, baked, scrubbed and had time to visit the neighbors. We knew everybody in town, exchanged patterns and recipes, had time to teach in Sabbath school, attend church services, Missionary society, 
THE PRAIRIE DOCTOR'S WIFE

Aid society, hold bazaars and give church dinners and dime socials. It was glorious and far from an idle life.

\section{CHRISTMAS CANDIES}

I remember that in years when we had no money to buy candy for the children at Christmas, the women of the church gathered in our home and made twenty-five pounds of candy for those Christmas boxes for the Sunday School. Mint wafers were made by using mashed potatoes and working pulverized sugar into it, flavoring with mint extract, coloring with dyes, rolling into sheets on the kitchen table and then cutting out the small wafers with the top of a salt shaker. Imagine twenty-five pounds of candy spread out to dry on your kitchen table! There were some chocolate creams, but not many. Sorghum was used to make the coating for the popcorn balls. Traditional Christmas trees were scarce for no evergreens grew in this prairie country. One year the tree was a small cottonwood tree decorated with strings of popcorn and a few candles with crescents and cornucopias made from gilt paper.

The church bazaars rivalled anything that can be found today. A few women who were skilled in doing fine needlework, always made beautiful hemstitched, crocheted and knitted articles for sale. Every scrap in the house was made into something of value and usually with some artistic skill. Only the other day, one of these women was asked to duplicate a cushion she made for one of these early day bazaars. It was made of scraps of velvet and was called a "biscuit cushion" due to its design.

The doctor's wife was usually the center of all these activities in the small town. She was held in 


\section{THE PRAIRIE DOCTOR'S WIFE}

high esteem by all, and much was expected of her. The Germans addressed her as "Frau Docterin."

\section{PINCHING POVERTY}

The first ten years for a pioneer doctor, were years of pinching financially, but with much faith in the future. The decision early in our married life, not to buy on credit (if we could possibly get along without doing so) sometimes proved hard to manage, but it also made us stronger in character. I recall how ten days before the stork visited our home for the first time, we did wish someone would pay his bill so we could buy the necessary flannels for the little one who was to come to us! These could not be purchased in our town but had to come by mail from Omaha, over a hundred miles away! Finally a bill was paid. The flannels were ordered and arrived on a late train on Saturday evening. The child was born before five o'clock on Monday morning. If we never before believed in Providence, we learned to do so then, for all things seemed to be provided at the right time. We were young and these things did not weigh heavily on our minds.

A store building around the corner from our home was completed and the church we attended celebrated by giving a big supper in this building, on our first wedding anniversary. No one had paid and we did not even have the fifty cents which it took to pay for the supper, so we stayed home. The baby girl had been added to the family and this gave us the excuse for staying at home- "We could not take her out and we had no one with whom to leave her." I believe that was one of the hardest trials I ever had to face-married a year and not even fifty cents to pay for the church supper. It took courage for 
THE PRAIRIE DOCTOR'S WIFE

young people to face everyday living. The whole atmosphere of our home was different when someone paid a bill-it smoothed the pathway and made it easier to keep up courage.

WIFE AS OFFICE GIRL AND ENTERTAINER

The office in the home in those early years was a necessity for the wife could act as office girl-not that there was so much business, but to hang on to every bit of it. Families came to the office early in the afternoon expecting to get attention at once and return to their homes in time to do the chores on the farm. The doctor might be out on a ten-mile trip. You knew he could not be home before five, but you told them to make themselves comfortable; he would be along about four. Custom demanded you stay at home with them-help to amuse the children and keep the father from fretting too much because it was getting late. No doctor at four and none at four thirty! By this time you had on hand a restless man and woman and it was your job to keep them from going to the other doctor. Finally after an hour of patiently watching down the street, the doctor's team was seen driving toward home. Social obligations and housework were forgotten in that hour, but you held the patient, only to learn they were a family that never paid! The white lies the doctor's wife told patients were necessary in order to earn a living, meagre as it was.

With the office in the house, the doctor's wife had occasion often to be hospitable. A patient with a broken arm would be brought ten miles by team to the office on a cold day. A cup of hot coffee that the doctor's wife brought after the arm was set, made the long ride home in the lumber wagon more 
THE PRAIRIE DOCTOR'S WIFE

bearable. A German woman who lived four miles from town, walked to town carrying her sick baby. The horses were all at work in the field and the baby needed medical attention. She had to wait several hours for the doctor. A cup of coffee and a little thoughtful attention made it much easier for both mother and child.

These pioneer women faced the problems of life, met them with courage and wasted no time in grieving over their lot. Last Christmas, while rehearsing the Sunday School program, a doctor's wife remarked "I was not born in a manger but I was born in a barn." She then told how her parents homesteaded north of town and built a barn to live in during that first summer. She was born in August when we usually had rains; the roof leaked and the baby was put in a box which served as a bed and this placed under the table to keep the child dry. In four days the mother was up and around doing the housework. This same mother was the neighborly kind who went at all hours of the night to the neighbor in distress; often no doctor had been called. It was women like these that made it possible for the men to develop this new country.

My husband was the medical member of the Commission of Insanity and it was customary for the sheriff to bring such cases to the office. About ten o'clock one morning the sheriff walked into the office with a man and before I could say a word, he told me to "watch the man and not let him get away, but hold him until the doctor comes." Then the sheriff slipped away. I was dumbfounded. Two babies in the kitchen and an insane man in the office! This man had recently been a patient of my husband and I had been to his home when he had 
THE PRAIRIE DOCTOR'S WIFE

typhoid fever. I had noticed that his eyes had a peculiar stare, but he had always been very friendly. So we sat and talked awhile. Then I suggesteu that he lie down and rest until the doctor arrived. He gave me a sharp look and said, "If you do what I tell you, then I will do what you want." My heart beat wildly. I had previously locked the outside office door. I thought of those babies, then screwed up my courage and laughingly said "Alright, I'll do it, but I would like to get you a cup of coffee." In those days we always kept a kettle of boiling water on the stove. Handing him a paper I left him. When I brought the coffee he seemed to think he had played a great joke on me, drank his coffee and we chatted another half hour. It was an immense relief when I saw the doctor drive up in front of the house. After a year or more at the state hospital, the patient recovered and we were good friends, but neither of us ever referred to the time when I held him in the office.

Families from the country planned to reach the doctor's office about noon-when they hoped to find him in. Many times a family of three or four was added to our dinner table-without notice-because the doctor was in the country and would not be home until two, and it was important to keep this family contented (they had driven in eight or ten miles to see him). Meanwhile the doctor's dinner was kept warming but he could not eat until after he had cared for the waiting family from the country. Perhaps the doctor returned from his town calls that afternoon to find his wife entertaining an old lady from a nearby town who had come on the afternoon train, for treatment for varicose veins. The zincgelatine preparation was then heated on the kitchen 
THE PRAIRIE DOCTOR'S WIFE

stove and either the wife or the growing daughter was called into the office to help with the application of this dressing to the leg. This done the family were responsible for the old lady's entertainment until the seven o'clock train bore her back to her home town that evening.

\section{PINK PILLS}

Occasionally, I was asked for some of those "pink pills" they had been getting for fever. People thought all I had to do was to go to the medicine shelf and shake a few pills out of the bottle. One night I was alone when there was an insistent ringing of the doorbell. I found a man standing there who wanted the doctor-insisted that he have him. His wife was in distress and he wanted to relieve her. I knew his wife was a morphine fiend. He begged and begged that I give him certain medicine, said he would take all the responsibility and so on. He finally realized that I would not yield and left rather provoked. The only remedy I ever handed out was earache medicine. I knew where this was kept, because I often used it for our own children.

\section{NEIGHBORLINESS}

There was an atmosphere of neighborliness that at times was trying. Patients walked into our office without knocking or ringing the doorbell. At that time the court house was on the next lot-the county jail back of it. Later these buildings were removed and we purchased the lots. The bedroom of our home was back of the office with only a door between. One hot summer evening when the baby was restless, I lay down beside her. It was dusk and no lamp had been lit in the office. Suddenly, I heard footsteps, and before I could get to the door, a man 
THE PRAIRIE DOCTOR'S WIFE

was standing in the doorway of my bedroom. I quickly recognized him as a man who had been in the jail. His wife had come to town to his trial, bringing the baby who became ill. My husband had cared for the child and had been told that he would get his pay when the husband was released. So the exprisoner had come to pay the bill and to thank me for our kindness to his family.

At another time, I was alone and sick abed in a room upstairs. I heard footsteps coming up the stairs and heard a man calling out "Vere ish de ductor, I vant him." I recognized him by the smell of his old pipe and he came on up and chatted a few minutes.

\section{DOCTOR'S WIFE AS CASHIER}

My husband and I realized that unless you got the money when a man came to pay, the bill might be forgotten, so from the very first, I had access to the business records and could tell a man the amount of his bill in a few minutes. In the early days, foreigners hesitated to pay a woman, but as time went on they grew accustomed to American ways, and paid me without hesitation. I kept check books from the two banks in town and made out their checks for them, always giving them a receipt for the amount received. Several men who made partial payments were sly and asked to have a receipt in full, thinking they could trick a woman.

\section{LAUNDERING THE SURGICAL LINEN}

Operations were done in the patient's homes and all laundry was brought to our home, surgical aprons, sheets, towels and everything. There was no public laundry in the town, and it would have cost too much for us to afford, if there had been. Even if the op- 
eration occurred Saturday noon, the laundry had to be done that afternoon, regardless of previous plans, for it might be needed again before the regular Monday washday. Moreover the soiled garments required attention at once. In case of a fracture, the bandages were laundered-ironed-and then yards and yards of bandages rolled over the knee on a clean towel. Later a small hand roller lightened the work.

CONSULTATIONS AS SOCIAL EVENTS

Consultations with doctors from other towns were hailed as events. It was usually arranged for the morning so that the consultant could come back with the doctor for dinner. When possible the wife came along and the women enjoyed the visit together.

SHORT ORDER HOUSE

A doctor's wife learned to prepare meals on short notice for it would never do to permit the husband to start out at five in the afternoon without his supper. Often in the morning he would start out at six and it behooved the wife to get up and have a hearty breakfast ready by the time he was ready to start. These arrangements were never considered a hardship-we were only too glad that these patients had called him and he was getting started in his professional career. We always looked forward, never backivard. 


\section{THE PRAIRIE DOCTOR'S WIFE}

\section{(Continued)}

Pioneer Doctor's Wife, Omnipresent. Doctor's Children -Children's Dresses. Heating and Ventilation of Pioneer Homes, Low Ceilings. We Buy a Home. P'ioneer Hospitality. Social Life. Wives Go to Medical Ilectings-The Auriliary.

PIONEER DOCTOR'S WIFE, OMNIPRESENT

It was sometimes necessary for the doctor's wife to arrange to send out fresh teams to cross-roads to meet him to save him from driving to town and then back again over part of the same road. It was a wonderful day for us, when rural telephones were installed, for it was often the means of getting in contact with the doctor when he was out on a case in the country, but at times it had its draw-backs. I recall one case in particular when he had a call to an obstetric case in which he was very much interested for it was his first contact with that family. I called and called, but got no response for this family was on a party line. I could hear them discuss a new apron pattern-the setting of hens and what they were preparing for dinner. Finally, when I was able to get my party, I was told he had gone four miles further north to see another case. Another doctor was called to the obstetrical case.

I think back on those days and wonder how a young mother could possibly do all that I did. Once each week the floors of that office were carefully scrubbed with a good solid scrubbing brush. This scrubbing was done on hands and knees in the early morning-before patients began to arrive. Then I proceeded to my own housework. In the midst of washing, ironing, baking, or cleaning, that office doorbell sounded, and everything was dropped. I 
THE PRAIRIE DOCTOR'S WIFE

smoothed my hair, straightened my apron, and dashed for the office to receive the patients. These constant interruptions delayed my housework particularly on Saturday, when the farmers came to town. One of my daughters recalls many Saturday afternoons when she was bathed and dressed and placed upon the kitchen table away from mischief, while mother scrubbed the kitchen floor and watched the evening supper cook on the one burner kerosene stove at the same time! That kitchen table was a treasure and could tell some tales of pioneer surgery if it would. It was six feet long and about two and one-half feet wide and had been the all important piece of furniture in my husband's first office, where it served as operating table, or patient's couch, etc., as occasion demanded. When he reached the stage of financial prosperity which enabled him to buy a proper office examination chair, I was only too glad to have this as an addition to my meagre kitchen furniture.

\section{DOCTOR'S CHILDREN}

The office in the home was in many ways an unfortunate thing for the doctor's children. The father came in for his hurried meals with not even a walk from the office in which to throw off his cares. His naps were snatched between calls on the couch in the living room and the children soon learned to be quiet at these times. Moreover with the office at the home, they received too much attention, particularly in a German community such as ours was, where the children of the doctor were treated with the same respect accorded to the minister's children.

After the children started to school, they considered it a treat to be taken with father on Saturday 
THE PRAIRIE DOCTOR'S WIFE

morning as he made his country calls, and it was a blessing to me to have them cared for. The country friends were pleased to see the doctor's children and made much of them. I remember once when the two

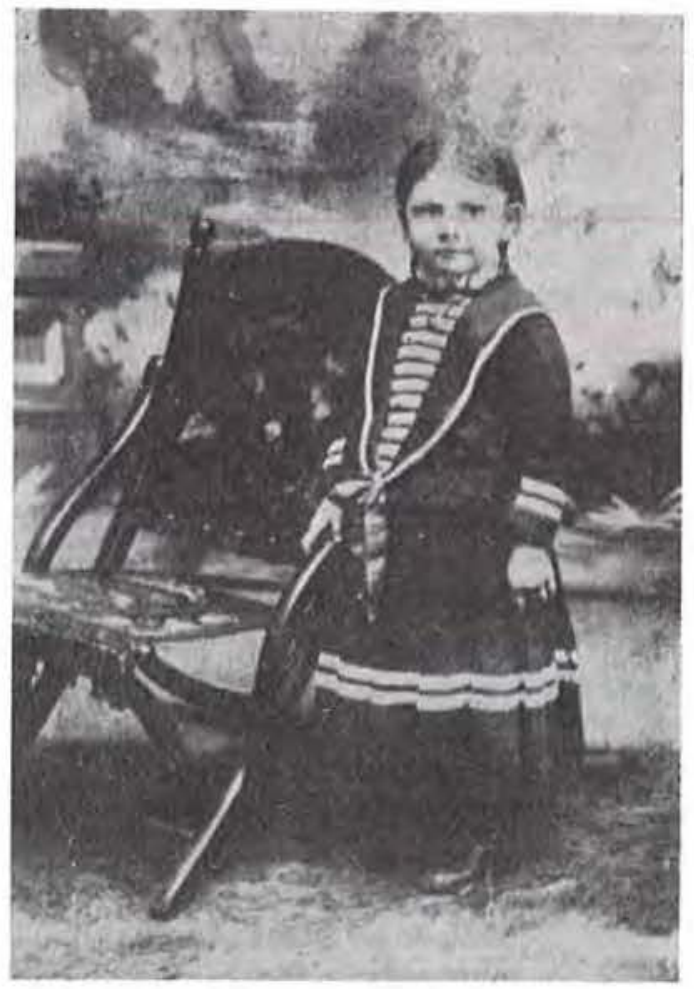

A Daughter in Sailor Suit.

older girls came home from a trip with their father to a German-Jewish family, and told how the old grandmother had reached up to the top shelf of the kitchen cuploard and brought down a jar of carefully hoarded hard candies which she passed to the 
doctor's children - while her own candy-hungry grandchildren looked on enviously.

I found a picture of the older children the other day and laughed to think how warmly they had been dressed; woolen underwear, (good red flannels) home knit stockings and mittens, woolen dresses, heavy calfskin shoes, heavy overshoes, and good warm outer garments made large enough so they could grow. These precautions were necessary. There were few sidewalks. School rooms were heated with big stoves-so that those children near the stove were too warm and those a few feet away too cold.

HEATING AND VENTILATION OF PIONEER HOMES

We hear of lack of ventilation in these homes. There was no need to open a window. Houses were so poorly built that unless cloth was stuffed around the window frames, it was impossible to sit near them. After the evening meal, when there was no longer anyone going out, it was customary to throw a rug or old coat across the bottom of the doorway to keep out the wind. The family huddled about the heating stove in which a few lumps of soft coal were burning, but the real heat came from the cobs which the children kept piling into the stove. It was impossible for the women of today - accustomed to test ovens with thermometers-to imagine the difficulty of keeping an even heat in the kitchen stove to bake bread and cake. If you wanted to bake an angel food cake-and they baked some good ones then-you piled on a definite number of corn cobs every ten minutes. It kept all hands busy piling in the corm cobs, which were usually brought to the kitchen in bushel baskets or an old tin wash-boiler. Some peo- 
ple even had barrels back of the stove for this purpose. No matter how carefully these cobs were picked over there was a certain amount of husks and fine dust against which to contend. One winter when corn sold for eight cents a bushel, we burned corn on the cob for we thought it was the cheapest fuel we could get. It gave a very hot fire, but by spring we found that we had burned out the grate. It made a cheerful fire and the children enjoyed listening to the crackling noise when the corn was red hot. The older people shook their heads-it hurt to burn a food but it was a necessity in a new country which had no timber. We adapted ourselves to conditions and led a simple contented life full of service and high ideals in standards of living.

\section{LOW CEILINGS}

Our homes were small in the beginning with low ceilings. The rooms upstairs often had only half height windows. In moving into our first house, a rented one, we were obliged to take off the upper ornamental part of the head end of the bed, to get it into the upstairs bedroom. The secretary in the office, we found was taller than the room, and so we had to remove the molding across the top of the case to get it in place. The only room which was kept warm over night was the office, and this in the middle west where winter temperatures often reach twenty below zero. The bedroom upstairs was cold as a barn. We conceived the brilliant idea of swinging a hammock above the six foot table in the office, and our first child slept in that hammock at night. We slept in the bedroom upstairs above the office and could hear the child's cry. Often one of us crept down to that room during the cold night and satis- 


\section{THE PRAIRIE DOCTOR'S WIFE}

fied ourselves that all was well with the child. Her bed in the daytime was a clothes basket in the kitchen. Sometimes a fire was built in the living room in the evening. Laundry work was done in the kitchen; no washing machine in those days-we rubbed clothes on the board. A clothes wringer was our first convenience.

\section{WE BUY A HOME}

Before the end of the second year we had purchased a home on the main street; a twenty-two foot lot with a one-story house consisting of three rooms and a lean-to for a kitchen. We had a large kitchen range and the neighbors joked about the impossibility of finding room in that lean-to for that stove. But we found a way. The door was taken off and turned the other way to make room for this stove. In those days dry goods came in very large wooden boxes. One of these served as kitchen table with oil cloth to cover it. A shelf was placed above this for lamp and clock and the kitchen furniture was complete. There was not even room enough for a chair. The living room served as dining room and there was a couch in this room which was used as a bed when relatives visited us. We soon purchased a twenty-two foot lot on the north side of us for which we promised to pay two hundred and twenty-five dollars. We gave two notes, one for one hundred dollars, with interest payable in a year-another for one hundred twenty-five dollars with interest and payable in two years. Fortunately the man who sold us the lot was a lawyer who suffered from a nervous breakdown. His wife had inherited a fortune and demanded for him professional attention almost every night. This service paid for the lot. 
THE PRAIRIE DOCTOR'S WIFE

Before the second child was born, an office-wing was built on this north lot. We once more had a living room and home life was more private. Later the house was raised and this gave us bedrooms upstairs. When succeeding springs arrived, people were disappointed if they did not see a pile of lumber in front of the residence for another addition. The town wag said that we built on twenty-eight times, but he must have counted times when new sidewalks were

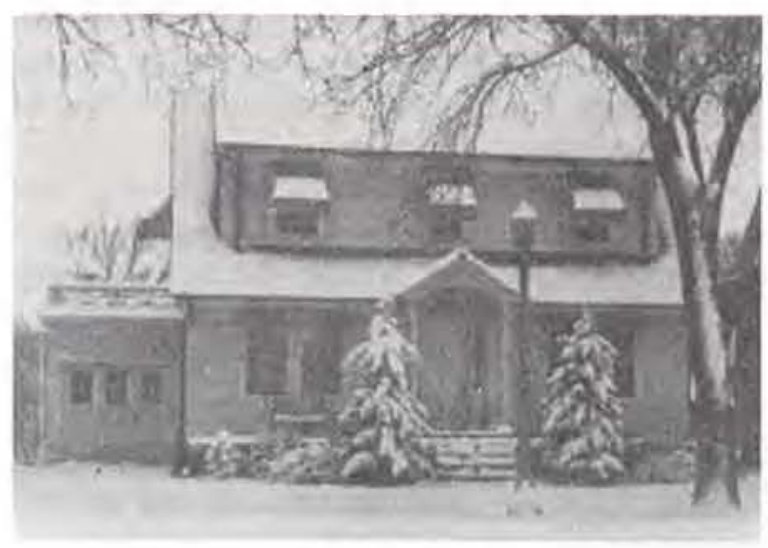

The New Home.

laid! Lots to the south of us were purchased until we had a lot 110 by 132 feet. This same story might be told of nearly all the homes of the pioneer settlers. By the time this home filled our dream of a big convenient comfortable home, the children were gone, we were getting old and faced with caring for a home much too large for us. The problem was solved by a young physician buying the old home with its office. We retained the south half of the lot on which we built a smaller more compact home.

Can you imagine what it meant to give up the 
THE PRAIRIE DOCTOR'S WIFE

home in which the three children had been raised; a home, the center of all social activities for these children and ourselves, where children came to do their practicing for Christmas and other entertainments - a home always open to club, church or every organization?

\section{PIONEER HOSPITALITY}

No matter what its size, there was always room in those pioneer homes for hospitality. We had plenty of bedding and always had ham and eggs and some kind of jam in the house-if not jam, we did have sorghum. This was the hospitality of pioneer life as lived by those doctors' families in the building up of the west.

The doctor's wife knew everybody, was a part of the community, and tried to make people feel that the doctor's family was willing to be of service to everyone. Our library, while not large, was freely used, by high school boys and girls and by adults.

SOCIAL LIFE

Our own social life was always limited by the doctor's calls. Many years, the guests for Christmas dinner arrived, only to find that an emergency call had summoned their host and that he must hastily eat a bit of the turkey or goose and go off to usher a new life into the world or perhaps perform an emergency operation. As the family grew up, it was never possible for them all to go to an entertainment or social, for someone must stay at home to answer the office doorbell.

There was never much jealousy among the doctors and their wives in our town. We were friendly, but never intimate. In the earlier years the doctors did not take their wives along with them to the State Medical meetings. We remained at home to care for 
THE PRAIRIE DOCTOR'S WIFE

the home, hold onto the business and use this opportunity while he was gone to house-clean the office. We had the freedom of the place then.

WIVES GO TO MEDICAL MEETINGSTHE AUXILIARY

Not until 1911 were the wives invited to go along and even invited to the banquet. It was my good fortune and perhaps the misfortune of the others, that I was seated at the speaker's table. I was sandwiched in on the program between two eminent doctors. My subject, "What a Doctor's Wife Should Be -Another Viewpoint."

Since then we have been invited each year and the wives look forward to the event. There is nothing which more quickly brings harmony in the medical profession than for doctors and their wives to know each other better. For that reason I have welcomed the Auxiliary of the American Medical Association which was formed in St. Louis in 1922. It fell to my lot to serve as the first president of the Nebraska Auxiliary and at the Washington meeting of the American Medical Association in 1927, I was elected a Vice President of the National Auxiliary. I consider the greatest good of these auxiliaries to be the friendships made and the interest aroused in the husbands' work, although the community services rendered by the Auxiliaries are not to be overlooked.

And now at the close of fifty-two years, as the wife of one of these doctors, (and the same doctor at that) with the office in the home all these years, with that home on the same location for all excepting two of these years, I can speak with real appreciation of the life of sacrifice and devotion that one doctor has given one community. Both of us have given our best! 
THE PRACTICE OF MEDICINE AMONG THE PRAIRIE INDIANS*

Indian Medicine Man. Medicine Bag. Therapentic Equipment. Elhics. Cupping-Laratives-Anodyues. Curing Suake Bitc, Indian Obstetrics-Abortions. Indian Inmunity to Infections. Fractures. Stone Age Surgery. Legerdemain. No Witcheraft Among Prairic Indians. Consultation. Indian Materia Mcdica. Dimanded Honorarimes.

\section{INDIAN MEDICINE MAN}

Ages before the coming of the white man the prairie lands of Nebraska were inhabited by Indians. As with all flesh they were subject to injury and disease and it follows that efforts were made to alleviate the suffering. In their primitive art of healing there was much misguided effort but there was also not a little that was truly beneficial. Every tribe had its medicine man and a very important personage he was. As a rule he held equal rank with the chief. He deported himself in a manner that inspired awe and reverence for had not the gods endowed him with supernatural powers of divining spirits and of healing? Magic was his stock in trade and he plied it well. His power to invoke spirits, both good and evil, was exercised in other ways than by healing the sick. He conjured the rain, he insured bountiful crops and contributed to the success of the hunt.

Apprenticeship under the tutelage of an experienced practitioner was the common procedure and usually this was begun at an early age. There were several years of apprenticeship for there was much to learn of ceremonies and therapeutic agencies.

-Vuluable assistance from Dr. Palmer Findley in the preparation of this article is hereby acknowledged. 
THE PRACTICE OF MEDICINE AMONG THE INDIANS

There was no standardized curriculum-every medicine man was a law unto himself. He devised his own means of treating disease and he chose his own particular spirits to cooperate with him in his mystic art. Brooks* tells us that in all this he sincerely believed and took great pride. His manner of dress was as varied as his practices; at times grotesque and ridiculous, but sometimes truly artistic.

\section{MEDICINE BAG}

His medicine bag was his precious possession and there was great rivalry in decorating it. It served the purpose of carrying medicinal herbs but this was but an incident; its real purpose was in storing personal fetishes. The medicine bag was also his vanity case, containing as it did the paint used to decorate the face for ceremonies.

\section{THERAPEUTIC EQUIPMENT}

The therapeutic equipment of the medicine man consisted of herbs, roots, barks and a large assortment of animal substances. His system of therapeutics was wholly empirical. Usually decoctions were made of these substances and a large potion was administered in a single dose. There was'also powders and inhalations. If all this failed then the ritual was resorted to, but always there were prayers and chants.

\section{ETHICS}

The medicine man had no regard for professional ethics; they were unknown to him as they are to some practitioners of the present time. He seldom divulged the nature of his remedies and never took

- Harlow Brooks quoted by stone, Eric. Medicine Among Ameriean Indians, p. 16.1932 Hoeber. 
THE PRACTICE OF MEDICINE AMONG THE INDIANS

his patient into his confidence. His was a profession based upon empiricism and mysticism. All wisdom and power rested with him, and so he jealously guarded his secrets.

He recognized fever by observing the dry, hot skin, the thirst and the prostration and then enjoined rest, sweating, purging and a restricted diet. With a sharp stone he sometimes let blood. Many drugs were given but they were of little value. Respiratory diseases were recognized but there was no differentiation between the common cold and the most deepseated involvements. Tuberculosis was a gift of the white man and was unknown to the primitive races until the white man invaded their territories.

\section{CUPPING-LAXATIVES-ANODYNES}

Cupping was practiced by scarifying with sharp stones and sucking at the wound. A later refinement was the use of a buffalo horn with the tip knocked off. Laxatives were employed where mineral springs and salt licks were available. Wild mint and wild verbana were used for the relief of abdominal pains and for nausea the abdomen was scarified and powdered ragweed applied. Tobacco leaves were applied to dropsical legs and for the relief of pain the peyote bean was prescribed.

Contagious diseases were largely disregarded and no attempt was made to isolate cases. The ravages of these diseases were appalling. The Indian was fertile soil for disease producing germs and died like flies when an epidemic broke among them. Nothing was known by them of nervous diseases. The white man brought syphilis but gonorrhoea existed among them long before the coming of the white race. 
THE PRACTICE OF MEDICINE AMONG THE INDIANS

CURING SNAKE BITE

The treatment of snake bite was often effective, due to the skill acquired by the medicine man. Suction was first applied and if the snake was known to be particularly venomous the wound was excised. Roots were applied to the wound in the form of poultices and a great variety of drugs were administered. Eric Stone* tells us that the tribes of the southwest that practice the Snake Dance permit young snakes to hite them and thus acquire immunity. They are said to gradually increase the age of the snake until they are able to withstand the bite of fully matured snakes,

INDIAN OBSTETRICS-ABORTIONS

In the management of obstetric cases it is the midwife or a female relative that officiates. The labors are usually short and relatively easy. This is so because the babies are small and the mother exercises to the time of labor. In the pure blooded Indian there is seldom disproportion between the baby and pelvis and abnormal positions of the baby in utero are rare. The labors are usually conducted in the family lodge or, as is often the case, a birth hut consisting of reeds or brush is constructed by the husband where the expectant mother retires at the onset of labor. The husband absents himself. Not infrequently there is no attendant, the mother acting in the dual capacity of parturient and midwife. The Crede method of expressing the placenta is universally practiced. The maternal and fetal mortality is small.

Some civilized Indians who own their lands and have theircitizenship still prefer the tepee and the

- Stone, Eric. Medicine Among the American Indians. 1932 Hoeber. 
ground floor for labor. One physician who does some practice among the Indians told me of a call he made to an Indian woman in labor and unable to deliver herself, who lay on a blanket on the floor of the tepee. Another physician told of finding a young woman in labor, lying absolutely nude on some new mown hay in the tepee. In the first case the doctor had to do an instrumental delivery with no assistance whatever, on the floor of the tepee in a rain and windstorm that cxtinguished the kerosene lamp and left him to work in the dark. In the other case the doctor insisted the woman go into the house on a perfectly good bed, but only after threatening to leave, was he able to get the patient to walk to the bed.

It is said that abortions are not frequently performed. In some tribes it is the custom to interrupt pregnancy at the third or fourth month where the father is supposed to be white. The reason given to justify the procedure is that such babies, half white and half Indians, are usually delivered with difficulty. There is justification for this assumption because such mixed blood does create larger babies with relatively large heads. It is said that the duration of labor among half breeds is twice that of pure breds and that difficult labor is far more common.

\section{INDIAN IMMUNITY TO INFECTION}

Authorities who have had opportunity to observe say that the Indian is relatively immune to infection of wounds. The explanation probably lies in the absence of virulent wound infecting micro-organisms rather than in any inherent immunity to infection on the part of the Indian. Whatever the explanation, it may be accepted as a fact that the wounds 
inflicted upon the Indian healed more quickly and with less infection than in the white race and that he could resist wounds that would be fatal to the white man. The Medicine man was very skillful in the treatment of wounds. He knew nothing of antisepsis but he did practice asepsis to a degree. The wounded were treated in their lodges. Dressings were changed frequently. Rarely was the wound closed and thus free drainage was assured. The dressings were clean and of a varied assortment. Powders and poultices were in common usage. The more extensive wounds were sutured with sinew on bone needles. Drainage was provided by inserting thin strips of bark. Wicks made of cloth or fiber were sometimes inserted into the wound. The removal of foreign bodies, shot and arrowheads, was skillfully performed. To control bleeding the wound was cauterized or packed with such material as eagle's down or the scrapings of hides, puff balls or sumac. The cautery consisted of the stalk of the yarrow, Achillea millefolium, about one inch in length. This was inserted into the wound and set afire. The tourniquet was known and used in excessive hemorrhages from wounds of the extremities.

\section{FRACTURES}

In the treatment of fractures the Indian knew how to provide immobilization. He did not provide extension. Splints were made of fresh rawhide and bark. Windows were cut in the splint for the dressing of compound fractures. Dislocations were cleverly treated, even of the hip.

Eric Stone says: "On the whole, their skill in the care of wounds, fractures and dislocations equalled 
THE PRACTICE OF MEDICINE AMONG THE INDIANS

and in some respects exceeded that of their white contemporary."

Captain Lute North, who died in 1935, aged about 90 , and who was an officer of the Pawnee Scouts of the sixties, related to the author the following: A Pawnee Scout was shot through the wrist, splintering the bones half way up the forearm. The army surgeon called from Fort Sedgwick, wanted to amputate the arm. The Pawnee refused amputation. He appealed to the commanding officer with the statement that if he could get back to his people, he believed he would be able to get the arm healed without amputation. He was sent with a wagon train to the railhead and went to the Pawnee reservation on the Loup river, in eastern Nebraska, and in less than six months his arm was well, although partly stiffened at the wrist. This would seem supporting evidence to the theory of the relative immunity of the Indian to infection.

STONE AGE SURGERY

Only flint and stone instruments were possessed by the Medicine man and with these crude tools he amputated fingers and toes, let blood, opened abscesses. It is said that the Indians of the Great Lakes drained pus from the chest, (empyema) and that trephining was done in pre-Columbian days. (Stone, Eric).

INDIAN LEGERDEMAIN

Ceremonial rites comprised no small part of the treatment. These sleight-of-hand performances never failed to awe and inspire the sick. There were arrows swallowed, but the arrow never passed down the gullet; intestines were drawn from the mouth of the conjurer but they never left his abdomen; suc- 
tion was made on the body of the patient, followed by the expectoration of pebbles, bone and arrowhead but there was no wound from which these foreign bodies could have been drawn. In all this the Medicine man was credited with supernatural powers. In his body resided the healing god and so he for a time became a deity. Ceremonial forms differed widely. Scarcely two Medicine men used the same technique but they were bent upon the same purpose, that of exorcising the evil spirits in driving them out of the sick body and of petitioning the good spirits to give aid and succor to the sick. They offered prayers and made sacrifices to their gods. They made unbelievable noises and brandished spears and clubs, and all this to the rhythmic beat of drums. Sacred powders were sprinkled over the patient. Not least of these grotesque performances was the dance which went on without ceasing. If the patient survived the ordeal and perchance recovered, the Medicine man claimed his reward and in this he was most exacting. The physical effect upon the patient was inspiring; he was accustomed to such noises and grimaces; no white man could have survived them.

NO WITCHCRAFT AMONG PRAIRIE INDIANS

It is said that witches and witcheraft did not exist among the prairie Indians. They thought disease sometimes had its origin in worms that had entered the body. Hence the practice of sucking and manipulations that were commonly in vogue. Magic caused disease and magic was resorted to for the purpose of driving out the evil magic. The Medicine men magicians boasted that they could transform themselves into birds, animals and stones, that they could fly. No one had ever seen them do these things but 
the credulous and gullible Indians took them at their word.

The Indian was wholly ignorant of the true nature of disease but he was a close observer and had -learned from experience many useful remedies. He was overburdened with the superstitious belief handed down from his forefathers that all disease came from evil spirits.

CONSULTATIONS

The following account of a consultation of doctors appears in The Magazine of American History, Vol. V, November, 1880: The sufferer was brought home in the evening and a doctor summoned at once. For some reason he delayed answering the call till the ensuing morning - quite possibly to add something of impressive importance to his coming. He was accompanied by another doctor. On entering the lodge they did not deign to notice anyone, and sat down in silence, and remained motionless till a pipe was filled and handed to them. The elder received it, held it up at arms length over his head for a moment, muttered some unintelligible sounds, lowered it, carefully took from the bowl with his thumb and forefinger a small portion of the tobacco and placed it on the edge of the hearth before him. One of the family then held a brand from the fire to the pipe till it was lighted. The doctor slowly puffed the smoke two or three times upward, downward, and toward each of the cardinal points, and taking the pipe by the bowl passed it to his companion, who went through the same form; and this was repeated till the contents were consumed. The pipe was then handed to the one who had lighted it. He emptied the ashes upon the hearth so that they should entirely cover the particles of tobacco before taken from it and de- 
posited there. He then touched the tips of his fingers to the ashes and passed his hands in succession over the pipe from the bowl to the end of the stem, and returned it to the owner who did the same.

The doctors now proceeded to inspect the patient's injuries, and after the examination was completed, began their practices. One of them took a mouthful of water from a calabash placed beside him, groaned, beat his breast, crept backward and forward on his hands and feet, took up some dust from the ground, rubbed it in his hands, made various intricate gestures, and then pretended to vomit this water, which all the while had been in his mouth, upon the hearth. Again he filled his mouth, and after going through an even more elaborate role, parted the hair upon the head of the patient, blew the water in small quantities upon the scalp, breast and other parts of the body. This was repeated several times.

He then applied his mouth, previously filled with water, to the sick man's head, and with groans seemed to be endeavoring with all his might to suck something from it. When this had continued some minutes, all at once he started back, and approaching the hearth, squirted the mouthful of water upon it as if drawn from the invalid's head. The same operation was repeated on several parts of his tody. He then took up some of the ashes emptied from the pipe, rubbed them in his hands, and blew them upon the patient's heed, breast, and wherever the suction had been tried. After all this opeose detail he took a minute quantity of dark powder from his medicine bag, sprinkled it on the burns, and departed. During all this performance, the other doctor was busily shaking his rattle, parading his medicine bag, and dancing with great violence over the sufferer. 
THE PRACTICE OF MEDICINE AMONG THE INDIANS

INDIAN MATERIA MEDICA

In the exhaustive study of The Omaha Tribe made by Alice C. Fletcher and Francis LaFlesche and published in the 27th annual report of the Bureau of American Ethnology, we read:

Among the roots used for medicinal purposes were the following: Sweet flag (Acorus ealamus S.) called by the Omaha, mokoninida. The root was chewed for disorder of the stomach. It was also put into the feed of the horses when ailing. When on the tribal hunt the people came to a marshy place where the sweet flag grew, the young men gathered the leaves, made wreaths, and wore them about the neck or head because of the pleasant odor.

The outer covering of the root of the Kentucky coffee tree (Gymnocladus canadensis) was used in hemorrhage, particularly from the nose or during childbirth. This root was used also when the kidneys failed to act. The native name of the tree was no'titahi. The root, powdered and mixed with water, was administered to women during protracted labor.

The root of the larger bladder ground cherry (Physalis viscora) was used in dressing wounds. The Omaha name for the root was pei'gatushi. This was one of the roots employed by the Buffalo doctors.

The root of the cat-tail (Typha) was called ca'hi and was used for dressing scalps. The root was pulverized and spread in a paste over the burn. The ripe blossom of the cat-tail was then used as a covering, the injured part being bound so $z$ s to keep the dressing in place. The blossom of the cat-tail was called waha'baigackothe. This word, meaning "To try the corn," is said to have originated in the following manner: The boys used to gather the cat-tail blos- 
THE PRACTICE OF MLDICINE AMONG THE INDIANS

soms and try to break them up so as to scatter the seeds. If they were successful they shouted "The corn is ripe', as the cat-tail blossom shed its seeds about the time the corn was ripe enough to eat.

The root of the hop vine (Humulus lupulus) was used for healing wounds; this was called mokobashosho, crooked root.

From the root of the wild rose was made a wash for inflamed eyes, known as wazhi'de.

The root of the wild cucumber vine Cucurbita perennis (ni'kashigamoko) 'human medicine,' was so called because the root was said to resemble the human form, was used medicinally. The root, pulverized and mixed with water, was taken for pains. Only that part of the root which corresponded with the seat of the pain was used, that is, if the pain was in the head, body or leg, that portion of the root resembling the particular part affected was taken, etc. This root was used also in protracted labor.

There were many other plants and roots known to the Omaha as having medicine qualities which were used by men and women of the tribe when attending the sick, but it has been impossible to obtain full knowledge of them. It can be safely said that, on the whole, medicinal remedies were more frequently resorted to in the case of sickness than niagical practices. In almost every instance, however, the remedy was accompanied by an appropriate formula of song or ritual.

\section{DEMANDEI HONORARIUMS}

Fees were always expected by the doctor called to attend the sick or injured. No humanitarian motives actuated him. He demanded honorariums, taking whatever he could lay his hands upon. Horses, wear- 
ing apparel, skins, feathers and beads were particularly attractive to him and to these he helped himself bountifully. His hideous make-up inspired his patients with awe and reverence. His face was painted red and yellow, his beaded, shell-bedecked hair hung about the shoulders, from the ears were suspended rings and shells and around the neck were necklaces of shells and beads. A bright colored shirt with hideous images painted on the breast, tight fitting trousers with beads and shells dangling from the sides and a gay colored blanket thrown loosely about the shoulders made up the attire of this progenitor of the Prairie Doctor of the Eighties. In his bombilations and clatter he was usually assisted by one or more Indians of the tribe who kept up their drummings and shoutings so as their strength endured.

The Indian in his conception of disease never associated cause and effect. It did not occur to him that disease came from natural causes, that he might have brought disease upon himself. He recognized contagion but did not know it was transmissible. To his untutored mind a sick man was under some sort of a "spell." He believed that all the infirmities of the body were due to evil spirits over which he had no control. This fetish possessed his soul and he was terrified. A child became sick and the father was blamed for having offended the evil spirits. A squaw fell sick and the blame was placed upon one of the other squaws, for bringing affliction on her. Logically all treatment consisted in driving out the evil spirits and this was the task assumed by the Medicine man. 
SOME EARLY MEDICAL HISTORY OF A PRAIRIE STATE

The Lewis and Clarke Expedition. Death of Sergeant Floyd. Sixth Lufantry-Fort Alkinson-Scurvy. Surgeon Gale-Ni-Ku-Mi-Papoose Mary. The LaFlesche Family. Dr. George L. Miller-Expedition Into Dakota Indian Country. Fort Kearny. Cholera on Overland Trail. Surgeon Latta. Dr. Phebe Oliver -Otoc Indians. Dr. Bancroft's Story of Siour. Massacre of Pawnees.

THE LEWIS AND CLARKE EXPEDITION

The earliest recorded history of medical activities in the Iowa-Nebraska section of the Missouri Valley relates to the Lewis and Clarke expedition ${ }^{(1)}$ in 1804. These references are few and scant in detail, as indeed are all references of a medical nature during the period of exploration and early settlement.

We read that the Lewis and Clarke expedition started from St. Louis with a keel boat fifty-five feet long, with sails and twenty-two oars, and two pirogues with six oars each. By the time the site of the present city of Omaha was reached, the men were troubled with boils and occasionally with dysentery. The boils were large tumors which broke out under the arms, on the legs, and generally on parts exposed to action, which sometimes became too painful to permit the men to work. After remaining some days they disappeared without any assistance except a poultice of the bark of elm or Indian meal. This disorder which was ascribed to the muddiness of the river water did not affect the general health of the party for the Journals say "Party has been much healthier on voyage than parties in any other Situation."

\footnotetext{
1. Original Journals of the Lewis and Clarke Expedition $180+-1806$, ed. by R. G. Thwaites. Dodd. 1904 .

193
} 


\section{SOME EARLY MEDICAL HISTORY}

\section{DEATH OF SERGEANT FLOYD}

When the expedition reached the vicinity of the present Sioux City, Sergeant Charles Floyd "Was taken very bad all at once with a Biliose Chorlock" and all care and attention was ineffectual to relieve him. He died on the twentieth of August, the first United States soldier to lose his life west of the Mississippi River.

"We buried him on the top of the bluff one-fourth mile below a small river to which we gave his name, he was buried with the honors of war much lamented, a Seeder post with the Name, Sergt. C. Floyd died here 20th of August 1804, was fixed at the head of his grave."

The Floyd monument, an imposing shaft on a high point on the southern outskirts of Sioux City now commemorates his sacrifice. One may hazard the guess that his death was due to the fulminating attack of appendicitis. Certainly, modern medicine recognizes no such fatal disease as bilious colic.

SIXTH INFANTRY-FORT ATKINSON-SCURVY

In September, 1819, fifteen years after the death of Sergeant Floyd, The Sixth Infantry, accompanied by two companies of sharpshooters, came up the Missouri River on the first steam boat ever to navigate the stream. They established Camp Missouri, later to be transformed into Fort Atkinson, named after the commanding officer, at or near where now is the village of Fort Calhoun, Nebraska. The troops established an out-post for the forthcoming Major Long Expedition of 1820 to explore the valley of the Platte River and to discover its source. It is stated that the establishment of this post had the further object of watching the British, too, who, in 
spite of the treaty following the War of 1812 , were supposed to be actively promoting discontent among the prairie Indians.

The troops had suffered from dysentery on the journey up the river, and were weakened from the long voyage. Because of the lateness of the season, building operations on the fort were rushed. Because of weakness, unsuitable food and the dampness of the river bottoms many developed respiratory

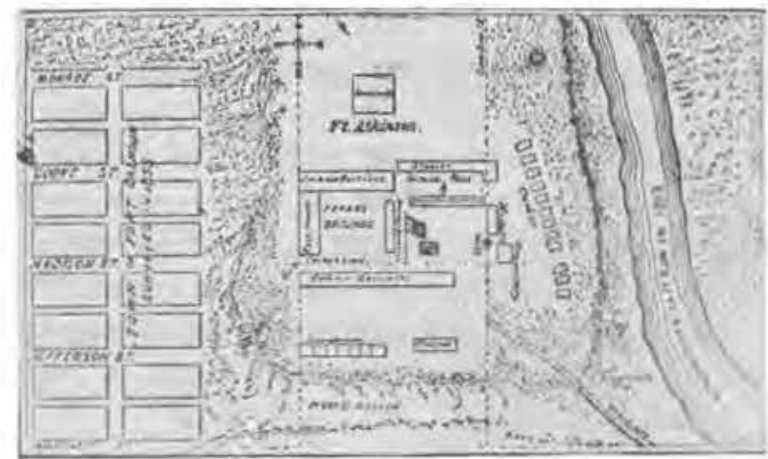

A pen sketch of $\mathrm{Ft}$. Atkinson. Also its relation to the present villase of Ft. Calloun. Nebr. (Nebraska State Historical Society.)

diseases, and some died. Food supplies during the winter were limited to salt meats, flour, Indian corn meal and other non-vitamine bearing foods. Wild game, plentiful on the arrival of the troops, soon became unbelievably scarce and practically unobtainable, due to persistent hunting of both troops and Indians. Scurvy broke out in the winter. Of the 788 soldiers then in camp, 560 contracted scurvy and 157 died. In early spring wild vegetables, of which the wild onion (Allium) ${ }^{(2)}$ the size of a hazelnut, is

\footnotetext{
2. There is folk-lore to the effect that an Indlan chieftain told the commandant of the antiscorbutic virtues of the wild inion.
} 
said to have been one, were obtainable. A herd of cattle to furnish fresh meat, milk and butter was driven in from Fort Osage on the south, early in April, 1820. These provided the needed vitamins, and scurvy disappeared.

Accompanying the regiment were Surgeon John (or Marion) Gale and Surgeon Thomas W. Mowier. The reports of surgeons Gale and Mowrer on the epidemic are well written and show a keen grasp of the desperate conditions that confronted them.

That scurvy is wholly a deficiency disease was not recognized at that time. To safeguard the health of the troops, various orders were issued by the commanding officer, forbidding soldiers to sleep in the open air, and requiring them to wear coats or some other covering at reveille and tattoo. Seventy men were sent to Fort Osage to relieve the congestion at Fort Atkinson. In April a hospital camp was established about three miles from the fort. It appears that those in authority must have had in mind a possible danger of contagion.

\section{SURGEON GALE-NI-KU-MI-PAPOOSE MARY}

Surgeon Gale furnishes us with a bit of social history of great interest which must here find place. $\mathrm{He}$ became enamoured of the Indian princess Ni-KuMi (or Ne-Co-Mi) daughter of the chief of the Ioways, married her and she bore him a daughter who was named Mary. After several years, so the story runs, Surgeon Gale left the fort for service elsewhere and wanted to abandon his squaw-wife, but wished to take his daughter, Mary, with him. $\mathrm{Ni}-\mathrm{Ku}-\mathrm{Mi}$, with the child, took to the woods along the Missouri where she remained in hiding until Surgeon Gale had taken the steamboat down river. 
$\mathrm{He}$ was transferred to Jefferson Barracks, later served at Fort Leavenworth and died at Fort Armstrong (Rock Island, Ill.) July 27, 1830. (3) His record as an army surgeon is of the very best.

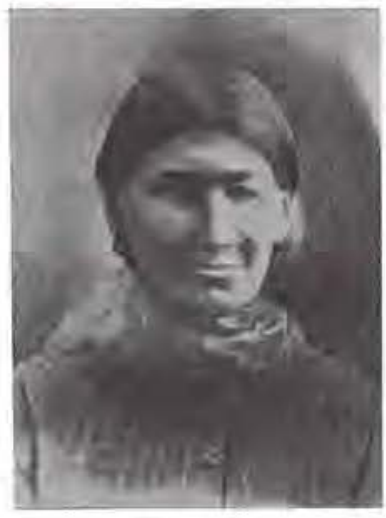

$\mathrm{Ni}-\mathrm{Ku}-\mathrm{Mi}$.

\section{THE LA FLESCHE FAMILY}

Mary grew to womanhood and married Joseph LaFlesche, half-breed chief of the Omahas. To this union was born a large family of children of whom two daughters and son became famous. (4) The younger daughter, Susan LaFlesche was educated in the East, attended the Woman's Medical College, Philadelphia, and was graduated with honors, one of the very few Indian women ever to have been graduated from a medical school.

Susan LaFlesche became tribal physician for the Omaha Indians, then about 1,300 in number, married a French-Sioux Indian, Henry Picotte, interested

\footnotetext{
3. Cutter, Irving. Dr. John Gate, A Pioneer Army Surgeon. Illinois Hist. Society.

4. Suzette Laflesche, better known ns "Bright Eyes," became noted as a writer and lecturer on Indian rights. Francis 1.aflesche an anthropolosist. was for years connected with the Smithsonian Institution and is quoted in the preceding chapter. 
SOME EARLY MEDICAL HISTORY

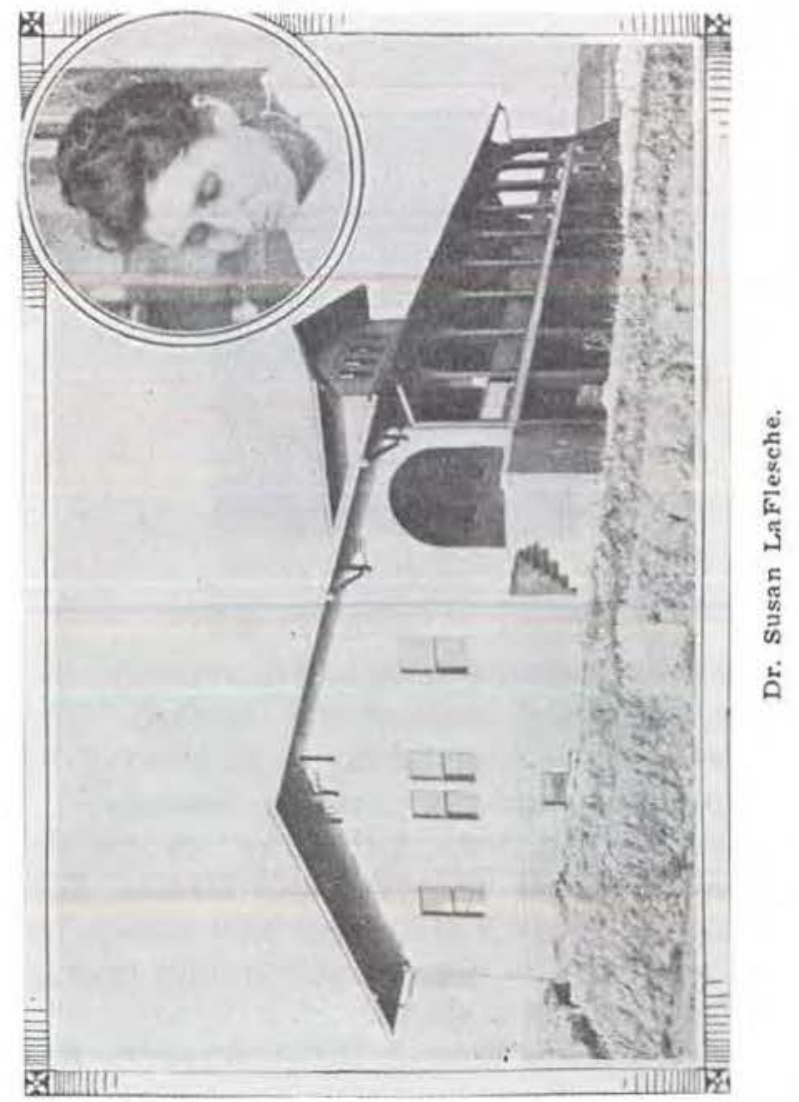


SOME EARLY MEDICAL HISTOKY

herself in the social and physical welfare of her tribe, and became their recognized leader. She succeeded in raising money to build a hospital for her people at Walthill, Nebraska, which was named after her the "Susan LaFlesche Hospital." She became interested in, and allied with organized medicine ${ }^{(5)}$ and died in her late forties, September 18, 1915.

The city of Omaha was platted in 1853-4, by Dr. Enos Lowe of Council Bluffs, president of the IowaNebraska Ferry Company.

EXPEDITION TO DAKOTA INDIAN COUNTRY

In June, 1855 , two Missouri steamers filled with troops of the Second Infantry, a part of military expedition into the heart of the Dakota Indian country, reached Omaha. The surgeon who was to have accompanied them failed to reach Fort Leavenworth in time to join the expedition and Captain Turnley called upon Mark W. Izard, then federal Governor of the territory, for information about a young physician, of whom he had heard mention at the "Lower Council Bluffs Landing" of that day. Governor Izard said that it was a case of Hobson's choice, as there was only one physician available, Dr. George Miller, who had located in Omaha in 1854, the first civilian physician.

DR. GEORGE L. MHLLER

Dr. Miller was asked to accompany the expedition, and assured that he would not be absent from home more than ten days. In an article written many years later, Dr. Miller says(6); "On the 17th day of June 1855 accompanied by my wife, I went on board

5. The Nebraska State Medical Association.

6. Nebraska State Historical Society Reports, Vol, 3, 1892Military Camp on Big Sioux-Dr, George L. Miler, pp. 119-124. 
the old and badly battered stern wheeler, The William S. Baird, with nobody in particular behind me save a few indifferent friends, and my father, with Indians in front of me and cholera all around me. ...

Cholera in 1855 assumed the form of an epidemic along the traveled thoroughfare and in leading cities. . . .

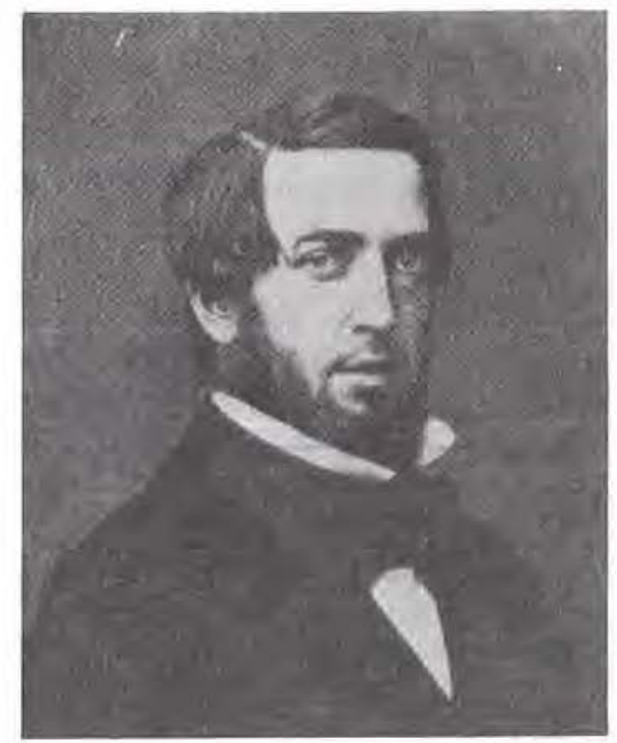

Dr: George L. Miller, in the early seventies.

Owing more to careful sanitary conditions and to pure air than to any skill of mine, only one was lost during the several weeks of the voyage to Fort Pierre. My business was to attend to all the sick persons on the two boats that were companions on this voyage. I was kept pretty busy. It was frequently necessary for me to be transferred from one boat to the other . . . even in the darkness of night." 
SOME EARLY MEDICAL HISTORY

It is interesting to note that instead of the promised ten days, the voyage to Fort Pierre occupied twenty-four days.

Dr. Miller later became a man of affairs in Omaha. He led the fight to locate the Union Pacific bridge, fought to retain the capitol in Omaha, became a nationally influential politician, and established and for many years edited the Omaha Herald.

\section{FORT KEARNY}

In 1848 the United States established the military post of Fort Kearny, six miles southeast of the present city of Kearney, on the banks of the Platte. A wealth of history must be connected with this military post established for protection to emigration on the Oregon and California trails. Unfortunately not much material relating to medicine is available.

Captain, later Major, John E. Summers, was stationed at Fort Kearny as surgeon from 1856 to 1862, when he was transferred to service in the Civil War under Grant, then at Vicksburg. He was Medical Inspector in the army of the Tennessee with the rank of Lieutenant Colonel and was eventually retired with the rank of Brigadier General. While stationed at Fort Kearny in 1861, he was for a time commander of the Post, a very unusual distinction to come to an army surgeon. His son Dr. John E. Summers of Omaha, recently deceased, nationally known surgeon, writer and teacher, was born at Fort Kearny. Dr. John E. Summers, Sr., liked to tell that the sutler of the fort called to see the new baby. He stood and studied the child, then said, "I do not see much else but nose." Years later in Omaha it was this very baby, born in this fort on the prairie, who cared for the sutler in his last illness. 


\section{SOME EARLY MEDICAL HISTORY}

From a New York Herald correspondent who accompanied the Utah Expedition in 1858 we gather that Fort Kearny was merely a station for troops and had no fortifications. There were at that time five unpainted wooden houses, several stories high and about two dozen low sod rouses "built by piling up sods on the top of each other, a foot or more thick for the sides; timbers are then laid across the top, boards placed over the timber, and sods, probably a foot deep, on top of that.

Such infamous buildings are a disgrace to any fort, territory, army government or nation. They are far inferior to Indian wigwams. They can oniy be rivalled by the mud hovels of the Irish or dirty Asiatics. . . . These mud piles are of all sizes, the largest one being about one hundred and forty feet long, forty feet wide, and twelve feet high."

The houses were arranged around a large open square or parade ground. Sixteen blockhouse guns, two field pieces, two mountain howitzers, and one prairie piece constituted the artillery defenses of the post. The barracks was described as seventy by thirty feet, two stories high and in bad order. Built for eighty-four men it housed about one hundred, the enlisted strength of the post.

"Capt. J. P. McCown, the commander of the post, was dispatched there last winter. ... He arrived at Kearny on the 5 th of March, and since that time has had timber drawn, built a sawmill, sawed lumber and built a fine bakery; also cut, drawn, sawed lumber for and framed a new commissary store. The cost to the government of that bakery, not including the soldiers' wages, was about $\$ 200$. Captain McCown is down on mud houses, and intends to have good substantial wooden buildings erected in their 
place. ... There are such severe storms of wind and snow in the winter that men have been blown away from the fort by them. ... Animals have been left in their stables for two days without water during a storm, because men could not venture out during the storm without being blown away and lost."

In 1869 the hospital at Fort Kearny was described by Surgeon Bradley: ${ }^{(8)}$ "The hospital building, a one story frame structure formerly used for company quarters has three ward rooms, each 25 by 30 feet, one store room 19 by 12 feet, a dispensary, 10 by 12 feet, and a laundry 10 by 10 feet. This building is well lighted, warmed by stoves, and ill ventilated, and it being old and dilapidated, is entirely unadapted for the uses for which it was built. A new hospital is much needed at this post. The dispensary is very much out of repair. The wards have a capacity of twenty beds, with an air space of 600 cubic feet per bed. No bath rooms are connected with the hospital."

$$
\text { CHOLERA ON OVERLAND TRAIL }
$$

The gold rush to California began in 1849. Cholera, says Osler in his Practice of Medicine, entered the country through New Orleans in 1848, and in 1849 spread widely along the Mississippi Valley and across the continent to California. It was reported very fatal among the Pawnees in 1849, and it was estimated that by the $7 \mathrm{th}$ of June of that year 200 California bound emigrants had died east of Fort Kearny.

It was estimated (9) that in the spring of 1850 , forty thousand emigrants started from St. Joseph,

\footnotetext{
S. Transactions of the Nebraskat State Historical Society, Volume XXI, page 308-310.

9. Nebraska State Historical Society Publications, Volume Ni, pates 223.226 .
} 
Missouri, and points north of Council Bluffs, for Caiifornia, Salt Lake City and Oregon via the Platte River routes. The number of horses, mules and cattle accompanying the emigrants was estimated above 100,000 .

Cholera was very prevalent in June, and broke out in every train in the Plum Creek Valley. A correspondent counted forty graves in sixty miles, and thinks 250 must have died the first half of the month. By August 9th, 700 lay buried between Fort Laramie and the Missouri River. At Plum Creek (now Lexington) June 27, 1850, S. C. Mason, scion of a prominent St. Louis family, died of cholera. A Doctor Knox is mentioned as having attended him and "sat up with him all night."

Of several detachments of troops passing along the same route during the height of the epidemic, "not a man was lost owing to strict attention of diet, water and camp regulations."

Emigrants drank water from stagnant pools and holes dug in the ground in preference to running water from the Platte, thinking it might be purer, and "The graves encircling the pools show the consequence."

A correspondent, "R. H. D.,"(10) who seems to have been a physician, writing under date of June 25,1850 of the cholera epidemic east of Fort Laramie, says: "When I wrote you last I stated the health of emigrants to be remarkably good. Some few cases of cholera had been reported, but I myself had seen none. Since then how changed the scene. The angel of death has spread his wings over our

\footnotetext{
10, Nebraska State Historical Society transactions, Vol. XX, равея 226-229.
} 


\section{SOME EARLY MEDICAL HISTORY}

way, and breathed his pestiferous breath upon the unfortunate emigrant.

"Many a poor unfortunate youth, far from home and friends, has breathed his last on the desert air, and found a lonely grave by the wayside; around his dying couch, no kind friends gathered to soothe and comfort the last sad moments of life; but, in an open wagon or tent, exposed to the stormy elements without, and the miserable comforts within, he bowed himself with stubborn submission, to the will of his creator, I have seen the father stand by the bed of his dying son, the brother by his brother, the friend by his friend; with them were nothing save but the stern sympathy of man's nature; and I can look on with partial indifference. They had but met the fate which every one of us might hourly expect. But on one occasion it became my duty to pronounce the hopeless condition of a dying husband father....

"I had been called to see a man who had with him his wife and seven children. His case I considered then almost desperate, but by close attention might have been saved. Several days after I chanced to see him again. As I sat by his side with my finger on his sinking pulse and heard in his throat the death rattle, the most ominous sign to the physician of approaching dissolution, his wife, with a smothered groan, asked me to tell her precisely his condition, saying she wished to know the worst. I told her she should not flatter herself any longer with hope, but be prepared for the worst. I arose to leave the tent, and as I did so returned the fee I had received on a former occasion, and I let drop a tear in sympathy for her desolate and bereaved condition. God grant I may not, on this trip, be again called upon to perform such a duty. 


\section{SOME EARLY MEDICAL HISTORY}

"Most physicians along the road believe the disease which has prevailed among emigrants with such fatality, to be epidemic cholera. Of this I am somewhat incredulous. Certainly, local causes sufficient -exist on the Platte to produce, if not the most violent forms of darrhoea (diarrhoea) to incite, at least, the most latent predisposition to cholera into unrestrained action. The entire Platte bottom is covered with saline matter, such as salt-petre, salaratus, etc. (I have used no analysis but that of taste.) Add to this the first emigrant sunk wells in the bottom. Into these have accumulated the filth and scum which 30,000 persons have left along the road. The use of this filthy water, together with exposure and unwholesome diet, are sufficient, in my opinion, to account for all the sickness which has occurred.

"On the north side of the Platte (Council Bluffs road) where emigration was less and water better, not a single case occurred."

\section{SURGEON LATTA}

Dr. William S. Latta was surgeon of the Second Nebraska Cavalry under Colonel R. W. Furnas (later governor) in a punitive expedition against the Dakota Indians. He leaves an interesting record of medical practice on the march. (11) He reports as of May 12, 1863, 10 cases of malarial fever-remittent, quotidian and tertian and comments: "Fevers have generally been of the remittent and intermittent character, have yielded to chologogue cathartics and tonics but with slight resort to febrifuges excepting in one or two instances which assumed to some extent a typhoid character. Still in no case was recovery very protracted."

11. The Dr. W. S. Iatta Manuseripts, owned by the Nebraska State Historical society. 


\section{SOME EARLY MEDICAL HISTORY}

We may well question the diagnosis of malaria in the above cases, since we know malaria to be a mosquito borne disease, and the more so, since no specific anti-malarial treatment seems to have been used to effect a cure.

Dr. Latta reported a case of "concussion of the brain," the result of a quarrel, the man being struck with the hammer of a pistol, fracturing the left parietal bone. Blood flowed from the ear. The man became delirious and bled freely. In the absence of a trephine, he made an incision parallel to the wound down to the bone and then elevated the depressed bone by pulling up on the scalp. The scalp wound was left open for drainage and a cold water dressing applied. The man rapidly recovered.

Impure water is blamed for torpidity of the liver, engorgement of the spleen, remittent and intermittent fevers, constipation and general biliary derangement, and evidence of scurvy. Succulent vegetables were not to be had, so Surgeon Latta encouraged the gathering of wild gooseberries and states that while green (stewed) they furnished a pretty good substitute for cranberries.

\section{DR. PHEBE OLIVER AMONG THE OTOES}

In the early seventies (1871 to 1872) Dr. Phebe A. Oliver, then a recent graduate of the Woman's Medical College of Philadelphia, came to the Otoe Indian agency in southern Nebraska as post physician. She later married John S. Briggs, the post trader, and after several years service at the post, removed with her husband to the Trenton community in Furnas County, where they homesteaded. For several years she was the only doctor in the county, as well as in southwestern Nebraska and northern Kansas, and 
made calls on horseback as far as 100 miles. She was said to have been a competent practitioner of medicine and surgery.

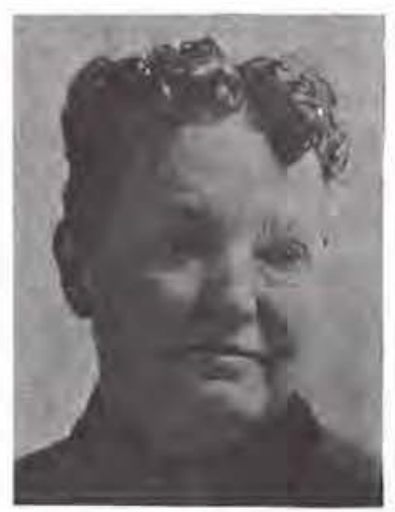

Dr. Phebe Oliver.

DR. BANCROFT AND THE SIOUX MASSACRE OF PAWNEES

Dr. W. M. Bancroft came from Philadelphia to Plum Creek, now Lexington, in April, 1873. He was called to attend Pawnee victims of the Sioux Massacre of Pawnees, which occurred August 5, 1873.

"It was the custom of the Pawnees(12) who were friendly and were located on a reservation near Columbus, Nebraska, to go on a fall hunt for buffalo meat for their winter use. The Sioux who were on the Pine Bluff reservation had an old grudge against the Pawnees, and knew when this hunt took place. The Pawnees made Plum Creek their starting point across the country southwest to the head of the Frenchman river. They camped about ten miles

12. Nebraska Pioneer Reminiscences, Published by Nobraska Society D. A. R. 1916 -Plum Creek or I,exington, Dr, William M. Bancroft, pp, 57-62. 
northwest of Culbertson, a town now on the B. \& M. Railroad. The camp was in the head of a pocket which led from a table land to the Republican River. The Sioux drove a herd of buffalo on the Pawnees while the latter were in camp. Not suspecting danger, the Pawnees began to kill the buffalo, when the Sioux came up, taking them by surprise. The Pawnees, being outnumbered, fled down the canon. The Sioux followed on either bank and cross-fired them, killing and wounding about a hundred. I was sent by the government with Mr. Longshore, the Indian agent of Columbus, and two guides to the scene of

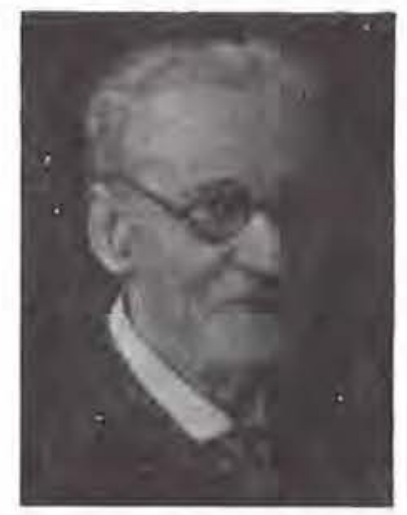

Dr. William M. Bancroft.

the massacre, which was about one hundred and forty miles southwest of Plum Creek, for the purpose of looking after the wounded who might have been left behind. We made this trip on horseback. The agent had the dead buried and we followed up the wounded. We found twenty-two at Arapahoe and ten or fifteen had left and started on the old Fort Kearny trail. We brought the twenty-two 


\section{SOME EARLY MEDICAL HISTORY}

wounded to Plum Creek, attended to their wounds, and then shipped them in a box car to the reservation at Columbus."

Of his private practice, Dr. Bancroft says in the same article: "My first trip to Wood river valley twenty miles north, was to attend James B. Mallott, one of the first settlers. They were afraid to let me go without a guard but I had no fear of the Indians, so they gave me a belt of cartridges and a Colt's revolver. Finally, MacCool, the county elerk, handed me a needle gun and commanded me to get back before dark. I started on horseback with his arsenal for Wood river and made the visit, but on my return I stopped to let the horse rest and eat blue stem. Soon the horse became frightened and began to paw and snort. On looking back toward the divide, I saw three Indians on horseback were heading my way. We were not long in getting started. I beat them by a mile to the valley, arriving safely at Tucker's farm on Buffalo creek. The Indians did not follow but rode along the foothills to the west. A party of four or five from Tucker's was not long in giving chase, but the Indians had disappeared in the hills. A little later Anton Abel, who lived a mile north of town, came in on the run and stated that a file of eight or ten Indians, with scalp sticks waving, were headed south a half mile west of town. A number mounted their horses and gave chase to the river where the Indians crossed and were lost to sight. We never suffered much loss or injury from the Indians. Many scares were reported, but like the buffalo after 1874-75, they were a thing of the past in our county.

"My practice for the first ten or twelve years among the sick and injured, covered a field almost 
SOME EARLY MEDICAL HISTORY

unlimited. I was called as far north as Broken Bow in the Loup Valley, fifty miles; east to Elm Creek, Buffalo county, twenty miles; west to Brady Island, Lincoln county, thirty-five miles, and south to the Republican River. Most of the time there were no roads or bridges."

Space forbids mention of many who in those early days ministered to white and Indian. They traveled the untrod wilderness and the monotonous and trackless prairie with Indian ponies and saddle bags, miles untold, up to one hundred or more on errands of mercy. This type of man was the real pioneer. In the appendix of this volume will be found a list of some of these early practicing physicians in Nebraska-men whose contributions to the State can never be estimated-unsung heroes of a vanished day. (See Appendix E).

By the late seventies the homesteader had pretty well occupied the boundless prairie; sod house, dugout and frame shack dotted the landscape, while an occasional frame house testified that the occupant was one of the few more fortunate homesteaders.

Thus came a new era, and through the decades that followed, modern invention and scientific progress brought to even the remote country doctor and his patients an easier mode of life and a skill never visioned by those who rode the prairies. 


\section{APPENDIX A \\ CHRONOLOGY OF MEDICAL PROGRESS}

Beginning with the discovery of the Tubercle bacillus by Koch in 1882, mentioned in the body of the text, medical discoveries followed in about the following order:

In 1882, Langenbach first suggested and performed cholecystectomy.

In 1882, Chiene started in Edinburgh, the first teaching laboratory for bacteriology.

In 1883, Pasteur introduced vaccination against anthrax.

In 1883, Klebs discovered the diphtheria bacillus and in 1884 Loeffler demonstrated that it is the cause of diphtheria. In 1889 Behring discovered diphtheria antitoxin and by 1894 it was placed on the market on a large scale.

In 1884, Loeffler of Vienna demonstrated the use of cocaine in eye surgery.

In 1884, Hughes Bennett and Godlee removed a tumor of the brain and demonstrated the practicability of brain surgery.

In 1885, Victor Horsley discoyered that partial removal of the thyroid gland is not followed by myxedema.

In 1886, von Bergmann introduced steam sterilization.

In 1886, Theobald Smith discovered the possibility of immunization.

In 1886, Belfield did the first suprapubic prostatectomy in America.

In 1887, the first operation for the removal of the appendix was done by Morton of Philadelphia.

In 1888 , the Widal reaction for the diagnosis of typhoid fever was discovered.

In 1889, Outerbridge devised a speculum for dilatation of the cervix in cases of stenosis when sterility exists.

About 1890, Weller Van Hook of Chicago, did a laparotomy for relief of perforation of the bowels in typhoid fever, the patient recovering.

In 1890, Halstead introduced rubber gloves for surgeons,

In 1895, Murphy produced circular anastomosis of arteries.

In 1895, Pasteur commenced his inoculations for preventing rabies in the human subject.

The discovery in 1895, by Roentgen, of the properties of 


\section{$\triangle P P E N D I X$}

the $\mathrm{x}$-ray, revolutionized the diagnosis and treatment of disease.

In 1897 , inoculation with typhoid vaccine was begun.

In 1899, the Reed Yellow Fever Commission proved that Yellow fever is transmitted by a certain mosquito, the Aedes Aegypti.

In 1900, Ricketts discovered that the wood tick is the cause of Rocky Mountain Spotted Fever.

In 1901, Takamine first produced adrenalin.

In 1902, Lane introduced the fixation of fractures, by plating.

In 1905 , Schaudin discovered that syphilis is due to the Spirochoeta pallida.

In 1907, Wassermann introduced his serum test for the diagnosis of syphilis.

In 1909, Ehrlich introduced 606 or Salvarsan for the treatment of syphilis.

In 1910, Sluder read his first paper advocating complete removal of the tonsil as a prevention of local infections.

About 1910, Albee of New York began to develop and perfect the technique of the most modern methods of orthopedic surgery; but Chapman of Boston had bonegrafted the tibia as early as 1865 . Phelps did some bone and tissue transplantation about 1890 . Bone pegs were used in 1887 .

In 1925, Banting and Best produced Insulin.

Pernicious anemia has been brought under partial control within recent years by the discovery that the liver contains a substance that has the power of raising the number of red blood cells. 


\section{APPENDIX B}

\section{DEVELOPMENT OF QUARANTINE AND HEALTH LAWS IN NEBRASKA}

As early as 1869 there was passed an act to incorporate cities of the first class (pop. 3,000 ) providing authority to establish a Board of Health invested with powers and duties to secure the city and the inhabitants thereof from the evils of contagious, malignant and infectious diseases.

An act in 1871 , relating to cities of 15,000 , placed the responsibility upon the mayor and extended jurisdiction five miles beyond the corporate limits of the city for enforcement of any health or quarantine ordinance or regulation.

Amendatory acts were passed in 1879, 1887, and 1889 , aimed to clarify previous acts, but it was not until 1891 that a law was passed requiring cities of the metropolitan class to have a board of health with the mayor as chairman.

In 1899, coincident with the pandemic of smallpox that swept over the United States as a result of the return of our soldiers from Cuba, the legislature established an emergency fund for suppression of epidemics and the prevention of diseases. The appropriation was for $\$ 1,500$, with provision for payment of bills and expenses incurred in suppression of an epidemic of smallpox. This was the first specific effort upon the part of the state toward executive action in the matter of public health.

The older reader will recall that following the Cuban invasion and the return of soldiers, there was much talk about "Cuban itch." At first thought to be a harmless although annoying skin affection, it had spread pretty well all over the country before it became generally known that "Cuban itch" was smallpox, usually in discreet form.

Cases contracted from the soldiers did not all develop into discreet smallpox. Many people developed the severer form and some died. The facts prompted the legislature then in session to enact the measure above mentioned. The money was used to employ an inspector to travel to points in the state that called for his services to settle disputes among the profession and the laity as to the nature of specific cases.

1901 signalized enactment of the first law which authorized county boards to make and enforce regulations to prevent 


\section{APPENDIX}

the introduction and spread of contagious diseases and to establish boards of health.

The 1903 legislature, by an amendatory act, authorized the appointment of county boards of health with jurisdiction over unincorporated parts of the several counties. Another important act enlarged the powers and duties of the state board of health and created the office of health inspector with duties as prescribed by the rules and regulations of the State Board of Health. This act also provided for report to the State Board of Health of the existence of contagious and infectious diseases.

In 1905 the first comprehensive law providing for collection and preservation of vital statistics was enacted $w i t h$ the State Board of Health designated as a state registrar and various local authorities as local registrars.

In 1911 an amendatory act made it obligatory upon county and village boards, if no local board of health exists, to enforce the quarantine rules and regulations of the State Board of Health.

The legislature of 1917 passed an act establishing a State Department of Health and providing its powers, duties, officers, assistants and procedure,

In 1919 the functions of the State Department of Health were conferred upon the Department of Public Welfare by the Civil Administrative Code of 1919.

In 1933 an amendatory act changed without alteration of function the name of the "Department of Public Welfare" to "Department of Health," and the name of the head from "Secretary" to "Director of Health."

During the intervening years supplementary acts were passed to establish a state Tuberculosis hospital, an Orthopedic hospital, to regulate maternity homes and boarding houses for children, to prohibit the use of the common drinking cup, a pure food law, a bactiological laboratory (1912); also a provision for the collection of marriage statistics and for the collection of birth statistics.

It is interesting in this connection to note that from the earliest days fumigation was the accepted method of disinfection. Like the Scotchman "I haed me doots" for many years about this procedure and years ago advised people to scrub the woodwork and floors with antiseptic solutions before fumigating. Less than five years ago the State De- 


\section{APPENDIX}

partment of Health of Nebraska abandoned fumigation as a disinfectant and advised antiseptic solutions. Even today, some intelligent people will tell me that they "feel just a little bit safer to fumigate."

The present Nebraska rules for terminal disinfection up-todate in every detail, are given below:

"FIRST: The patient and those in contact shall be bathed with an antiseptic solution. This should be done by a bath of warm water and soap, then washing of the body with a mild antiseptic solution. Bi-chloride of mercury, in strength of 1 to 5000 is recommended for this purpose, care being taken that the patient does not get the solution in the mouth or eyes.

"SECOND: Everything in the sick room or that has come in contact with the patient and that is of no special value, (papers, magazines, clothes, wooden toys, etc.) should be burned.

"THIRD: Before removal from patient's room, washable clothing, linens used by patient and by those in contact, shall be immersed in a $2 \%$ solution liquor cresolis compound U. S. P., $5 \%$ solution carbolic acid, or an equivalent disinfectant, and remain in such solution for half an hour, then boiled for half an hour.

"FOURTH: Blankets and other articles presenting free surfaces and not too thick can be made safe by exposure in the open air to direct sun rays for three or four days, or sufficiently long to get fully twenty-four hours of direct sunshine. Such articles as rugs, carpets, etc., treated in the same way should, in addition, be brushed with a $2 \%$ solution liquor cresolis compound U. S. P., a $5 \%$ solution carbolic acid, or an equivalent disinfectant.

"FIFTH: Thorough washing of the woodwork, wood and metal furnishings with hot water and soap, combined with disinfection through the use of a $2 \%$ solution liquor cresolis compound U. S. P., a $5 \%$ solution carbolic acid of door knobs, open crevices, and such room furnishings as may have come in contact with patient's hands or hands of attendants may be relied upon to protect against re-infection from the room. The need of repapering, calcimining, painting, etc. is left to the discretion of the board."

Since 1912 the state laboratory service has been available 


\section{APPENDIX}

for diagnosis of obscure cases and has added a much valued aid to the medical profession of Nebraska.

The enactment of the Basic Science law and the Social Security Act are current history and need not be mentioned in this appendix. 


\section{APPENDIX C}

\section{EARLY LAWS REGULATING PRACTICE OF MEDICINE IN NEBRASKA}

The first effort at regulation of medical practice was an act to establish the Nebraska Medical Society, approved March 2, 1855 . This act provided that the physician must be a member of the society to practice legally.

The second step to regulate the practice of medicine was an act approved March 3,1881 , which specified filing with county clerk certain qualifications before entitled to practice.

An amended act to regulate practice of medicine was approved March 1, 1883. An act to establish a state board of health, to regulate the practice of medicine in 1891, was the first provision for issuance of a certificate or license in definite form.

Subsequent amendments progressively increased the standards or requirements for a license to practice medicine. 


\section{APPENDIX D}

THE MALARIAL MOSQUITO IN NEBRASKA

According to a recent personal communication from Dr. Myron H. Swenk, Chairman of the Department of Entomology, University of Nebraska, there is positive evidence of the occurrence of both Anopheles punctipennis Say and Anopheles quadimaculatus Say in the State of Nebraska. He reports finding dozens of Anopheles quadrimaculatus Say engorged with blood and clinging to the top of his tent while camping on the White river, near Glen in Sioux County, Nebraska, during the summers of 1905 and 1906. In 1903 Prof. Lawrence Bruner collected specimens of Anopheles punctipennis Say in a building on the University campus at Lincoln, Nebr., and about that time also found great numbers of them along Salt Creek near Waverly, Lancaster County, Nebr. Howard, Dyar and Knab in their "The Mosquitoes of North and Central America and the West Indies" state the range of Anopheles quadrimaculatus as "North America east of the Rocky Mountains from Canada to Mexico," and give the range for Anopheles punctipennis as "southern Canada, United States and southward to central Mexico."

Although some Medical dictionaries say that Anopheles punetipennis apparently does not transmit the malaria germ, this is not in conformity with statements on this point as secured from some of the later books on medical entomology by authorities like William A. Riley and by Robert Matheson, both published in 1932. They agree that Anopheles punctipennis is a vector of both tertian malaria, the common form in the United States and of aestivo-autumnal (or subtertian, malignant or pernicious) malaria, although they state definitely that it is not an important vector of those forms of malaria. All agree also that it does not transmit the quartan type of malaria (P, malariae).

Anopheles quadrimaculatus is a very important vector of all forms of malaria, and is considered the most important species in malaria transmission in this country, 


\section{APPENDIX E}

Some Physicians Who Settled in Nebraska at An Early Date, With Place of Settlement.

James P. Peck, Omaha, 1856, who had attained renown in the cholera epidemic of Sandusky, Ohio.

Gilbert Monell, Omaha, 1857, first President of the $\mathrm{Ne}$ braska Medical Society. Grandfather of the late Senator Gilbert M. Hitchcock.

Augustus Roeder, Omaha, 1857, father of several generations of physicians and surgeons.

I. S. Rippey. These four men were officers in Omaha Medical Society which organized with 13 members on June $14,1866$.

Aurelius Bowen, Nebraska City, 1856, served in the Civil War, was an early legislator, one of the incorporators of the Omaha School for the Deaf and Blind, and author of the bill creating the Institution for the Blind at Nebraska City.

R. R. Livington, Plattsmouth, 1859, was a Brigadier General in the Civil War, and chief surgeon of the Burlington Lines throughout Nebraska.

Harvey Link, Millard, 1856, was a homesteader and member of the Legislature. He was a progressive physician and old style gentleman.

Samuel Mercer, Omaha, 1856, was for many years chief surgeon of the Union Pacific and father of the Omaha street car system.

James H. Peabody, Omaha, 1866, pioneer surgeon.

Jacob B. Denise, Omaha, 1867, pioneer oculist.

Victor H. Coffmann, Omaha, 1867, was formerly a Civil War surgeon, said to have had the largest practice in Omaha in his day.

Paul Grossman, Omaha, 1877, who did the earliest Caesarean section in Nebraska.

J. M. Borglum, Omaha, 1869, removed to Fremont, 1874. Father of two famous sons, sculptor Gutzon Borglum and pianist August Borglum.

A. S. Von Mansfelde, Ashland, 1875, Surgeon, for many years prominently identified with the Nebraska State Medical Society.

C. G. Stillman, Columbus, 1859.

Alexander Bear, Fremont, 1867, later moved to West Point 


\begin{abstract}
APPENDIX
and in 1872 moved to Norfolk, where he became known as the pioneer physician of Elkhorn Valley.

Thomas C. Sexton (who came with Bear to Fremont), first physician at Fontenelle. Still living at Fremont (June, 1937).

Luther J. Abbott on Pappio Creek near present village of Irvington, 1861, moved to vicinity of Fontenelle 1866, then to Fremont.

N. B. Larsh, Nebraska City, 1859. Served in the territorial legislature of 1861-2, in the State Senate 1872-3. First Superintendent of the State Hospital for the Insane, 1870-71, and third President of the Nebraska Medical Society, 1870.

Charles J. Stewart, Auburn, 1857. He had been an assistant surgeon in the Civil War. Superintendent of the State Hospital for the Insane, 1871-75.

E. W. Bullard, Pawnee City, 1863 , with his young son, John W., later to become a prominent physician in southern Nebraska.

M. W. Stone, surgeon in the Civil War, was with General Carr's expedition sent out to quell the Brule and Ogallala Indians in 1866. While stationed at North Platte he helped to organize Lincoln County, and was the first Union Pacific surgeon appointed at North Platte.

T. E. Mitchell, Columbus, 1873. A distinguished surgeon of the Civil War.

George W. Johnson, Fairmont, 1873, first resident physician in Fillmore County.

George W. Wilkinson, Dakota county, 1858. Surgeon in the First Nebraska Cavalry in the Civil War. Later physician to Winnebago Indians for two years, agent for the Omahas and Winnebagos for several years. Register of Land Office at Dakota City. Sometime superintendent of the Norfolk State Hospital.

Thomas L. Myers, York County, 1869, removed to Aurora, 1873.

George W. Collins, Pawnee City, 1865. Physician and lawyer, Speaker of the House of Representatives, 1870.

Frederick Renner, Nebraska City, 1856. Dr. Renner was a native of Bavaria. Joined the surveying party of Colonel Charles A. Manners, then engaged in establishing a boundary line between Kansas and Nebraska. Later he practiced medicine at Nebraska City in 1861, where he established the Nebraska Staats Zeitung.
\end{abstract}




\section{APPENDIX F}

\section{FIRST MEDICAL SOCIETIES IN NEBRASKA}

The first meeting of the physicians of Omaha, looking toward the organization of a medical society, was held June 14, 1866, when the Omaha Medical Society was organized with 13 members. The officers were: President, Dr. J, P. Peck; Vice-President, Dr. August Roeder; Secretary, Dr. I. N. Rippey, and Treasurer, Dr. J. H. Peabody. This society met with a good degree of regularity, devoting itself to the discussion of papers presented and to other matters touching with the interests of its members. On December 17, 1866, a fee-bill was adopted.

At a meeting held February 10, 1868, preliminary steps were taken to organize a State Medical Society. This action culminated in the following June in perfecting that organization, the successor of which, the Nebraska State Medical Association, today, we are all rather proud.

Dr. J. M. McKesson eame to Lincoln in 1863 . Dr. H. D. Gilbert, Dr. George W. French, and Dr. J. W. Strickland were in practice in the vicinity of Lincoln before 1870. The medical profession of Lincoln was organized first May 24, 1869. of the pioneer physicians the only ones who appear as members of the Nebraska State Medical Society organized in 1868 are Drs. F. G. Fuller and L. H. Robbins (both 1870).

Dr. A. R. Mitchell located in Lincoln in 1879 and was one of the organizers of the "Lincoln Medical Society," in November 1880 . Dr. Mitchell was a prominent physician in Lincoln until his death in 1933, He was President of the Nebraska State Medical Society, 1900; delegate to the American Medical Association a number of times, and for 17 years preceding his death was one of the Trustees of the American Medical Association. 


\section{THE AUTHOR}

Francis A. Long was born near Kreidersville, Northampton County, Pennsylvania, on February 16, 1859. He attended the district school for ten years. In December, 1876, the family moved to Iowa, and he spent a year at the Moulton, (Iowa), Normal and High School. This book tells of his later education and experiences. It does not however tell of his marriage on December 2, 1884, at West Point, Nebraska, to Maggie E. Miller, whom he brought as a bride to Madison, where he established his practice in June, 1882. To an unusual extent, she shared with him the experiences of his country practice in this one community with which they were both so closely identified during the next fifty-two years. Dr. Long died on November 24, 1937, a little more than six months after his devoted wife. 



\section{Pioneering the Good Life... A Century of Preparation}

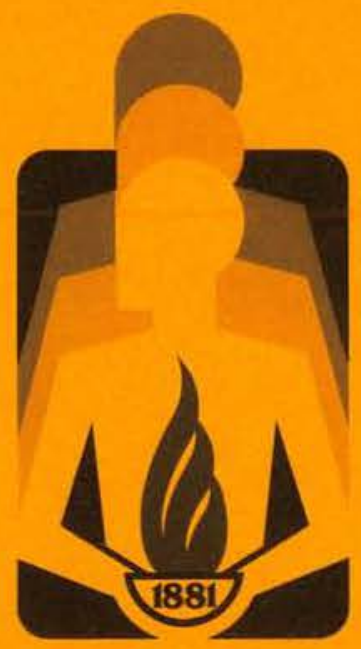

University of Nebraska Medical Center

Centennial History Committee

Chairman: Frank J. Menolascino, M.D.

Members: Harley Anderson, M.D. Reba Benschoter, Ph.D.

Robert Coleman, M.A.

Dean Alastair Connell, M.D.

Walter Friedlander, M.D.

Lorraine Hedman, M.P.N.

Bernice Hetzner, M.A.

Edward Holyoke, M.D., Ph.D.

John Latta, Ph.D.

Rose Reynolds, B.A.

Richard Wilson, M.D. 